Tamara Barbosa Gaspar

\title{
Análise da relação entre bem-estar e transporte no município de São Paulo
}

São Paulo

2021 
Tamara Barbosa Gaspar

\section{Análise da relação entre bem-estar e transporte no município de São Paulo}

Trabalho apresentado à Escola Politécnica da Universidade de São Paulo para obtenção do título de Mestre em Ciências

São Paulo

2021 


\title{
Análise da relação entre bem-estar e transporte no município de São Paulo
}

\author{
Versão Revisada
}

Trabalho apresentado à Escola Politécnica da Universidade de São Paulo para obtenção do título de Mestre em Ciências

Universidade de São Paulo - USP

Escola Politécnica

Programa de Pós-graduação em Engenharia de Transportes

Área de concentração: Informações Espaciais

Orientadora: Profa. Dra. Mariana Abrantes Giannotti

São Paulo

2021 
Autorizo a reprodução e divulgação total ou parcial deste trabalho, por qualquer meio convencional ou eletrônico, para fins de estudo e pesquisa, desde que citada a fonte.

Este exemplar foi revisado e corrigido em relação à versão original, sob responsabilidade única do autor e com a anuência de seu orientador.

São Paulo, de de

Assinatura do autor:

Assinatura do orientador: 


\section{Gaspar, Tamara Barbosa}

Análise da relação entre bem-estare transporte no município de São Paulo - versão revisada - São Paulo, 2021.

$94 \mathrm{p}$.

Dissertação (Mestrado) - Escola Politécnica da Universidade de São Paulo. Departamento de Engenharia de Transportes. 1.Engenharia de transportes 2. Planejamento de transportes 3. Mobilidade urbana I. Universidade de São Paulo. Escola Politécnica. Departamento de Engenharia de Transportes II.t. 


\section{AGRADECIMENTOS}

A pesquisa acadêmica é sempre fruto de trabalho árduo, construído a partir da contribuição de inúmeras pessoas. Muitas delas, por sua colaboração direta a toda comunidade científica, são citadas ao longo do trabalho quando faço uso de suas publicações e podem ser todas consultadas na lista de referência bibliográfica ao final da dissertação.

Porém algumas delas, além da colaboração formal acadêmica, contribuíram também com este trabalho de outras formas: por meio de conversas, incentivos, inspiração e amparo. Por isso, uso este espaço para expressar o meu mais sincero agradecimento.

À Profa Dra Mariana Giannotti, pela confiança, paciência e colaboração construtiva no desenvolvimento deste trabalho.

À Rede Nossa São Paulo e Ibope Inteligência, representados aqui nominalmente pela Patricia Pavanelli que disponibilizou os bancos de dados utilizados.

Aos colegas de trabalho da IFC, da Steer e da Logit que me acompanharam nas diferentes fases desta jornada e permitiram que este feito pudesse se concretizar.

Ao Gabriel Mormilho, por sua gentileza e disponibilidade em ajudar, ensinar e debater em diversos momentos importantes da pesquisa.

À Beatriz Santos pelo companheirismo, desde o início desta jornada e em vários momentos decisivos deste processo.

Aos colegas do Geomove Bruna Pizzol, Tainá Bittencourt e Diego Tomasiello por estarem abertos a ajudar sempre que precisei.

À Haydee Svab, Felipe Dias, Fabio Lofrano e Daniela Rozados pela inspiração (não só) acadêmica que me trazem. Que sorte eu tenho de poder chamá-los de amigos.

À Anne, pela revisão do texto e principalmente pela amizade de toda a vida, pelos encontros e conversas, nos momentos bons e nos difíceis.

Aos amigos, pelo apoio e compreensão nos momentos que precisei me ausentar devido a este projeto, e principalmente, pela alegria e bons papos de quando estivemos juntos.

E à minha família: Victor, pela parceria e carinho, e meus pais por tudo que fizeram e fazem por mim.

Por fim, gostaria de agradecer a você que chegou a esta pesquisa buscando entender mais sobre como o transporte pode contribuir com o bem-estar. Espero que o conteúdo aqui apresentado te ajude nesta compreensão. 


\section{RESUMO}

O presente trabalho tem como objetivo analisar a relação entre a qualidade do transporte e o bem-estar subjetivo das pessoas, tendo como referência o estudo de caso do município de São Paulo.

A partir da base de respostas da Pesquisa IRBEM - Indicadores de Referência de Bem-estar no Município - , com análises de correspondência entre diversas perguntas relacionadas ao bem-estare a percepção quanto ao transporte no município, observouse uma associação positiva nos aspectos relativos a qualida de dos serviços de transporte e a satisfação com a própria qualidade de vida.

Para alguns aspectos relativos à qualidade do transporte, foram feitas análises considerando dados de operação dos ônibus e da Pesquisa Origem Destino do Metrô de 2017, a partir dos quais é possível analisar sua distribuição espacial no município. São eles: percepção de tempo de deslocamento, percepção de tempo de espera do ônibus e percepção do custo da tarifa de transporte público.

Este estudo conclui que a qualidade do transporte é um dos fatores que impactam o bem-estar subjetivo e que, devido as suas características desiguais no território de São Paulo, há locais com fatores relacionados ao transporte que favorecem a satisfação com a vida (em geral localizados em áreas centrais) e locais em que estes elementos desfavorecem o bem-estar (regiões mais periféricas da cidade).

Palavras-chave: bem-estar; bem-estar subjetivo; satisfação com a vida; satisfação com transporte; qualidade do transporte. 


\section{ABSTRACT}

This thesis addresses issues about the relationship between the quality of transport and the subjective well-being, taking as a reference the case study of the city of São Paulo.

Based on the data of the IRBEM Survey - Reference Well-being Indicators in the Municipality, with analysis of correspondence between several questions related to well-being and the perception regarding transport in the city, a positive association was observed in the aspects of quality of transport services and satisfaction with the quality of life itself.

For some aspects related to the quality of transport, analyzes were made considering data on buses operation and the 2017 Origin Destination Household Survey of the Metro, from which it is possible to verify the spatial distribution.

This study concludes that the quality of transport is one of the factors that impact subjective well-being and that, due to its unequal characteristics in the territory of São Paulo, there are places with factors related to transport that favor satisfaction with life, in general they are located in central areas, and places where these elements are unfavorable for the well-being, located in more peripheral regions of the city.

Keywords: well-being; subjective well-being; satisfaction with life; transport satisfaction; quality of transport. 


\section{SUMÁRIO}

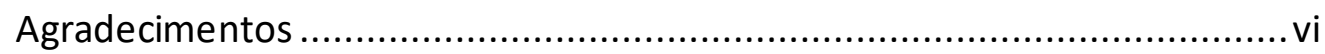

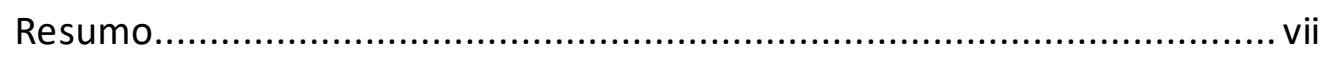

Abstract ..................................................................................... viii

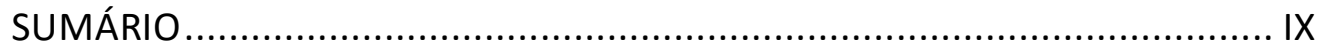

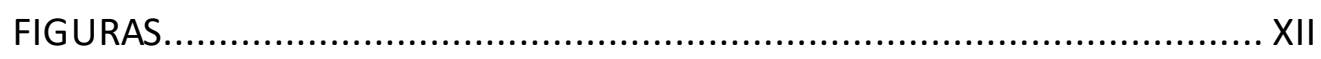

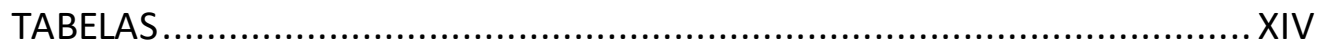

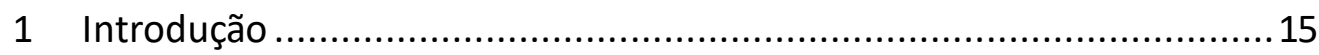

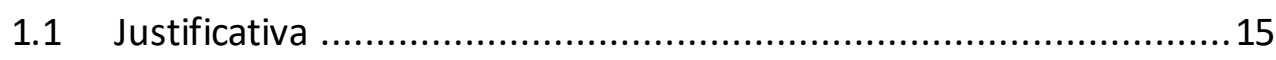

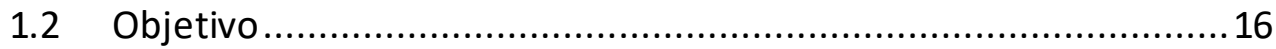

1.3 Estrutura do documento ................................................... 16

2 Revisão da literatura ........................................................... 18

2.1 Bem-estar .................................................................... 18

2.1.1 Indicadores de bem-estar....................................................19

2.2 Relação entre bem-estar e transporte urbano ..............................23

2.2.1 Dificuldade de transporte ..............................................24

2.2.2 Indicadores de dificuldade de transporte ...............................26

2.3 Limitações metodológicas .......................................................29

3 Transporte e bem-estar em São Paulo ............................................. 31

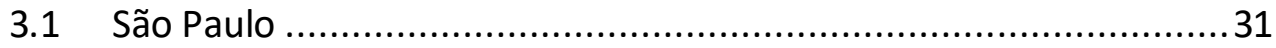

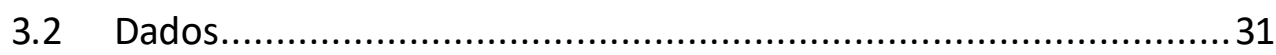

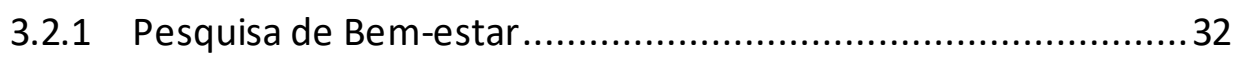

3.2.2 Pesquisa Origem-Destino 2017 ............................................32

3.2.3 Dados operacionais de transporte ......................................33

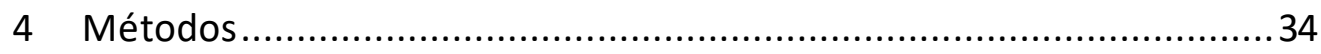

4.1 Análise de variáveis categóricas ............................................. 34

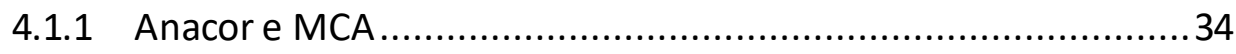

4.2 Apresentação dos resultados ............................................... 35 


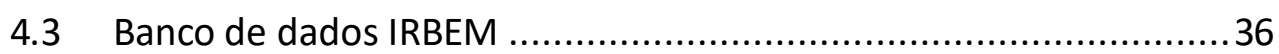

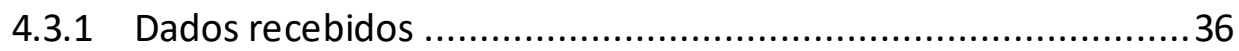

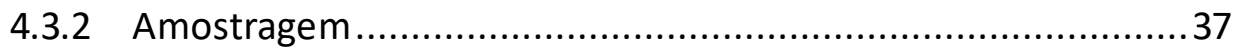

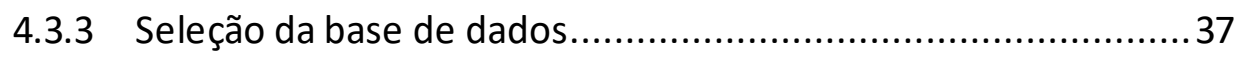

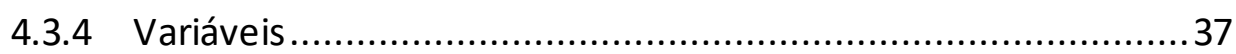

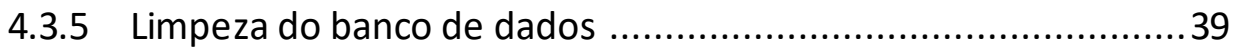

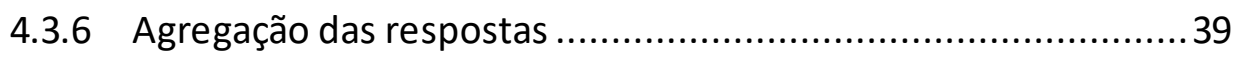

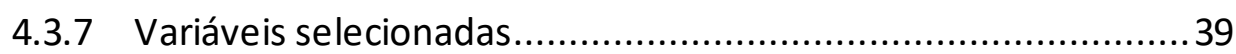

$4.4 \quad$ Análises complementares ...............................................42

4.4.1 Origem-Destino ................................................................. 43

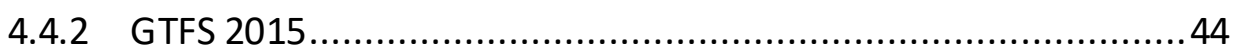

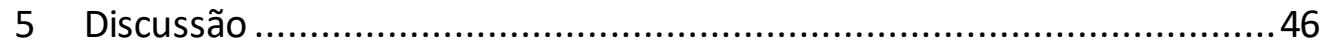

5.1 Bem-estar e dificuldade de transporte em São Paulo ...................46

5.2 Relação entre bem-estar e dificuldade de transporte ..................49

5.2.1 Bem-estar e satisfação com o tempo de deslocamento ............49

5.2.2 Bem-estar e Satisfação com tempo de espera do ônibus ..........54

5.2.3 Bem-estar e Satisfação com a tarifa do transporte público .......60

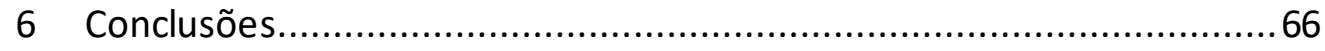

7 Referências bibliográficas .............................................................68

Anexol. Bem-estar e variáveis socioeconômicas ......................................77

Análises de Correspondência Simples ...............................................77

Bem-estar e Ocupação .................................................................. 77

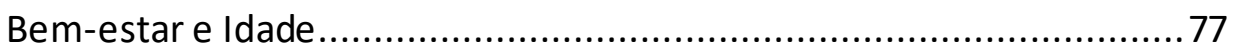

Bem-estar e Grau de instrução .........................................................79

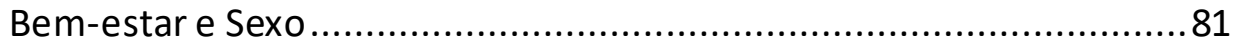

Bem-estar e Estado civil ................................................................ 81

Análises de Correspondência Múltiplas .............................................8 82

Bem-estar, Renda Familiar e Grau de instru ção ..................................82

Bem-estar, Renda Familiar e Idade ............................................ 84

Anexoll. Bem-estar e variáveis de transporte .......................................8 85 
Análises de Correspondência Simples

Bem-estar e Satisfação com as questões de transporte e trânsito de maneira geral 85

Bem-estar e Satisfação com o tamanho da rede de Metrô 87

Bem-estar e Satisfação com soluções para diminuir o trânsito da cidade

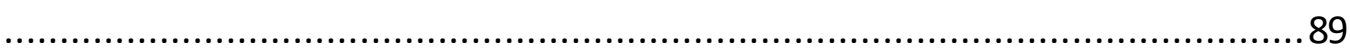

Bem-estar e Satisfação com a segurança no trânsito ..........................91

Bem-estar e Satisfação com a prioridade do transporte coletivo no sistema viário 93 


\section{FIGURAS}

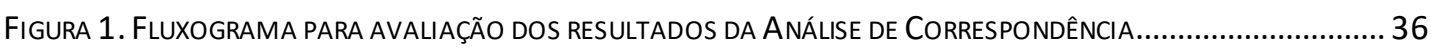

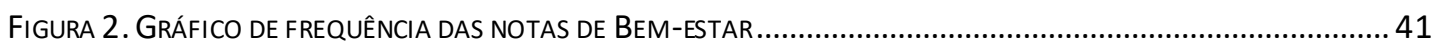

FIGURA 3. GRÁFICO DE FREQUÊNCIA DAS NOTAS DE SATISFAÇÃO COM O TRANSPORTE GERAL...................................42

FIGURA 4. GRÁFICO DE FREQUÊNCIA DAS NOTAS DE SATISFAÇÃO COM TEMPO DE DESLOCAMENTO..............................42

FIGURA 5.GRÁFICO DE FREQUÊNCIA DAS NOTAS DE SATISFAÇÃO COM TEMPO DE ESPERA DO ÔNIBUS ........................... 42

FIGURA 6. GRÁFICO DE FREQUÊNCIA DAS NOTAS DE SATISFAÇÃO COM A TARIFA DE TRANSPORTE PÚBLICO ....................42

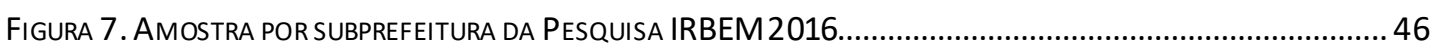

FIGURA 8. FREQUÊNCIA DAS NOTAS DE BEM-ESTAR POR SUBPREFEITURA ............................................................4 47

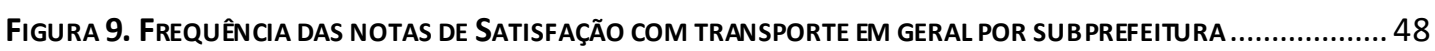

Figura 10. FrequênCIA dAS NotAS de SATISFAÇÃo COM TEMPO dE DESLOCAMENTO POR SUBPREFEITURA............. 48

FIGURA 11. FREQUÊNCIA DAS NOTAS DE SATISFAÇÃO COM TEMPO DE ESPERA DO ÔNIBUS POR SUBP REFEITURA ............ 48

FIGURA 12. FREQUÊNCIA DAS NOTAS DE SATISFAÇÃO COM TARIFA DO TRANSPORTE PÚBLICO POR SUBPREFEITURA ........48

Figura 13. AnÁlise de CorrespondênCIa entre Bem-estar e SatisfaÇÃo com Tempo de Deslocamento .........51

FIGURA 14. TEMPO MÉDIO DE DESLOCAMENTO NO PERÍODO PICO MANHÃ -OD 2017 .......................................53

FIGURA 15. TEMPO MÉdIO DE DESLOCAMENTO POR MODOS MOTORIZADO NO PERÍODO PICO MANHÃ S - OD 2017...53

FIGURA 16. TEMPO MÉdIO DE DESLOCAMENTO DE TRANSPORTE PÚBLI CO NO PERÍODO PICO MANHÃ - OD 2017 ........ 53

FIGURA 17. TEMPO MÉDIO DE DESLOCAMENTO NO PERÍODO PICO TARDE - OD 2017 ............................................53

FIGURA 18. TEMPO MÉdIO DE DESLOCAMENTO POR MODOS MOTORIZADOS NO PERÍ OdO PICO TARDE - OD 2017......53

FIGURA 19. TEMPO MÉDIO DE DESLOCAMENTO POR TRANSPORTE PÚBLICO NO PERÍODO PICO TARDE - OD $2017 \ldots . . . .53$

FIGURA 20. ANÁLISE DE CORRESPONDÊNCIA ENTRE BEM-ESTAR E TEMPO DE ESPERA DO ÔNIBUS ...............................5 54

FiguRA 21. ANÁLISE DE CORRESPONDÊNCIA ENTRE BEM-ESTAR E SATISFAÇÃo COM TEMPO DE ESPERA DOS ÔNIBUS ....56

FIGURA 22. ANÁLISE DE CORRESPONDÊNCIA ENTRE SATISFAÇÃO COM TEMPO DE ESPERA DO ÔNIBUS E TEMPO DE ESPERA

DO ÔNIBUS

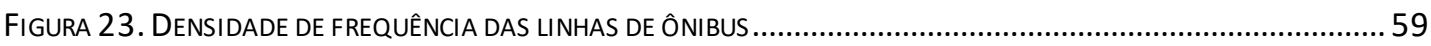

FIGURA 24. ANÁlISE DE CORRESPONDÊNCIA ENTRE BEM-ESTAR E SATISFAÇÃO COM A TARIFA DE TRANSPORTE PÚBLICO 61

FIGURA 25. MAPA PERCEPTUAL RESULTANTE DA ANÁLISE DE CORRESPONDÊNCIA ENTRE BEM-ESTAR E SATISFAÇÃO COM A TARIFA DE TRANSPORTE PÚBLICO 63

FIGURA 26 ANÁLISE DE CORRESPONDÊNCIA ENTRE SATISFAÇÃO COM TARIFA DE TRANSPORTE PÚBLICO E RENDA FAMILIAR

FIGURA 27. DISTRIBUIÇÃO POR ZONAS DO PERCENTUAL MÉDIO DE GASTO MENSAL COM TRANSPORTE COLETIVO, PELAS PESSOAS QUE UTILIZAM TRANSPORTE COLETIVO

FIGURA 28. ANÁLISE DE CORRESPONDÊNCIA ENTRE BEM-ESTAR E OCUPAÇÃo …................................................. 77

FIGURA 29. ANÁLISE DE CORRESPONDÊNCIA ENTRE BEM-ESTAR E IDADE .......................................................... 78

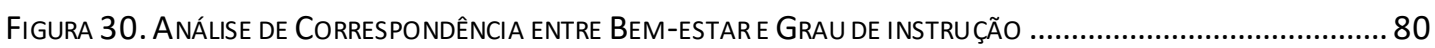

FIGURA 31. ANÁLISE DE CORRESPONDÊNCIA ENTRE BEM-ESTAR E SEXO ............................................................. 81

FIgURA 32. ANÁLISE de CORRESPONDÊNCIA ENTRE BEM-ESTAR E ESTAdo CIVIL................................................8 81

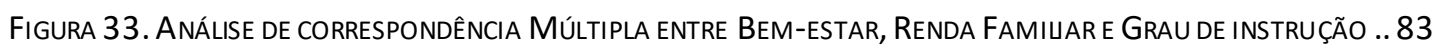

Figura 34. TABELA de CONTINGÊnCIA GERADA No StATA - RendA FAMILIAR E IDADE.

Figura 35. ANÁLISE DE CORRESPONDÊNCIA ENTRE BEM-ESTAR E SATISFAÇÃo COM TRANSPORTE E TRÂNSITO EM GERAL

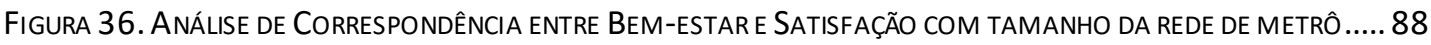

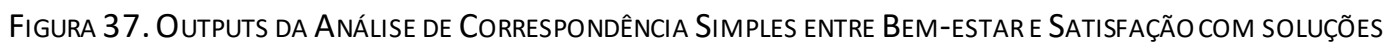
PARA DIMINUIR O TRÂNSITO 
Figura 38. ANÁlise de CoRRESPONDÊNCIA SiMPLES ENTRE BEM-ESTAR E SATISFAÇÃo COM SEGURANÇA No tRÂNSITO92 FIGURA 39. OUTPUTS dA ANÁLISE DE CORRESPONDÊNCIA ENTRE BEM-ESTAR E SATISFAÇÃo COM A PRIORIDADE DO TRANSPORTE COLETIVO NO SISTEMA VIÁRIO.. 


\section{TABELAS}

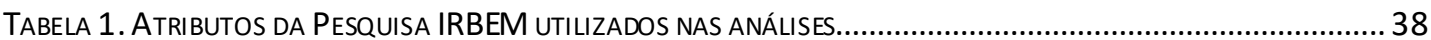

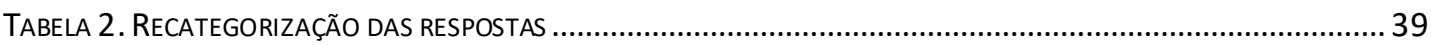

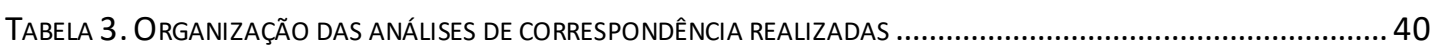

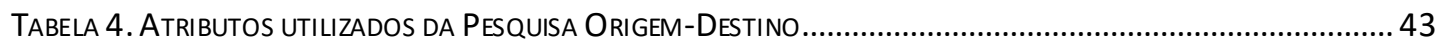

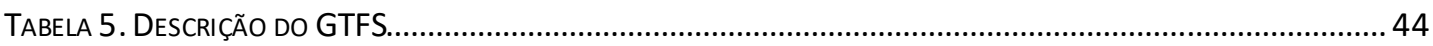




\section{INTRODUÇÃO}

O debate sobre considerar o bem-estar como foco no planejamento das cidades cresceu na última década. Em 2010, o governo do Reino Unido iniciou o programa Measuring National Well-being - MNW (Medição Nacional de Bem-Estar, em tradução livre), que busca produzir e monitorar indicadores confiáveis de bem-estar nacional e relacioná-los com indicadores de saúde, de meio ambiente, econômicos e de segurança (ONS, 2018). Já em 2015, durante o encontro das Nações Unidas para o Desenvolvimento Sustentável, líderes do mundo firmaram um acordo de cooperação para tornar as cidades mais inclusivas, seguras e sustentáveis com o objetivo de melhorar a saúde e bem-estar (ITAMARATY, 2016).

Sob a perspectiva do planejamento de transporte, esta é uma pauta relevante, uma vez que o transporte desempenha papel importante no cotidiano das pessoas e na realização das suas atividades diárias (CARDOSO, 2008). Inclusive, há autores que defendem que os projetos e políticas de transporte devem focar na melhoria do bemestar e não apenas do aumento de mobilidade (KANH e JUSTER, 2002; STANLEY e STANLEY, 2007). No entanto, para isso é necessária a compreensão de como o transporte, de fato, influencia o bem-estar das pessoas.

Delbosc (2012) compilou diversos estudos que investigaram essa relação, utilizando indicadores já consagrados na literatura acadêmica da área de psicologia para mensurar o bem-estar, relacionando-os a indicadores de transporte urbano e sociais. Estes estudos foram realizados, em sua maioria, no Reino Unido e na Austrália. Isso se deveu, principalmente, à disponibilidade de dados nestes países, os quais realizam pesquisas específicas sobre o bem-estar e demais aspectos sociais - entre eles saúde, exclusão social e dificuldade de transporte, como a já citada Measuring National Wellbeing (MNW), no Reino Unido (ONS, 2018) e a Main Metropolitan Survey (MMS) na Austrália (CURRIE et al., 2010).

Tendo como referência estes estudos, a presente pesquisa se propõe a avaliar a relação do bem-estar e transporte urbano para a cidade de São Paulo, que apresenta características sociais bastante diferentes dos locais citados.

\subsection{Justificativa}

São Paulo é uma das maiores cidades do mundo e está entre as principais metrópoles dos países em desenvolvimento. Com 11,9 milhões de habitantes e o maior PIB do país (SEADE, 2020) a capital paulistana sofre diariamente com os efeitos de um sistema de transporte insuficiente. Segundo a Pesquisa Origem-Destino do Metrô de 2017, o total de viagens realizadas ao dia foi superior a 42 milhões na Região Metropolitana de São Paulo (RMSP), com tempo médio de 34 minutos, considerando 
toda a população e avaliando todos os modos de transporte. Esse tempo médio praticamente dobra, chega a 1 hora, para quem utilizava transporte coletivo (METRÔSP, 2019).

Em relação ao bem-estar, a Pesquisa Viver em São Paulo (IBOPE, 2018), realizada em dezembro de 2017 indica que 42\% da população está insatisfeita com sua qualidade de vida. Considerando a escala de notas entre 1 e 10, sendo 1 nada satisfeito e 10 completamente satisfeito, e pesquisa identificou que a satisfação média da cidade é de 6,0. Entretanto, o estudo não apresenta nenhuma análise espacial que permita avaliar se este indicador varia entre as regiões do município.

Tendo em vista, portanto, as relações entre bem-estar e transporte verificadas em outros países por meio de diversos estudos, o presente trabalho propõe a análise de como se estabelece a relação entre estes elementos na cidade de São Paulo. Para isso, a associação entre indicadores de bem-estare de transporte é investigada inicialmente por uma abordagem não espacial, devido ao tipo e quantidade de dados dispostos na Pesquisa Viver em São Paulo. E posteriormente, pormeio de análise complementar com dados de operação da SPTrans e da Pesquisa Origem-Destino do Metrô de São Paulo, aborda-se como eles estão distribuídos espacialmente na cidade e seus possíveis reflexos na vida dos habitantes da cidade.

Espera-se ainda que os resultados deste trabalho sejam base de apoio para subsequentes discussões sobre diretrizes práticas para políticas públicas de transporte urbano, de forma que considerem seus impactos sobre os demais aspectos sociais e econômicos de uma região, visando uma cidade mais humana e com habitantes maior bem-estar.

\subsection{Objetivo}

Esta pesquisa tem como objetivo avaliar a relação entre bem-estar e transporte em uma cidade com alta desigualdade sócio espacial, a partir de um estudo de caso no município de São Paulo.

Os objetivos específicos são:

i. Verificar a ocorrência da relação entre bem-estar e transporte por meio da análise dos dados da pesquisa sobre bem-estar

ii. Identificar quais características do transporte que podem ser identificadas como influentes no bem-estar

iii. Analisar a distribuição espacial dos fatores relacionados ao transporte que interferem no bem-estar dos cidadãos paulistanos.

\subsection{Estrutura do documento}

Este documento visa explicitar todos os dados, conceitos e procedimentos utilizados na elaboração da pesquisa que se mostraram relevantes para a sua conclusão. 
O conteúdo está organizado em sete capítulos, sendo o primeiro esta introdução. No segundo capítulo é apresentada revisão bibliográfica do conceito de bem-estare de estudos que tratam de como este se relaciona com o transporte urbano. No terceiro capítulo são apresentados uma breve contextualização da área de estudo e os dados que serão utilizados para as análises. O quarto capítulo, por sua vez, apresenta a metodologia utilizada na análise dos dados e sua aplicação. O quinto capítulo, então, apresenta os principais resultados obtidos pela metodologia de análise de correspondência bem como pelas análises complementares. O sexto capítulo consolida o que foi analisado, traz as principais considerações deste estudo e sugestões de pesquisas futuras relativas ao tema. O último capítulo apresenta a relação de referências bibliográficas utilizadas na pesquisa. Por fim, os anexos mostram o compilado de todas as análises estatísticas realizadas. 


\section{REVISÃO DA LITERATURA}

Este capítulo tem por objetivo apresentar os principais conceitos abordados neste estudo, assim como dar um panorama geral de como o tema tem sido tratado no campo de estudo do planejamento de transportes.

O capítulo se desenvolve em duas partes. A primeira apresenta o conceito de bem-estar aplicado ao estudo e suas referências bibliográficas. A segunda traz uma base de estudos sobre a relação entre bem-estar e transporte urbano, com suas considerações, métodos e conclusões. Ao final do capítulo apresenta-se considerações gerais do levantamento bibliográfico e ponderações quanto às metodologias utilizadas.

\subsection{Bem-estar}

Há diversas linhas de pensamentos dentro das áreas de estudo da Psicologia e da Filosofia que definem bem-estar e termos relacionados ou equivalentes a este. Porém, como um conceito único para ser utilizado nesta pesquisa, há certa dificuldade na definição de bem-estar, uma vez que diferentes autores, de diversos campos da ciência se apoiam em abordagens e interpretações distintas (KAHN e JUSTER, 2002).

Os estudos que utilizam o bem-estar de forma mensurável (SPINNEY et al., 2009; STANLEY et al., 2010; DELBOSC e CURRIE, 2011b; XIA et al., 2016; MA et al., 2018; , entre outros), tanto de forma quantitativa como qualitativa, partem em geral da definição de Diener (1984) de "bem-estar subjetivo", do inglês subjective well-being (SWB), que diz respeito a como as pessoas avaliam suas vidas e suas experiências de forma individual e subjetiva.

Diener (1984) conceitua que o bem-estar subjetivo é composto pelos seguintes elementos: satisfação com a vida (julgamentos globais da vida), satisfação com aspectos relevantes da vida (por exemplo, satisfação no trabalho), emoções positivas e emoções negativas. Uma pessoa, portanto, tem abundante bem-estar subjetivo quando ela está engajada em atividades interessantes, sente muitas emoções positivas e poucas emoções negativas e está satisfeita com a sua vida. Ou seja, em termos mais simples, tem a ver com ter uma vida feliz.

De forma mais ampla e irrestrita, os termos "bem-estar", "satisfação com a vida" ou ainda "felicidade" são utilizados por diversos autores para representar o referido bem-estar subjetivo. Já o termo "qualidade de vida", por sua vez, apesar de em alguns momentos ser utilizado de forma equivalente a "bem-estar", é mais apropriado para se referir às condições básicas de vida e à saúde (PEREIRA et al. 2012). Portanto, para evitar uma sobreposição de conceitos, este termo será poupado nas discussões conseguintes. No caso da citação de estudos que utilizam o termo "qualidade de vida" representando somente os aspectos de bem-estar, o termo será substituído de modo a evitar ambiguidade. 
Diener coloca ainda que há diversos fatores que influenciam diretamente o bemestar individual, como personalidade, contexto/circunstâncias, fatores demográficos e atividades cotidianas, como atividade física e alimentação (DIENER, 1984). E este é o principal motivo que pode tornar difícil a investigação do bem-estar relacionado a fatores externos (KAHN e JUSTER, 2002).

Apesar da dificuldade em isolar os fatores que influenciam o bem-estar subjetivo, diferentes áreas do conhecimento utilizam este conceito, buscando compreender como ele se relaciona com variados aspectos externos ao indivíduo. No campo das Ciências Sociais, por exemplo, investiga-se os impactos da segurança pública, da inclusão social ou do respeito aos direitos humanos sobre a satisfação com a vida. Já na Economia, apesar do senso-comum de que haveria uma relação direta entre satisfação com a vida e situação financeira, diversos estudos investigaram a relação entre indicadores de bem-estar com indicadores de renda ou de nível econômico e não encontraram uma relação direta (MYERS, 2000; DIENER, 1984; e EASTERLIN, 2005). Neste sentido, Headey et al. (2004) e Deiner e Seligman (2004) concluíram que o ganho de rendimento não é diretamente relacionado ao aumento de satisfação com a vida, porém Layard (2005) identificou que apesar da renda não gerar impacto diretamente no bem-estar, a perda de rendimento é bastante influente. Enquanto Clark e Oswaldo (1994), Winkelmann e Winkelmann (1998) e Delbosc e Currie (2011a) identificaram que o desemprego provoca estresse e tem uma grande influência na satisfação com a vida, sendo este efeito maior que simplesmente a redução de renda. Por fim, em sua análise conjunta de diversos estudos que tratam de bem-estar, Delbosc (2012) observou que é comum a relação de bem-estar subjetivo com indicadores que representam integração com a sociedade, como índices de exclusão social.

Em resumo, os principais fatores econômicos que influenciam o bem-estar são a extrema pobreza, a redução de renda e o desemprego (LAYARD, 2005; DELBOSC e CURRIE, 2011a; WINKELMANN e WINKELMANN, 1998). Nota-se, portanto, que o transporte tem potencial impacto no bem-estar, uma vez que a falta deste é uma das principais barreiras para se conseguir emprego, como levantado pela Social Exclusion Unit (2003) no Reino Unido, e de acessar as oportunidades de trabalho, estudoe lazer, de forma geral (GOMIDE, 2006). Além destes fatores econômicos, as relações interpessoais significativas e os problemas de saúde também aparecem com alto índice de correlação com o bem-estar (DELBOSC, 2012), demonstrando novamente a relação com o transporte, uma vez que a promoção deste é um dos principais mecanismos de redução de barreiras no acesso a locais de promoção de saúde e de tratamento de doenças (GOMIDE, 2006).

\subsubsection{Indicadores de bem-estar}

Segundo Januzzi (2005), indicadores são medidas que permitem a operacionalização de um conceito abstrato, traduzindo em temos operacionais as 
dimensões sociais de interesse definidas a partir de escolhas teóricas ou mesmo políticas.

Internacionalmente, diversos órgãos estabeleceram guias de como medir qualidade de vida e bem-estar em cidades e países, sendo possível a comparação entre eles, como é o caso da Organização Mundial da Saúde (OMS) e da Organização para a Cooperação e Desenvolvimento Econômico (OCDE) (BOARINI el al 2006). O mais reconhecido deles é o Índice de Desenvolvimento Humano (IDH), definido pela Organização das Nações Unidas (ONU), que considera as dimensões básicas do desenvolvimento humano - longevidade, conhecimento e recursos econômicos.

$\mathrm{O} I \mathrm{IH}$, apesar de medir a qualidade de vida, costuma ser utilizado em pesquisas acadêmicas para representar o conceito de bem-estar, principalmente no campo das Ciências Econômicas (CLOUTIER et al., 2017). Por sua vez, os estudos que tratam de bemestar no campo de conhecimento do planejamento de transporte apresentam uma variedade de métricas diferentes para representar a satisfação com a vida. Popova (2017), por exemplo, utiliza um indicador demográfico para representar o bem-estar, no caso, a renda. Porém, a maioria dos estudos utilizam resultados de pesquisas direcionadas ao tema, como é o caso de Spinney et al. (2009) que analisaram o bemestar a partir do nível de concordância com frases relacionadas a felicidade e satisfação com a vida, e de Bestgard et al. (2011) que utilizaram dados de frequência semanal de bom e mau humor declarados pelos entrevistados.

No Brasil, o Observatório da Metrópole (RIBEIRO e RIBEIRO, 2016) desenvolveu o Índice do Bem-estar Urbano, que avalia o bem-estar usufruído pela população nas cidades brasileiras a partir das condições de mobilidade, habitacionais, de ambiente urbano, atendimento em serviços coletivos e infraestrutura urbana em que está inserida.

Vella-Broderick e Delbosc (2011) recomendam que, para análises que consideram o bem-estar em um nível individual, em especial quando este é relacionado com indicadores externos urbanos, como é o caso do transporte, a caracterização do bem-estar seja representada a partir dos indicadores abaixo, que serão explicados nas subseções a seguir:

i. Escala de Satisfação com a Vida (Satisfaction with Life Scale)

ii. Índice de Bem-estar Pessoal (Personal Well-being Index - PWI),

iii. Escala de Efeitos Positivos e Negativos (Positive Affects and Negative Affects Scale - PANAS).

Ma et al. (2018), por exemplo, utilizaram a Escala de Satisfação com a Vida para representar o bem-estar em seu estudo, encontrando forte relação entre satisfação com a vida e dificuldade de transporte. Staney et al. (2001), por sua vez, optaram pelo Índice de Bem-estar Pessoal (PWI). Já Delbosc e Currie (2011b, 2011c) avaliaram a relação do 
bem-estar com o transporte utilizando os três indicadores mencionados e obtiveram resultados muito semelhantes entre eles.

\subsubsection{Escala de Satisfação com a Vida (SWLS) - Diener et al., 1985}

A Escala de Satisfação com a Vida (Satisfaction with Life Scale - SWLS) é um indicador do tipo de constructo único, pois considera em si apenas variações do mesmo conceito: a satisfação com a vida.

Diener et al. (1985) definiram uma forma de mensurar a satisfação com a vida a partir de cinco afirmações sobre as quais os entrevistados deveriam responder na escala de resposta tipo Likert de 1 a 7, na qual 1 concorda-se fortemente e 7 discorda-se fortemente com cada frase.

As afirmações apresentadas aos entrevistados foram, em tradução literal:

- Sob a maioria dos aspectos, minha vida está próxima do meu ideal.

- As minhas condições de vida são excelentes.

- Estou satisfeito com minha vida.

- Até agora eu tenho conseguido as coisas importantes que eu quero na vida.

- Se eupudesse escolher, não mudaria quase nada na min ha vida.

Segundo a metodologia, a Escala de Satisfação com a Vida de uma pessoa é calculada pela média das suas notas referentes a cada afirmação. Quanto maior o valor obtido, maior a sua satisfação com a vida.

$$
S W L S=\frac{1}{7} \sum_{n=1}^{7}\left(\text { nota }_{n}\right)
$$

Os autores sugerem que a metodologia seja seguida à risca, entretanto apresentam diretrizes para casos em que a escala seja reduzida, por exemplo, para 1 a 5 .

\subsubsection{2 Índice de bem-estar pessoal (PWI) - International Well-being Group, 2013}

O Índice de Bem-estar Pessoal, do inglês Personal Well-being Index (PWI), desenvolvido pelo Grupo Internacional de Bem-estar é construído a partir da resposta de entrevistados que indicam o quão satisfeitos estão com diferentes aspectos de suas vidas.

Primeiramente, se pergunta "Quão satisfeito você está com a sua vida como um todo?" e na sequência são feitas 7 perguntas sobre o nível de satisfação com os domínios que compõe a vida: padrão de vida, saúde, realizações, relacionamentos, segurança, conexão com a comunidade e segurança futura. A metodologia também prevê uma pergunta adicional referente à satisfação com a própria espiritualidade ou religião. As 
respostas são feitas utilizando a escala Likert de 0 a 10, onde 0 significa "completamente não satisfeito" e 10 significa "completamente satisfeito". É importante destacar que a primeira pergunta, referente a vida como um todo, não faz parte das variáveis analisadas para o cálculo do PWI, porém ela é importante por apresentar o contexto da entrevista aos respondentes.

Para o cálculo do PWI de cada respondente, propõe-se primeiramente que as notas referentes a cada afirmação sejam convertidas para uma escala $0-100$. Na sequência, o PWI individual é calculado pela média dessas notas, conforme apresentado na equação a seguir, sendo k o número de afirmações apresentadas (7 ou 8). Quanto maior o valor do PWI, maior a satisfação com a vida.

$$
P W I=\frac{1}{k} \sum_{n=1}^{k}\left(\text { nota } a_{n}\right)
$$

A metodologia prevê também que as respostas de cada indivíduo podem ser compiladas e analisadas conjuntamente como um grupo, sendo os PWI individuais referenciados à distribuição normal da população total.

\subsubsection{PANAS - Watson, Clark e Tellegen, 1988}

Já o método PANAS considera dois indicadores fortemente e negativamente correlacionados entre si. Por um lado, o indicador de Efeitos Positivos (Positive Affects PA) reflete o nível de bom humor que a pessoa se encontra. Um alto valor de PA representa um estado de muita energia, alta concentração e engajamento com prazer, enquanto um baixo valor de PA se refere a tristeza e letargia. Por outro, o indicador de Efeitos Negativos (Negative Affects - NA) é utilizado para medir o nível de mau humor. Valores altos para NA caracterizam raiva e nervosismo enquanto valores baixos de NA representam estado de calma e serenidade. Esses dois fatores, então, representam as dimensões do estado emocional.

Os indicadores são calculados a partir da reação a 20 sentimentos apresentados em uma sequência aleatória, onde se deve utilizar a escala Likert de 1 a 5 , em que 1 significa que não se identifica e 5 que se identifica extremamente. Os sentimentos referentes ao indicador de PA são: atento(a), interessado(a), alerta, animado(a), entusiasmado(a), inspirado(a), orgulhoso(a), determinado(a), forte e ativo(a).E os sentimentos referentes ao indicador de NA são: angustiado(a), triste, hostil, irritado(a), assustado(a), envergonhado(a), culpado(a), nervoso(a) e ansioso(a).

Os indicadores PA e NA são calculados pela média das notas respondidas aos sentimentos de cada grupo. Nas equações, identificam-se os sentimentos do grupo positivo como " $p$ " e os do grupo negativo como " $n$ ". 


$$
\begin{aligned}
& P A=\frac{1}{10} \sum_{p=1}^{10}\left(\operatorname{nota}_{p}\right) \\
& N A=\frac{1}{10} \sum_{n=1}^{10}\left(\operatorname{nota}_{n}\right)
\end{aligned}
$$

O PANAS pode representar o bem-estar em qualquer período, entretanto os autores sugerem que as declarações de como as pessoas se sentem naquele exato momento são menos confiáveis por estarem mais sujeitas a variações emocionais. Ao direcionar as questões para um período maior, os resultados obtidos refletem maior estabilidade.

\subsubsection{Nota sobre o cálculo dos indicadores}

Os três indicadores apresentados e consagrados na literatura acadêmica de bemestar subjetivo utilizam escalas de resposta subjetivas, como a escala Likert, para obter dos entrevistados informações sobre a satisfação com a vida. Para todos eles, a metodologia recomenda ao final somar as notas obtidas em cada uma das afirmações e tirar a média, com a finalidade de se obter um indicador único.

Entretanto, esta é uma prática controversa. Fávero e Belfiore (2017) são categóricos ao apontar que a ponderação arbitrária de variáveis qualitativas, como é o caso da escala Likert, não deve ser feita. Os autores sugerem outras ferramentas, como a análise de correspondência, como opção para análise de escalas subjetivas de respostas.

Para o presente estudo, a autora optou por ater-se às recomendações da modelagem estatística e tratando os indicadores como variáveis categóricas, como apresentado no capítulo 4 - Métodos.

\subsection{Relação entre bem-estar e transporte urbano}

O transporte tem um papel fundamental na vida cotidiana das pessoas, pois é por meio dele que se viabiliza o acesso a locais e oportunidades, e com isso, se realizam as atividades fundamentais (GOMIDE, 2006). E a alta relação que o desempenho dessas atividades tem com a satisfação com a vida (DELBOSC, 2012; CLARK e OSWALDO, 1994; WINKELMANN e WINKELMANN, 1998; DELBOSC e CURRIE, 2011a), faz com que o transporte seja um elemento potencialmente influente no bem-estar das pessoas.

Esta influência pode ocorrer de diversas formas. Os benefícios psicológicos provocados pela "liberdade de viajar" geram senso de autonomia e controle da própria vida (METZ, 2000; WHELAN et al., 2006; VELLA-BRODERICK E DELBOSC, 2011), enquanto o transporte ativo, por também ser uma atividade física, pode promover aumento do bem-estar através da melhoria da saúde. Paez e Whalen (2010) verificaram ainda que 
pessoas que utilizam meios de transporte ativo para viajar tem mais diversão du rante a viagem, por meio de uma pesquisa direcionada para este fim no Canadá. E Hansson et al. (2011) identificaram que na Suíça os quem se locomove a pé e de bicicleta relata melhoria na saúde, níveis mais baixos de exaustão e estresse e menos dias de trabalho perdidos do que os motoristas de automóveis. Porém, pontua-se que estas conclusões saíram de estudos em países com infraestruturas para transporte ativo de qualidade, 0 que não ocorre para a maioria dos municípios brasileiros, em especial para São Paulo.

A análise da relação entre transporte e bem-estar é um tema de estudo relativamente recente, sendo as primeiras publicações da década de 90. Delbosc (2012) levantou uma série de estudos já desenvolvidos desde então que tinham por objetivo analisar a influência do transporte no bem-estar subjetivo. As análises realizadas nestes estudos, em sua maioria, são referentes a apenas uma região ou cidade e relacionam o bem-estar da população com o transporte da região, sob a perspectiva do "transport disadvantage".

"Transport disadvantage" é um termo consagrado na literatura internacional, porém com difícil tradução para o português, devido a gama de conceitos que ele abarca, por vezes complexos. Dodson et al. (2004) levantaram diversos estudos e verificaram que a terminologia usada não é consistente, pois pode se referir a falta de infraestrutura de transporte, limitação na mobilidade, falta de acessibilidade, falta de conectividade, estresse durante a viagem e inequidade de transporte. Currie e Delbosc (2011) acrescentam ainda que pode se referir tanto a uma região (location-based transport disadvantage) ou às pessoas (transport disadvantage people). E Lucas (2012) adiciona uma terceira interpretação ao colocar que pessoas têm experiência de "disadvantage transportation", fazendo uma atribuição da desvantagem, ou dificuldade de transporte, como característica da viagem realizada.

Neste estudo, será utilizada a expressão em português "dificuldade de transporte" como sinônimo de "transport disadvantage". O termo "dificuldade de transporte" será utilizado para representar as características de transporte de um local, que se relacionam com aspectos negativos da situação de quem realiza viagens partindo desse local, tendo como base a definição utilizada nos estudos que relacionam os impactos do transporte na vida cotidiana das pessoas, além do bem-estar, como acidentes nas vias e acessibilidade a oportunidades de a trabalho, educação, saúde, compra de comida e atividades sociais e culturais (SOCIAL EXCLUSION UNIT, 2003; DELBOSC, 2012).

\subsubsection{Dificuldade de transporte}

Ao analisar diversos casos conjuntamente, Delbosc (2012) verificou que a avaliação da dificuldade de transporte nos estudos que o relacionam com o bem-estar subjetivo ocorre geralmente sob as seguintes abordagens conceituais: infraestrutura de transporte, mobilidade, acessibilidade e satisfação com a viagem ou com o transporte. 
E para cada tipo de abordagem, diversos indicadores são possíveis. A seguir apresentamse exemplos de estudos que representaram a dificuldade de transporte sob estes aspectos, objetivando traçar um panorama de como outros autores realizaram a análise da relação entre transporte e bem-estar, suas conclusões e métodos utilizados.

A avaliação da quantidade e qualidade da infraestrutura de transporte de um local é uma das formas mais comum de se medir a dificuldade de transporte de uma região, sendo bastante utilizado para avaliação de projetos de engenharia ou políticas de transporte (FERRAZ e TORRES, 2004). Popova (2017) investigou a influência de rodovias e algumas características viárias no bem-estar dos residentes no seu entorno, tanto em áreas rurais quanto urbanas, por meio de análise de correlação. A autora verificou que a pobreza, utilizada como proxy de bem-estar neste estudo, tem uma relação positiva com as áreas rurais e uma relação negativa com a extensão das rodovias, representando, portanto, que nos locais com maior densidade viária há menos pobreza. Já Currie et al. (2010), utilizando equações estruturais, avaliou a oferta de serviços de transporte público nas regiões de Melbourne representada pela frequência dos serviços ao longo da semana e a noite, relacionando-a com indicadores de bemestar e de exclusão social. Xia et al. (2016), por sua vez, recorreu a análise de variância e verificou o potencial de captação do transporte público por região nas cidades de Perth e Sydney, considerando a área de influência, frequência e capacidade dos sistemas de transporte, e concluiu que a oferta de transporte está diretamente relacionada a fatores de exclusão social.

É importante ter em conta que a infraestrutura de transporte não impacta somente seus usuários, como também as demais pessoas, devido as externalidades causadas (DELBOSC, 2012). Esses impactos podem ser tanto positivos, principalmente relacionada a aspectos econômicos e de segurança, quanto negativos, como poluição do ar, sonora e visual, que podem influenciar o bem-estare saúde da população (FRANK et al., 2006). Além disso, a inserção de uma nova infraestrutura de transporte provoca efeitos nas dinâmicas de uso do solo e imobiliária de uma região, como gentrificação ou mudanças no perfil de ocupação, que também influenciam o cotidiano daquela comunidade (HUMPHREY, 2005).

A mobilidade, por sua vez, é a forma de avaliar o transporte pela capacidade potencial de que o indivíduo tem de realizar viagens (HANSON, 2004). Muitos pesquisadores investigam a relação da mobilidade com o bem-estar em grupos de idosos, pois a idade avançada se apresenta como uma grande restrição à mobilidade, sugerindo, então, que seu papel em promover o bem-estar é particularmente importante para este grupo de pessoas (BANISTER E BOWLING, 2004; MOLLENKOPF et al., 2005; SPINNEY et al., 2009). Mollenkopf et al. (2005), ao estudar grupos de idosos em diversos países europeus, identificaram por meio de equações estruturais que a realização de viagens tem forte influência positiva na qualidade de vida. Mais especificamente, Banister e Bowling (2004), através de análises de categorias puderam 
avaliar as declarações das pessoas de mais idade do Reino Unido quanto à dificuldade de caminhar, à presença de doença crônica e à proximidade a serviços como saúde e compararam às suas declarações sobre seu bem-estar, indicando que a dificuldade de caminhada e a presença de doença são elementos que reduzem a percepção de qualidade de vida. Contudo, a relação entre mobilidade e bem-estar não ocorre somente em grupos de idosos, como verificaram Stanley et al. (2010) para a pop ulação Melbourne, de forma geral. Por meio de mínimos quadrados, os autores identificaram que o aumento de mobilidade está altamente relacionado à redução da exclusão social e indiretamente ligado à melhoria de bem-estar.

Outra vertente de análise do transporte e da sua relação com o bem-estaré por meio da acessibilidade, que está relacionada ao potencial de oportunidades que podem ser acessadas a partir de determinado local (HANSSEN, 1959). As oportunidades aqui se referem a toda e qualquer atividade ou local em que se realizam atividades, sendo os principais locais aqueles de trabalho, de educação, de atendimento à saúde, de lazer, de cultura e de participação social (VAN WEE et al. 2001; VAN WEE e GEURS, 2004; SANTOS, 2016; MORENO-MONROY et al., 2018). Mollenkopf et al. (2005) relacionaram a realização de atividades fora da residência e a disponibilidade de modos de transporte na região à satisfação com a vida, verificando uma alta relação com o bem-estar para o grupo estudado. E Neusten et al. (2013) identificaram que a maior acessibilidade permite maior interação social e participação em sociedade, que, por sua vez, aumenta o nível de satisfação com a vida. Já Delbosc (2012), a partir da análise conjunta de diversos estudos sobre transporte e bem-estar, conclui que o sistema de transporte tem um papel importante na influência do bem-estar, principalmente pela viabilização do acesso às atividades relacionadas aos "domínios da vida", como trabalho, saúde e lazer.

Por fim, outra abordagem utilizada na investigação de como transporte e bemestar estão relacionados é quanto a satisfação com a viagem (PRITCHARD, 2019) ou com o transporte (DELBOSC e CURRIE, 2011a). Os estudos (CHALOUX, 2019; VOS e WITLOX, 2017) apontam que um bem-estar subjetivo mais alto se associe positivamente à satisfação no deslocamento. Ou seja, que a satisfação geral com a vida provavelmente resultará em uma satisfação maior com o deslocamento, apesar de que não se espera que seja particularmente forte. Bestgard et al. 2011, por sua vez, identificaram que o bem-estar é diretamente relacionado a avaliação de satisfação com as viagens e com as atividades realizadas diariamente, a partir de métodos de regressão. Já Delbosc e Currie (2011a) mostraram que a percepção do usuário em relação ao transporte afeta não apenas o bem-estar, como também está relacionado com a possibilidade de exclusão social.

\subsubsection{Indicadores de dificuldade de transporte}

As características de transporte podem ser analisadas sob diferentes aspectos, havendo então uma diversidade de métricas utilizadas para representá-las. 
Do ponto de vista de estudos técnicos de planejamento de transporte, é comum avaliar os efeitos na mobilidade com o uso de métricas centradas em princípios econômicos, como custo-benefício e monetização do tempo. O cálculo de benefícios de um projeto ou política pública, em geral, é relacionado à quantidade de tempo economizado que ele vai gerar para a sociedade, baseando-se em valores fixos de tempo dos usuários do sistema ,ou valores proporcionais à renda média da classe social que ela pertence (FERRAZ e TORRES, 2004; DELBOSC, 2012). Mackie et al. (2001) argumentam que considerar economia de tempo para avaliar investimentos em transporte tem valor por dois motivos: primeiro, permite que a redução da desutilidade da viagem realizada; e segundo, permite a utilização deste tempo economizado com atividades que possam satisfazer mais as pessoas, seja financeiramente ou psicologicamente.

Entretanto, alguns pesquisadores questionam se a economia de tempo de viagem por si só é revertida em aumento da qualidade de vida e bem-estar das pessoas, como Mokhtarian e Salomon (2001) os quais identificaram haver casos em que a viagem mais longa pode ser prazerosa ou que o tempo economizado não é utilizado em atividades mais benéficas psicologicamente. Lucas et al. (2009) também destacam o fato de que a monetização do tempo pode levar a conclusões enviesadas, como ocorre com a avaliação de economia de tempo gerada por investimentos em infraestrutura viária. Este tipo de projeto, em geral, traz mais benefícios para parcela da população motorizada, que já tem maior mobilidade, e menos para a parcela da população com pouco ou nenhum acesso aos meios motorizados individuais. Além disso, este tipo de modelagem, em geral, tem dificuldade de representar as desutilidades relacionadas a transferência de modos, conforto da viagem e percepção de segurança do usuário (ORTUZAR e WILLUMSEN, 2011).

No caso dos estudos que tratam da relação bem-estare transporte, a maioria o faz sob a ótica da dificuldade de transporte (DELBOSC, 2012), que, como já apresentado, trata das características de transporte de um local, relacionadas aos aspectos negativos da situação de quem realiza viagens partindo desses locais e pode ser representada por diferentes métricas (DODSON et al., 2004). Desta forma, a seguir são apresentadas as principais medidas de dificuldade de transporte utilizadas em estudos com escopo semelhante e/ou relacionados ao tema desta pesquisa, retomando as abordagens conceituais já apresentadas: infraestrutura, mobilidade, acessibilidade e satisfação.

Ao representar a dificuldade de transporte pela qualidade ou quantidade de infraestrutura de transporte, os principais indicadores utilizados compreendem informações sobre a oferta de transporte e seu alcance. Além de Popova (2017), que utilizou a extensão e densidade viária para avaliar a diferença na dificuldade de transporte em áreas rurais e urbanas na Letônia, Murray et al. (1998) consideraram como indicador a população atendida por linhas de transporte público em Brisbane, na Austrália. Para o cálculo, considerou-se a área de até 400 metros a partir dos pontos de embarque, tendo essa distância como a adequada para uma caminhada confortável e, 
também, um padrão pela qual as agências de planejamento de transporte medem a captação das rotas de transporte público.

Currie (2010) propôs um Indicador de Oferta baseado na quantidade de serviços de transporte e no seu potencial de captação de usuários. O indicador de oferta uma região $\mathrm{A} 1\left(S I_{S A 1}\right)$ é calculado considerando a soma de todo seu potencial de captação de usuários - que por sua vez é calculado considerando a área de captação a partir do ponto de embarque $\left(A_{B i}\right)$ frente ao total da área da região avaliada $\left(A_{S A 1}\right)_{-}$, multiplicada pela frequência de serviço de transporte no ponto em questão.

$$
S I_{S A 1}=\sum \frac{A_{B i}}{A_{S A 1}} * S L_{B i}
$$

Para cada tipo de serviço, é considerada uma área de captação, a depender da capacidade do modo de transporte. $O$ autor sugere raios de $400 \mathrm{~m}$ para pontos de ônibus e de $800 \mathrm{~m}$ para estações de transporte sobre trilhos. Ao relacionar o Indicador de Oferta das regiões administrativas de Melbourne com seus indicadores econômicos e sociais, Currie (2010) identificou que as áreas com maiores necessidades eram as com menores ofertas de transporte.

Xia et al. (2016) se baseou no Indicador de Oferta definido por Currie (2010), porém normalizado, permitindo assim a análise comparativa dos sistemas de transporte de Perth e Sydney. Além disso, os autores também consideraram outros indicadores de oferta para caracterizar a dificuldade de transporte destas cidades, como número médio de pontos de embarque por região, frequência média dos serviços de transporte público e percentual da área coberta pelo transporte público.

Conforme já apresentado, a dificuldade de transporte também é avaliada por meio de indicadores de mobilidade. Stanley et al. (2010) e Lucas (2012) são exemplos de estudos que utilizam as métricas de média de viagens realizadas por habitante e posse de automóveis. Já Delbosc e Currie (2011b) consideram, além destas, o número de embarques em transporte público, percentual de viagens realizadas por cada modo e distância média das viagens.

Dentro da abordagem de acessibilidade, primeiramente Hansen (1959) conceitua a medida de acessibilidade por meio da medida de distância (ou tempo de viagem) entre duas regiões para contabilização da dificuldade de acesso às oportunidades. A acessibilidade de uma região $i$ para oportunidades de uma região $j$ $\left(A_{i-j}\right)$ é então calculada pelo número de oportunidades na região $j\left(S_{j}\right)$, dividido pela impedância de distância ou tempo $\left(T_{i-j}\right)$ entre as duas zonas. A acessibilidade da região $i$ então é a soma de sua acessibilidade a todas outras regiões $j$. 


$$
A_{i-j}=\frac{S_{j}}{T_{i-j}}
$$

Diversos autores contribuíram posteriormente com análises de oportunidades específicas, como trabalho, educação e saúde (VAN WEE et al. 2001; VAN WEE e GEURS, 2004; PAEZ, SCOTT e MORENCY, 2012; SANTOS, 2016; MORENO-MONROY et al., 2018) com o objetivo de avaliar o impacto que o transporte tem nos dife rentes aspectos da vida cotidiana dos indivíduos.

Por fim, indicadores subjetivos são utilizados na caracterização da dificuldade de transporte dentro da abordagem de satisfação. Em geral, estes indicadores são obtidos a partir da declaração de usuários do sistema de transporte em entrevistas que questionam, por exemplo, o nível de dificuldade em se deslocar, dificuldade de realizar atividades e qualidade do transporte, entre outros (DELBOSC e CURRIE, 2011 b; SOCIAL EXCLUSION UNIT, 2003; MA et al, 2018). Tais indicadores podem ser relacionados tanto à percepção quanto à qualidade e disponibilidade do transporte quanto às características da viagem em si. Um ponto importante dos indicadores subjetivos é a cautela na interpretação dos dados, pois uma pessoa com carro em uma viagem de três quilômetros pode se sentir "muito insatisfeita" devido ao congestionamento no trajeto. Enquanto uma outra pessoa em uma viagem de ônibus de 20 quilômetros também pode se sentir "muito insatisfeita" devido ao tempo de viagem ou nível de desconforto (DELBOSC, 2012).

Também é comum utilizar mais de um indicador para caracterizar a dificuldade de transporte de uma região. Deste modo, é possível investigar se a relação encontrada se refere a algum aspecto específico considerado no indicador, não previsto inicialmente. Delbosc e Currie (2011b), por exemplo, utilizaram 12 indicadores diferentes para caracterizar o transporte e mais 34 perguntas relacionadas à dificuldade de transporte em seu estudo em Melbourne e concluíram que a relação com o bemestar é mais clara para este caso considerando a dificuldade de transporte representada pela frequência que o usuário tem dificuldade no acesso a atividades, devido à falta de transporte.

\subsection{Limitações metodológicas}

Delbosc (2012) coloca que as maiores limitação dos estudos que buscam relacionar a deficiência de transporte com o bem-estar são a definição das métricas de dificuldade de transporte e avaliação de seu impacto no resultado do estudo. As variáveis consideradas vão desde respostas objetivas, como número de viagens realizada (STANLEY et al. 2011, DELBOSC e CURRIE, 2011b) às mais subjetivas, como percepção da qualidade da viagem realizada (DELBOSC e CURRIE, 2011a e b, MA et al. 2018). 
A variedade de proxys para bem-estare satisfação de vida observada nos estudos também é grande. São utilizados desde indicadores estabelecidos por órgãos internacionais idôneos (CLOUTIER, 2017) como indicadores medidos em pesquisas de temáticas abrangentes, devido à falta de levantamentos mais apropriados (POPOVA, 2017).

Por fim, é importante ter em mente que devido a disponibilidade de dados e a dificuldade de se conseguir informações mais detalhadas, pesquisas que utilizam dados secundários e indicadores gerais, muitas vezes, não conseguem capturar sutilezas ou não permitem a investigação de algum ponto específico. Sendo importantes, então, tanto a criatividade do pesquisador na exploração dos dados, quanto a atenção do espectador para o fato que as análises se estendem ao limite do que permitem os dados disponíveis. 


\section{TRANSPORTE E BEM-ESTAR EM SÃO PAULO}

Neste capítulo são apresentados a área de estudo e os dados utilizados na observação de como ocorre a relação entre bem-estar e transporte, no caso do município de São Paulo.

\subsection{São Paulo}

Por suas características de grande disparidade econômica e social e, também, pela disponibilidade de dados sobre deslocamentos diários (METRÔ-SP, 2008), a cidade de São Paulo é objeto de investigações acadêmicas que buscam relacionar o transporte com aspectos sociais.

A desigualdade econômica tem características geográficas e, dentre outros aspectos, se reflete em uma desigualdade de acesso à cidade. Gomide (2003) e Rosa (2006) avaliaram que as dificuldades de transporte variam para as diferentes faixas de renda. Já Sposati (2013) avaliou a exclusão social na cidade de São Paulo utilizando dados de mobilidade (METRÔ-SP, 2008) e identificou altos níveis de exclusão social nas áreas periféricas do município. E Marques (2014), por sua vez, analisou a distribuição das classes sociais no território de São Paulo utilizando informações referente ao tipo de emprego, constatando uma cidade bastante segregada, em especial no que diz respeito às classes superiores, que apresentam pouca integração com as demais classes no território paulistano.

Sob a ótica do bem-estar, há poucos estudos até o momento para a cidade de São Paulo. Forattini (1991) foi um dos primeiros a debater ainda no século XX os impactos de que o ambiente urbano pode causar no bem-estar individual das pessoas, apresentando o estudo de caso de São Paulo. Na comparação com outros municípios brasileiros, pelo IBEU - Índice de Bem-estar Urbano, a capital paulistana apresenta um bom índice, com 0,812. Entretanto, na dimensão de mobilidade urbana que compõe o índice, é a pior capital brasileira com nota 0,623 (RIBEIRO e RIBEIRO, 2016).

$\mathrm{Na}$ sequência, são apresentados os dados utilizados nesta pesquisa para compreensão da dinâmica entre bem-estar e transporte para o município de São Paulo.

\subsection{Dados}

Foram utilizados neste estudo os bancos de dados resultantes das Pesquisas Ir Bem e Viver em São Paulo (2008-2018), para as análises de bem-estar, e da Pesquisa de Origem e Destino de 2017 do Metrô de São Paulo (METRÔ-SP, 2019) e de operação dos sistemas de transporte contidas no arquivo de GTFS (TOMASIELLO et al., 2019) para as análises de variáveis relacionadas ao transporte no município.

Destaca-se que o uso de dados secundários, como é o caso desta pesquisa, promove vantagens e desvantagens ao estudo. A facilidade de se ter os dados em 
grande quantidade amostral, sem a necessidade da coleta, certamente é o maior benefício. Já como desvantagem tem-se que o propósito da coleta destes dados não é o mesmo para o qual serão utilizados neste estudo (MALHORTA, 2001). Apesar deste não ser um impeditivo, é importante ter claro as limitações que impõem às análises, principalmente no que tange a representatividade da amostra para determinado grupo de indivíduos ou região e que este não é um estudo experimental, ou seja, o estudo não se propõe a realizar alterações nas variáveis de transporte de modo a medir seu efeito no bem-estar, não podendo estabelecer relações diretas de causa e efeito. Com estas ressalvas colocadas, o capítulo que discorre a seguir apresentará os dados que serão utilizados na pesquisa.

\subsubsection{Pesquisa de Bem-estar}

A primeira edição da Pesquisa Viver em São Paulo foi realizada em janeiro de 2008, com o objetivo de investigar a percepção da população quanto à qualidade de vida, administração pública e confiança nas instituições. Em 2010, na terceira edição, a Pesquisa teve seu escopo ampliado e passou a se chamar IRBEM - Indicadores de Referência de Bem-estar no Município. Além da percepção da população quanto à qualidade de vida, administração pública e confiança nas instituições, ela passou a abordar também o acesso a serviços essenciais e a satisfação da população com diversos aspectos relacionados ao bem-estar, entre eles trabalho, saúde, consumo, religião e espiritualidade, entre outros. A amostra de entrevistas cada ano era superior a 1500, sendo todas elas realizadas com a metodologia face a face domiciliar (IBOPE, 2016).

O ano de 2017 foi o último de realização da IRBEM e, em 2018, a pesquisa voltou a se chamar Viver em São Paulo, com escopo semelhante ao original, porém mais reduzido e com enfoque apenas na qualidade de vida. No mesmo ano também ocorreu uma redução no tamanho da amostra de entrevistas. Além disso, a metodologia de pesquisa passou a ser realizada de maneira híbrida, isto é, utilizando entrevistas online para a classe A, B e C1 e face a face domiciliar para as classes C2, D e E (IBOPE, 2017).

De forma geral, a pesquisa traz perguntas referentes a percepção dos cidadãos quanto a aspectos relacionados a qualidade de vida e ao funcionamento dos serviços públicos e instituições. Em geral as perguntas recorrem à escala de notas de 1 a 10, com 1 representando a total insatisfação e 10 a total satisfação com o tema perguntado.

Para a presente pesquisa, optou-se pelo recorte temporal e uso dos resultados da Pesquisa de 2016, em que o bem-estar médio no município foi de 4,7. Os critérios para esta seleção são apresentados no item 4.3.3 deste documento.

\subsubsection{Pesquisa Origem-Destino 2017}

A Pesquisa Origem e Destino é realizada pela Companhia do Metrô de São Paulo na Região Metropolitana de São Paulo a cada dezanos, desde 1967. Com o propósito de diagnosticar a situação de mobilidade da região e, com isso, orientar o planejamento de 
transporte futuro. Esta é a principal pesquisa realizada na região com foco na caracterização dos deslocamentos diários da população.

As informações obtidas com as pesquisas são diversas e continuamente são utilizadas como base de estudos para orientar o planejamento de transportes da região. Dentre os principais dados estão o total de viagens diárias, índice de mobilidade, divisão modal, motivos de viagens e tempo médio de duração das viagens, para a região e desagregado pelas zonas, além da própria matriz de viagens que identifica os fluxos que ocorrem diariamente entre as zonas da RMSP.

\subsubsection{Dados operacionais de transporte}

As informações referentes a operação do transporte no município de São Paulo têm como fonte o material elaborado por Tomasiello et al. (2019), que a partir da previsão operacional divulgada pela SPTrans, por meio do GTFS (do inglês General Transit Feed Specification), associou o temporeal registrado pelos ônibus, com dados de GPS.

Os arquivos de Tomasiello et al. (2019), então, possuem a informação do horário registrado por cada serviço de transporte, em cada ponto de ônibus ou estação, no dia útil de 07 abril de 2015. 


\section{MÉTODOS}

No presente capítulo apresentam-se os dados utilizados e os métodos de análise estatística a eles aplicados.

\subsection{Análise de variáveis categóricas}

As variáveis podem ser classificadas como quantitativas (ou métricas) e qualitativas (ou não métricas, ou ainda categóricas). As variáveis qualitativas são aquelas que representam as características de um indivíduo, objeto ou elemento, e por isso não podem ser medidas ou quantificadas (FAVERO e BELFIORE, 2017). O tratamento "categórica" vem no sentido de que as características são descritas de formas limitadas, respeitando um número máximo de componentes por categorias, como, por exemplo, faixas etárias de uma população, ou escala Likert.

Por sua definição de que não podem ser medidas, as análises de variáveis categóricas devem ser realizadas com cautela, pois a elas não se aplicam conceitos como média e desvio-padrão (FAVERO e BELFIORE, 2017). Assim, retiram-se das opções os métodos de regressão para estudo deste tipo de variável.

\subsubsection{Anacor e MCA}

As respostas das perguntas referentes ao bem-estar e satisfação com o transporte presentes na Pesquisa IRBEM de 2016 são apresentadas na escala de notas que representam a intensidade da satisfação do indivíduo. Por esse motivo serão tratadas aqui como variáveis qualitativas e, como tais, devem ser explorados utilizando técnicas capazes de lidar com as limitações deste tipo de variável.

A análise de correspondência simples (ANACOR) e a análise de correspondência múltipla (MCA) são técnicas exploratórias multivariadas, de análise numérica e gráfica, capazes de indicar a relação de interdependência entre duas ou mais variáveis qualitativas, fornecendo um mapa perceptual, ou diagrama de dispersão, com o qual se interpreta as similaridades e diferenças de comportamento entre as variáveis e entre as categorias (FAVERO, 2017).

\subsubsection{Correspondência entre as variáveis}

Para concluir que há associação é preciso que a tabela de frequências esperada seja estatisticamente diferente da tabela de frequências observada. Esta diferença é conferida pelo teste Chi-quadrado. Quando $\chi^{2}>\chi^{2}$ crítico, rejeitando, portanto, a hipótese nula que de que as variáveis se associam de forma aleatória. Ou seja, conclui-se que há correspondência entre as variáveis.

Para análise de correspondência múltipla, o teste Chi-quadrado deve ser realizado para todas as combinações de variáveis e, no caso de algum par de variáveis não apresentar correspondência, este deve ser retirado da análise. 


\subsubsection{Correspondência entre as categorias}

Além da verificação se há correspondência entre as variáveis, analisa-se como esta ocorre para as categorias de cada variável.

Primeiramente, a análise de resíduos padronizados ajustados permite a avaliação do padrão característico das variáveis, segundo o excesso ou falta de ocorrências da combinação entre cada categoria. Com isso, esta análise indica como ocorre a associação entre as categorias das variáveis. A correspondência positiva indica que as categorias se associam de forma direta, enquanto a correspondência negativa representaa associação de forma oposta.

Uma vez que a associação entre categorias ocorre de maneira coerente, seguese com a análise para a decomposição inercial. Nesta etapa são quantificadas as inércias principais parciais das correspondências e a inércia principal total, que corresponde finalmente à intensidade da associação entre as categorias.

O mapa perceptual, montado a partir das inercias principais parciais (ou dimensões), funciona como um diagrama de dispersão, representando as categorias em relação aos eixos de coordenadas ortogonais em forma de pontos, onde, de forma visual, se consegue captar a associação entre as categorias das variáveis. $O$ valor calculado para cada dimensão representa o quanto ela é explicativa na correspondência entre as categorias.

\subsection{Apresentação dos resultados}

Os resultados das Análises de Correspondências, apresentados no próximo capítulo, seguirão a sequência do fluxograma a seguir, de forma a permitir sua melhor compreensão. 
1. Correspondência

entre as variáveis pelo

Teste $\chi^{2}$

2. Correspondência

entre as categorias pela

Análise dos Resíduos

Padronizados Ajustados

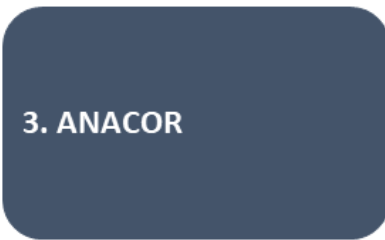

4. Mapa Perceptual
Se Prob. $\chi^{2}$ é menor que 0,05 , a hipótese de associação aleatória é rejeita da e pode se afirmar, ao nível de significância de 5\%, que há correspondência entre as variáveis

Há correspondência entre as categorias quando o resíduo ajustadoé superior, em módulo, de 1,96.

Se o resíduo for positivo (indicado em azul) significa que a correspondência é positiva, ou seja, as categorias têm relação direta. Se o resíduo for negativo (indicado em vermelho), essa correspondência é inversa.

Após a verificação da correspondência entre as variáveise o nível de intensidade que ela ocorre entre as categorias, roda- se a Análise de Correspondência para obtenção das inércias parciais.

As inercias principais parciais e total, ou dimensões, correspondem à intensidade da associação entre as categorias.

A partir das maiores inercias principais parciais é elaborado o Mapa Perceptual que permite analisar graficamente a correspondência entre as categorias.

Figura 1. Fluxograma para avaliação dos resultados da Análise de CorrespondênCia

\subsection{Banco de dados IRBEM}

\subsubsection{Dados recebidos}

O Ibope Inteligência disponibilizou para este estudo os Bancos de respostas das pesquisas Viver em São Paulo de 2009 e IRBEM de 2010 a 2018 no dia 29 de novembro de 2018, mediante a solicitação da pesquisadora realizada no dia 22 de outubro de 2018.

O total de entrevistas realizadas na pesquisa varia ao longo dos anos entre 800 e 1512 pessoas entrevistadas e as perguntas realizadas em cada ano também variam. Para o tema de satisfação com a vida, as pesquisas apresentam ao menos uma das seguintes perguntas

- Qual seu grau de satisfação em relação a sua qualidade de vida na cidade de São Paulo?

- Considerando o último ano, o senhor(a) diria que a sua qualidade de vida melhorou?

- Caso pudesse, o senhor(a) sairia de São Paulo para viver em outra cidade, ou não sairia de São Paulo?

Nas pesquisas constam ainda perguntas do tipo "Qual o grau de satisfação com ?" pela qual se investiga a satisfação com diversos aspectos da vida cotidiana, entre eles transporte. 


\subsubsection{Amostragem}

A amostra das pesquisas de 2009 a 2016 foi calculada considerando o intervalo de confiança de $95 \%$ e a margem de erro máxima de $3 \%$. As variáveis consideradas para as cotas amostrais tiveram como referência os valores dos Censos 2000 e 2010 (IBOPE, 2016). São elas:

- Sexo: Masculino e Feminino;

- Grupos de idade: $16-17,18-24,25-29,30-39,40-49,50-69$ e 70 anos e mais;

- Instrução - Até 4a série do fund., 5a a 8a série do fund., Ens. Médio e Superior;

- Condição de atividade: Ocupado e Não ocupado.

É importante destacar que, como a pesquisa é realizada em poucos dias, sempre no mês de janeiro ou dezembro, entende-se que pode haver um viés em seus resultados, pois medidas mais imparciais de uso do tempo consistem em diários de eventos de 24 horas, com o desenho de levantamento ótimo envolvendo a coleta de múltiplos diários de tempo refletindo diferentes dias da semana e estações do ano. (KAHN e JUSTER, 2002).

\subsubsection{Seleção da base de dados}

A seleção das pesquisas foi feita com base em três critérios. O primeiro é referente ao tamanho da amostra, sendo excluídas as duas pesquisas com amostras menores (2017 e 2018). O segundo critério se deve a diversidade de abordagem quanto ao aspecto da satisfação com a vida, optando-se por priorizar as pesquisas em que foi realizada a pergunta "Qual o seu grau de satisfação com a sua qualidade de vida na cidade de São Paulo?", devido a semelhança da pergunta com as afirmações da Escala de Satisfação com a Vida (DIENER et al., 1985) e com a pergunta para a formulação do PWI - Indicador de Bem-estar Pessoal (INTERNATIONAL WELL-BEING GROUP, 2013). Por fim, o terceiro critério é que a pesquisa contivesse perguntas relativas ao transporte e dessa forma permitisse analisar a relação entre este e o bem-estar. Apenas a pesquisa de 2018 não abordou este tema.

Considerando a aplicação dos três critérios, as pesquisas dos anos 2009, 2013, 2014, 2015 e 2016 são cabíveis de análise. Optou-se, portanto, por trabalhar com a pesquisa de 2016, por sua proximidade temporal com os demais dados analisados, listados na sequência.

\subsubsection{Variáveis}

A seguir são apresentadas as perguntas de caracterização socioeconômica e relativas a transporte da Pesquisa IRBEM de 2016 que serão utilizadas nas análises para investigação da relação com o bem-estar. 
Tabela 1. Atributos da Pesquisa IRBEM utilizados nas análises

\begin{tabular}{|c|c|}
\hline CLASSIFICAÇÃO & PERGUNTAS dO FORMULÁRIO \\
\hline \multirow{9}{*}{$\begin{array}{l}\text { PERGUNTAS PARA } \\
\text { CARACTERIZAÇÃO } \\
\text { SOCIOECONÔMICA }\end{array}$} & P.3) SEXO \\
\hline & P.4) IDADE \\
\hline & P.6) ESCOLARIDADE \\
\hline & P.7) ESTADO CIVIL \\
\hline & P.8) OCUPAÇÃO \\
\hline & P.9) CRITÉRIO ECONÔMICO \\
\hline & $\begin{array}{l}\text { P.12) AGORA, VOU FAZER UMA PERGUNTA EXATAMENTE COMO É FEITA PELO IBGE PARA } \\
\text { CLASSIFICAÇÃO DA POPULAÇÃO BRASILEIRA. A SUA COR OU RAÇA É: }\end{array}$ \\
\hline & REND1) EM QUAL DESTAS FAIXAS ESTÁA SUA RENDA INDIVIDUAL DO MÊS PASSADO? \\
\hline & $\begin{array}{l}\text { REND2) E EM QUAL DESTAS FAIXAS ESTÁ A RENDA TOTAL DA SUA FAMÍLIA NO MÊS } \\
\text { PASSADO, SOMANDO AS RENDAS DE TODAS AS PESSOAS QUE MORAM COM VOCÊ, } \\
\text { INCLUSIVE A SUA? }\end{array}$ \\
\hline \multirow{4}{*}{$\begin{array}{l}\text { PERGUNTAS OBJETIVAS DE } \\
\text { TRANSPORTE }\end{array}$} & P.04A) COM QUE FREQUÊNCIA O(A) SR(A) UTILIZA ÔNIBUS NA CIDADE DE SÃo PAULO? \\
\hline & $\begin{array}{l}\text { P.04B) COM QUE FREQUÊNCIA O(A) SR(A) UTILIZA AUTOMÓVEL, SEJA PRÓPRIO OU } \\
\text { ATRAVÉS DE TÁXI OU CARONA, NA CIDADE DE SÃO PAULO? }\end{array}$ \\
\hline & $\begin{array}{l}\text { P.11) QUANTO TEMPO EM MÉDIA O(A) SR(A) DIRIA QUE LEVA PARA SE DESLOCAR DE CASA } \\
\text { AO TRABALHO, CONSIDERANDO A IDA E A VOLTA? }\end{array}$ \\
\hline & P.04A) COM QUE FREQUÊNCIA O(A) SR(A) UTILIZA ÔNIBUS NA CIDADE DE SÃo PAULO? \\
\hline \multirow{10}{*}{$\begin{array}{l}\text { PERGUNTAS DE SATISFAÇÃO } \\
\text { COM ASPECTOS DO TRANSPORTE }\end{array}$} & $\begin{array}{l}\text { P.02L.01A) USANDO A ESCALA DE } 1 \text { A 10, QUAL É A SUA SATISFAÇÃO COM: AS QUESTÕES } \\
\text { DE TRANSPORTE E TRÂNSITO NA CIDADE DE SÃO PAULO, DE UMA MANEIRA GERAL }\end{array}$ \\
\hline & $\begin{array}{l}\text { P.02L.01) USANDO A ESCALA DE } 1 \text { A 10, QUALÉ A SUA SATISFAÇÃO COM: TEMPO DE } \\
\text { ESPERA NOS PONTOS DE ÔNIBUS }\end{array}$ \\
\hline & $\begin{array}{l}\text { P.02L.02) USANDO A ESCALA DE } 1 \text { A 10, QUALÉ A SUA SATISFAÇÃO COM: TEMPO DE } \\
\text { DESLOCAMENTO NA CIDADE }\end{array}$ \\
\hline & $\begin{array}{l}\text { P.02L.03) USANDO A ESCALA DE } 1 \text { A 10, QUAL É A SUA SATISFAÇÃO COM: SEGURANÇA } \\
\text { NO TRÂNSITO }\end{array}$ \\
\hline & $\begin{array}{l}\text { P.02L.04) USANDO A ESCALA DE } 1 \text { A 10, QUAL É A SUA SATISFAÇÃO COM: PRIORIDADE } \\
\text { AO TRANSPORTE COLETIVO NO SISTEMA VIÁRIO }\end{array}$ \\
\hline & $\begin{array}{l}\text { P.02L.05) USANDO A ESCALA DE } 1 \text { A 10, QUAL É A SUA SATISFAÇÃO COM: QUALIDADE } \\
\text { DAS CALÇADAS }\end{array}$ \\
\hline & $\begin{array}{l}\text { P.02L.06) USANDO A ESCALA DE } 1 \text { A 10, QUALÉ A SUA SATISFAÇÃO COM: TARIFAS DO } \\
\text { TRANSPORTE PÚBLICO }\end{array}$ \\
\hline & $\begin{array}{l}\text { P.02L.07) USANDO A ESCALA DE } 1 \text { A 10, QUAL É A SUA SATISFAÇÃO COM: QUANTIDADE } \\
\text { DE CICLOVIAS NA CIDADE }\end{array}$ \\
\hline & $\begin{array}{l}\text { P.03L) GOSTARIA DE SABER O GRAU DE IMPORTÂNCIA DE CADA UM DELES NA SUA } \\
\text { QUALIDADE DE VIDA NA CIDADE DE SÃO PAULO: TRANSPORTE/TRÂNSITO - MOBILIDADE }\end{array}$ \\
\hline & $\begin{array}{l}\text { P.10) DE } 1 \text { A 10, QUE NOTA O(A) SR(A) DARIA PARA AS INFORMAÇÕES DISPONIBI LIZADAS } \\
\text { NOS PONTOS DE ÔNIBUS DA CIDADE, COMO LINHAS, ITINERÁRIOS E HORÁRIOS DE } \\
\text { EMBARQUE? }\end{array}$ \\
\hline
\end{tabular}




\subsubsection{Limpeza do banco de dados}

No tratamento dos dados, prévio a investigação das associações entre variáveis, excluiu-se do banco as respostas "Não respondeu", "Não sabe" e "Não se aplica" para a pergunta "Qual o seu grau de satisfação com a sua qualidade de vida na cidade de São Paulo?", utilizada para identificar a escala de bem-estar do respondente. A redução da amostra com este procedimento foi de 243, totalizando 1269 respostas consideradas. Além disso, ao analisar a correspondência de bem-estar às demais variáveis categóricas, também foram excluídas as observações em que não houvesse resposta dentro da escala de 1 a 10 para alguma das variáveis analisadas.

Adicionalmente, nas perguntas relativas ao sistema de ônibus, a análise de correspondência foi feita considerando somente as respostas de quem se declarou como usuário de ônibus. A amostra de usuários de ônibus é de 895 respostas consideradas.

\subsubsection{Agregação das respostas}

Com intuito de favorecer a visualização e interpretação dos resultados (SILVA, 2012), todas as variáveis qualitativas com 10 categorias tiveram suas categorias agregadas em 5, segundo a correspondência apresentada na Tabela 2.

TABela 2. ReCATEgorizaÇÃo dAs Respostas

\begin{tabular}{|c|c|}
\hline NOTA APRESENTADA NO BD & CLASSIFICAÇ̃̃O \\
\hline $9 \mathrm{E} 10$ & $\mathrm{~A}$ \\
\hline $7 \mathrm{E} 8$ & $\mathrm{~B}$ \\
\hline $5 \mathrm{E} 6$ & $\mathrm{C}$ \\
\hline $3 \mathrm{E} 4$ & $\mathrm{D}$ \\
\hline $1 \mathrm{E} 2$ & $\mathrm{E}$ \\
\hline
\end{tabular}

\subsubsection{Variáveis selecionadas}

Para identificar como ocorre a relação entre bem-estar e transporte no município de São Paulo, tendo em vista os dados disponíveis e métodos apresentados, realizou-se análises de correspondência simples e múltiplas entre as variáveis de bemestar, socioeconômicas e relativas a transporte presentes no banco de resposta da Pesquisa IRBEM de 2016. A seguir, detalha-se um pouco as análises realizadas.

Em relação ao enquadramento metodológico para tratamento dos dados disponíveis relacionados a bem-estar, foram utilizados como referência a Escala de Satisfação com a Vida e o Índice de Bem-estar Pessoal PWI, assim como recomendado por Vella-Broderick e Delbosc (2011). Contudo, foram necessárias adaptações na metodologia, uma vez que o questionário das pesquisas Viver em São Paulo e IRBEM não são perfeitamente fidedignos às propostas de Diener et al. (1985) e do International Well-being Group (2013). 
A pergunta utilizada para indicação do nível de bem-estaré "Qual o seu grau de satisfação com a sua qualidade de vida na cidade de São Paulo?".

Já a dificuldade de transporte pode ser avaliada por meio de diversas perguntas relativas a satisfação com aspectos específicos do transporte na cidade, além da mais global: "Qual o seu grau de satisfação com as questões de transporte e trânsito de maneira geral?"

A tabela a seguir apresenta as variáveis socioeconômicas e as relativas ao transporte presentes no banco de respostas, bem como a forma como foram agregadas para a análise de correspondência simples e múltipla juntamente com a variável de bemestar.

\section{TABELA 3. ORgANIZAÇÃo dAS ANÁlISES de CORRESPONDÊNCIA REALIZADAS}

\begin{tabular}{|c|c|c|}
\hline TIPO dE VARIÁVEL & ANÁLISE de CoRRESPONDÊNCIA & VARIÁVEIS \\
\hline \multirow{11}{*}{ SOCIOECONÔMICAS } & \multirow{6}{*}{ SIMPLES } & BEM-estaRe OCUPAÇÃo \\
\hline & & BEM-ESTAR E IDADE \\
\hline & & BEM-ESTAR E RENDA FAMILIAR \\
\hline & & BEM-ESTAR E GRAU DE INSTRUÇÃo \\
\hline & & BEM-ESTAR E SEXo \\
\hline & & BEM-ESTAR E ESTADO CIVIL \\
\hline & \multirow{5}{*}{ MÚLTIPLA } & BEM-ESTAR, RENDA FAMILIAR E GRAU DE INSTRUÇÃO \\
\hline & & BEM-ESTAR, RENDA FAMILIAR E IDADE \\
\hline & & BEM-ESTAR, RENDA FAMILIAR E OCUPAÇÃO \\
\hline & & BEM-ESTAR, RENDA FAMILIAR, OCUPAÇÃ̃ E IDADE \\
\hline & & BEM-estar, SEXo e ocupação \\
\hline \multirow{9}{*}{ TRANSPORTE } & \multirow{9}{*}{ SIMPLES } & BEM-ESTARE TEMPO DE ESPERA DE ÔNIBUS \\
\hline & & $\begin{array}{l}\text { BEM-ESTAR E SATISFAÇÃO COM AS QUESTÕES DE TRANSPORTE } \\
\text { E TRÂNSITO DE MANEIRA GERAL }\end{array}$ \\
\hline & & $\begin{array}{l}\text { BEM-ESTARE SATISFAÇÃO COM O TAMANHO DA REDE DE } \\
\text { METRÔ }\end{array}$ \\
\hline & & $\begin{array}{l}\text { BEM-ESTAR E SATISFAÇÃO COM SOLUÇõES PARA DIMINUIR O } \\
\text { TRÂNSITO DA CIDADE }\end{array}$ \\
\hline & & $\begin{array}{l}\text { BEM-ESTARE SATISFAÇÃO COM TEMPO DE ESPERA DOS } \\
\text { ÔNIBUS }\end{array}$ \\
\hline & & $\begin{array}{l}\text { BEM-ESTAR E SATISFAÇÃO COM TEMPO DE DESLOCAMENTO } \\
\text { NA CIDADE }\end{array}$ \\
\hline & & BEM-ESTAR E SATISFAÇÃO COM A SEGURANÇA NO TRÂNSITO \\
\hline & & $\begin{array}{l}\text { BEM-ESTAR E SATISFAÇÃO COM A PRIORIDADE DO } \\
\text { TRANSPORTE COLETIVO NO SISTEMA VIÁRIO }\end{array}$ \\
\hline & & $\begin{array}{l}\text { BEM-ESTARE SATISFAÇÃO COM A TARIFA DO TRANSPORTE } \\
\text { PÚBLICO }\end{array}$ \\
\hline
\end{tabular}


Também se investigou a análise de correspondência entre "tempo de espera de ônibus" e "satisfação com tempo de espera do ônibus" e entre "renda familiar" e "satisfação com a tarifa do transporte público", independentemente da variável de bemestar. O resultado de todos os testes realizados, mesmo aqueles para os quais não houve resultado de correspondência, são apresentados nos anexos deste documento.

É importante destacar que, de acordo com o que se recomenda, a análise de correspondência múltipla foi aplicada somente para variáveis que apresentaram correspondência simples entre todas as variáveis (FAVEROE BELFIORE, 2017).

A seguir, são apresentados gráficos das frequências de notas agregadas para as principais variáveis utilizadas na análise de correspondência, apresentada no capítulo seguinte.

A frequência das notas referentes a pergunta "Qual o seu grau de satisfação com a sua qualidade de vida na cidade de São Paulo?", que representa o bem-estar, indicam que as pessoas em São Paulo não estavam muito satisfeitas em 2016, pois $37 \%$ dos entrevistados responderam entre 5 e 6 e outros 39\% abaixo disso. Apenas 23\% da amostra disse que seu nível de satisfação é igual ou superior a 7.

\section{Bem-estar}

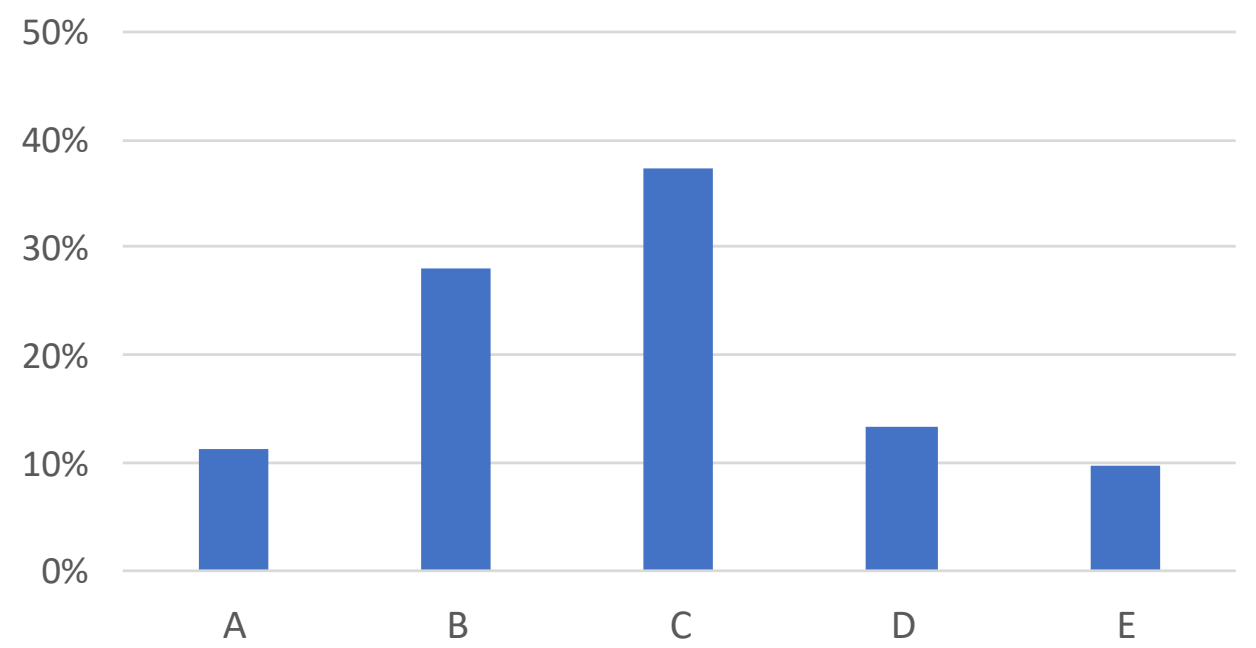

Figura 2. GRÁfico de fREQUÊNCIA dAS NOtAS de BEM-ESTAR

A Rede Nossa São Paulo, responsável pela Pesquisa IRBEM, calcula um indicador médio de bem-estar para o município. Até 2012, este cálculo considerava a média aritmética das respostas e a partir de 2013 passou a ser ponderada com os pesos de importância indicados pelos respondentes. Em 2016, o Índice de Bem-estarmédio para São Paulo foi de 4,7 (IBOPE INTELIGÊNCIA, 2016).

Já em relação a satisfação com o transporte, se observa que tanto de forma geral como para aspectos específicos do sistema, a população paulistana está satisfeita, com mais de $57 \%$ das notas iguais a 7 ou mais. 


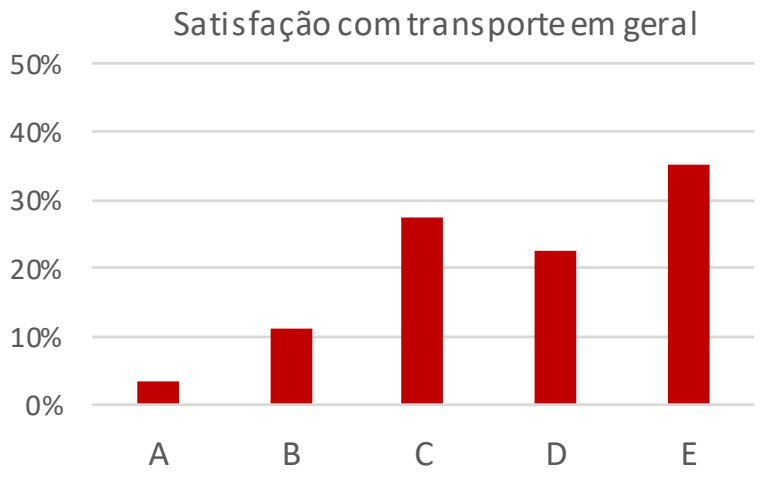

Figura 3. GRÁfico de fRequêncla das notas de SATISFAÇÃO COM O TRANSPORTE GERAL

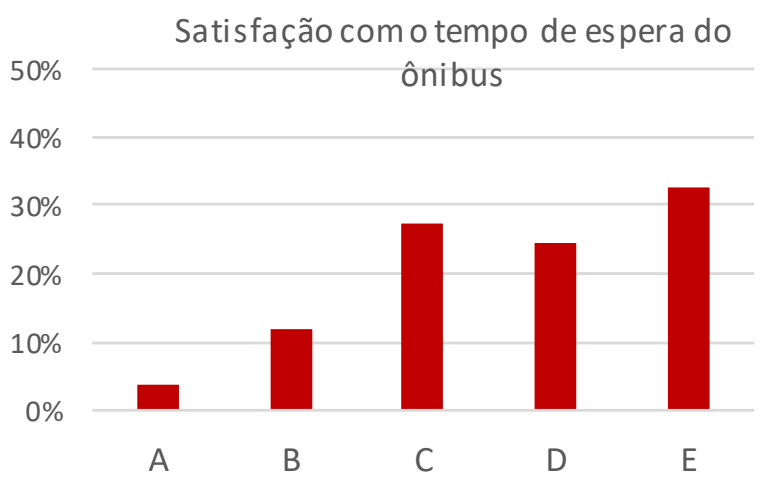

Figura 5. Gráfico de fREQUÊNCIA dAS nOtAS de SATISFAÇ̃̃o COM TEMPO DE ESPERA DO ÔNIBUS

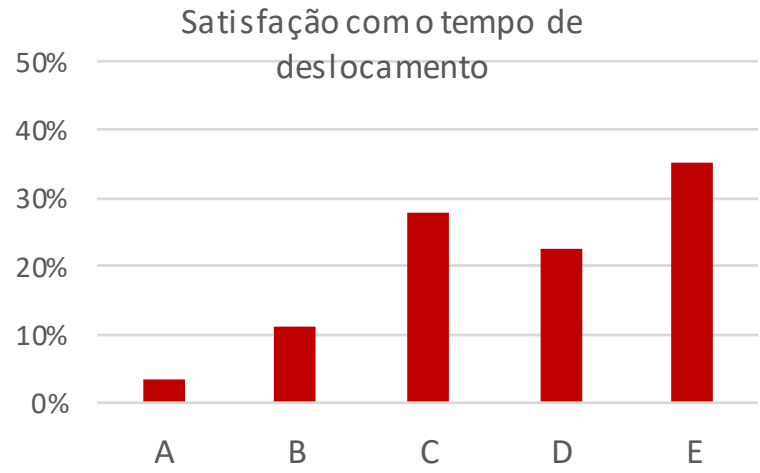

Figura 4. GRÁfICO de fREQUÊNCIA dAS NOtAS de SATISFAÇÃO COM TEMPO DE DESLOCAMENTO

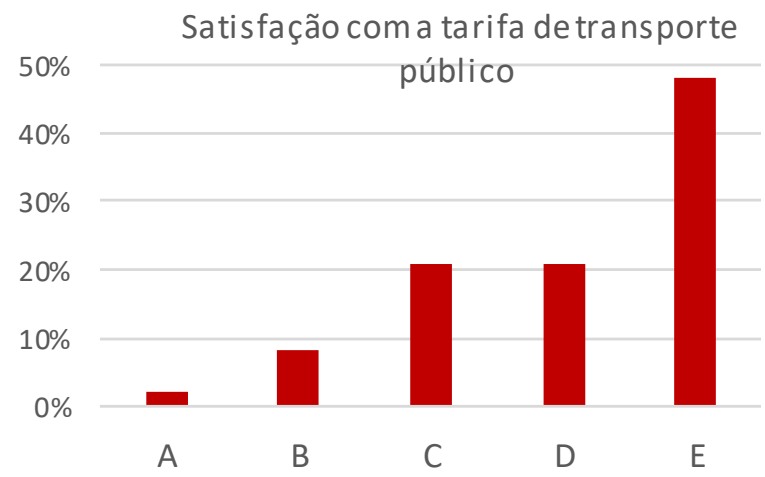

Figura 6. Gráfico de fREQUÊNCIA dAs NOtAS de SATISFAÇÃO COM A TARIFA DE TRANSPORTE PÚBLICO

A Rede Nossa São Paulo também calcula um índice médio de satisfação com o trânsito e transporte, considerando todas as perguntas referentes ao te ma. Em 2016 este índice foi de 3,9 (IBOPE INTELIGÊNCIA, 2016).

\subsection{Análises complementares}

Após identificadas as principais características de transporte que estão associados ao bem-estar subjetivo, buscou-se analisar como estas se distribuem espacialmente pelo território de São Paulo.

A seguir são apresentados os dados utilizados para tais análises, bem como o cálculo dos indicadores desenvolvidos. 


\subsubsection{Origem-Destino}

\subsubsection{Amostragem}

A amostra é calculada pela estratificação por zona $O D$, considerando nível de confiança de $92 \%$ e margem de erro inferior a $6 \%$ e resultou em 32.000 domicílios para 2017 (METRÔ-SP, 2019). "Zona OD” é como são chamadas as unidades de áreas para as quais são apresentados os resultados da Pesquisa Origem e Destino. Este zoneamento é definido tendo como referência a compatibilidade com o limite dos municípios da RMSP e dos distritos da cidade de São Paulo e com os limites dos setores censitários do IBGE - Instituto Brasileiro de Geografia e Estatística.

\subsubsection{2 Área de estudo}

Para atender a área de estudo definida para esta pesquisa, foram selecionadas somente as zonas pertencentes ao município de São Paulo para as análises do banco da Pesquisa de Origem-Destino.

\subsubsection{Dados utilizados}

A tabela a seguir apresenta as perguntas de caracterização dos usuários e de seus deslocamentos da Pesquisa Origem Destino de 2017 que serão utilizadas no presente estudo.

Tabela 4. Atributos utilizados da Pesquisa Origem-Destino

\begin{tabular}{|c|c|}
\hline CLASSIFICAÇÃO & Atributo \\
\hline \multirow{3}{*}{ CARACTERIZAÇÃO DOS DOMICÍLIOS } & ZONA DE RESIDÊNCIA \\
\hline & NÚMERO DE PESSOAS NA FAMÍLIA \\
\hline & RENDA MÉDIA FAMILIAR \\
\hline \multirow{3}{*}{ CARACTERIZAÇÃO DOS DESLOCAMENTOS } & MODO PRINCIPAL \\
\hline & TEMPO DE DESLOCAMENTO \\
\hline & ZONA DE ORIGEM \\
\hline
\end{tabular}

\subsubsection{Tempo de viagem e gasto com transporte público}

Além dos atributos retirados diretamente da Pesquisa Origem-Destino, foram calculados outros indicadores para a avaliação da distribuição espacial de características de mobilidade, que como apresentado adiante, tem associação com o bem-estar subjetivo. São eles: tempo médio de deslocamento e percentual da renda mensal comprometida no gasto com transporte.

O tempo médio de deslocamento da zona foi calculado considerando este um atributo referente a zona de origem da viagem. Para representação de viagens que tem peso importante na rotina dos cidadãos, optou-se por utilizar nesta análise as viagens mandatórias - motivo estudo e trabalho - que têm o horário de início no período pico 
da manhã, entre 6:00 e 9:00 ou no período pico da tarde, entre 16:00 e 19:00. Foram calculados tempos médios considerando viagens de todos os modos, utilizando modos motorizados e exclusivas de transporte público.

Para a avaliação do percentual gasto com transporte público, foi estimado o custo das viagens mandatórias (motivo trabalho ou estudo) utilizando transporte público, em relação a renda individual média das pessoas que realizam viagens de transporte público em uma zona. Para o cálculo do custo mensal foram considerados os valores de tarifas por modo e integrações vigentes em julho de 2017 e a média de 22 dias úteis no mês. Para obtenção do valor de renda individual média, calculou-se tendo como base a mediana da renda familiar da zona e o número de habitantes por domicílio

Destaca-se que estes indicadores foram calculados para cada zona do município de São Paulo, sendo esta a menor unidade de desagregação geográfica utilizada.

\subsubsection{GTFS 2015}

As informações operacionais datam de 07 de abril de 2015 e são dispostas em 10 arquivos de tipo texto, listados na tabela abaixo juntamente com a descrição da informação contida (TOMASIELLO et al., 2019).

TABela 5. Descrição do GTFS

\begin{tabular}{|c|c|}
\hline ARQUIVO & DESCRIÇÃO \\
\hline AGENCY.TXT & DESCRIÇÃO GERAL DA AGÊNCIA DE TRANSPORTE \\
\hline CALENDAR.TXT & PERÍODO DA INFORMAÇÃO \\
\hline FARE_ATTRIBUTES.TXT & TARIFA DOS SISTEMAS DE TRANSPORTE PÚBLICO COLETIVOS E SUAS INTEGRAÇÕES \\
\hline FARE_RULES.TXT & SERVIÇOS DE CADA SISTEMA DE TRANSPORTE \\
\hline FREQUENCIES.TXT & INTERVALO DE OPERAÇÃO DAS VIAGENS DE CADA SERVIÇO, POR HORA \\
\hline ROUTES.TXT & LINHAS DE ÔNIBUS, METRÔ E TREM \\
\hline SHAPES.TXT & COORDENADAS GEOGRÁFICAS DO TRAJETO DAS VIAGENS REALIZADAS PELAS LINHAS \\
\hline STOP.TXT & COORDENADAS GEOGRÁFICAS DAS PARADAS DE ÔNIBUS E ESTAÇÕES \\
\hline STOPTIMES.TXT & HORÁRIO DE CHEGADA E PARTIDA DE CADA LINHA NAS PARADAS DE SEUTRAJETO \\
\hline TRIPS.TXT & VIAGENS REALIZADAS PELAS LINHAS \\
\hline
\end{tabular}

Do processamento destes dados é possível extrair diversas informações sobre operação do transporte público no referido dia. Pela associação com os dados da Pesquisa IRBEM, especificamente a pergunta relativa à satisfação com tempo de espera do ônibus, filtrou-se somente as informações referentes ao serviço de ônibus excluindo assim os dados de operação de metrô e trem da análise.

A seguir, listam-se as informações extraídas do GTFS que serão utilizadas no presente estudo:

- $\quad$ Frequência e intervalo de cada linha; 
- $\quad$ Frequência e intervalo entre qualquer linha em determinado ponto de ônibus ou estação; e

- Sequência de pontos atendidos por determinada linha.

\subsubsection{Período}

A análise dos dados de frequência das linhas de ônibus foi realizada somente para o período pico manhã, contido entre seis e nove horas do período matutino.

\subsubsection{Tempo de espera do ônibus}

Com os registros disponíveis no arquivo stoptimes.txt do GTFS, calculou-se para cada ponto de ônibus o intervalo de tempo registrado por cada veículo que passa por ele no período pico manhã. A partir desses valores, obteve-se o intervalo médio entre qualquer linha e entre cada linha específica, para cada ponto de ônibus. Calculou-se também os intervalos mínimos e máximos dos serviços.

Pela coordenada geográfica do ponto de ônibus, foi possível analisar as informações espacialmente e representar os tempos médio de espera entre qualquer serviço de ônibus graficamente, pelo Mapa de Densidade de Kernel.

Os intervalos médios, mínimos e máximos entre a mesma linha em cada ponto foram calculados, porém não apresentados aqui, pela pouca variância na distribuição espacial, pois menos de $10 \%$ das linhas municipais de São Paulo operam com intervalo médio inferior a uma hora no período pico manhã e quase $90 \%$ possui intervalo entre 1 hora e 1 hora e 15 minutos. 


\section{DISCUSSÃO}

\subsection{Bem-estar e dificuldade de transporte em São Paulo}

Antes de iniciar a investigação a respeito da relação entre bem-estar e transporte no município, é preciso compreender como as variáveis identificadas na Pesquisa IRBEM de 2016 para representar estes aspectos ocorrem espacialmente no território de São Paulo.

Os dados foram analisados por subprefeitura, que é a unidade geográfica disponível no banco de dados, com a mesma agregação de respostas utilizadas nas análises de correspondência subsequentes. Como se vê no mapa a seguir, a quantidade de entrevistas varia entre as subprefeituras e, por isso optou-se por apresentar as frequências das notas de bem-estar e satisfação com transporte por porcentagem.

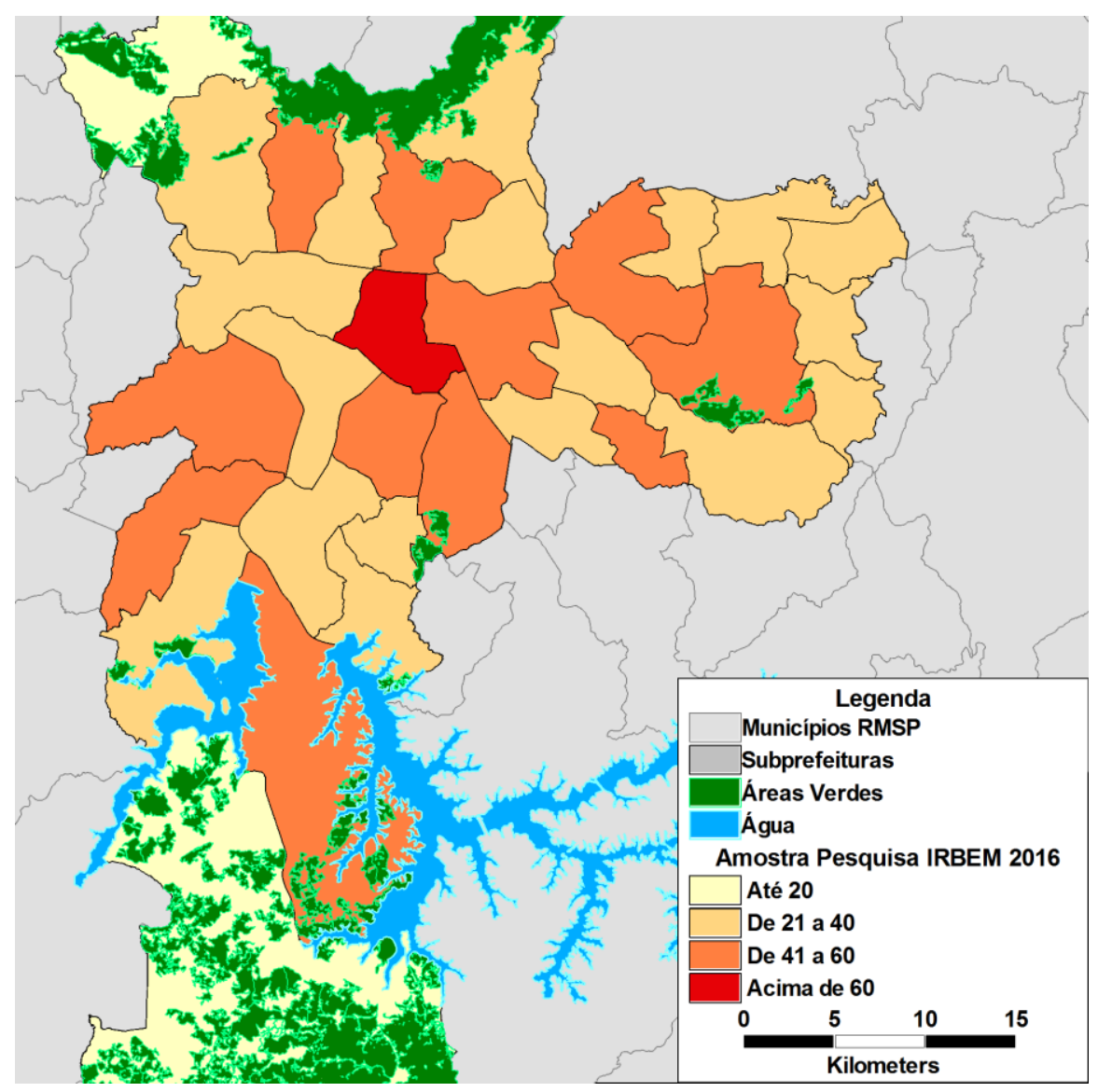

Figura 7. Amostra POR SUbPREFeITURA da PESQUISA IRBEM 2016

Na sequência apresentam-se mapas com a frequência das respostas com a mesma agregação de respostas utilizadas nas análises de correspondência subsequentes.

O mapa a seguir mostra que as notas de bem-estar apresentam uma distribuição de frequência semelhante em quase todo o município, sendo que as regiões de Cidade Ademar, Perus e Vila Guilherme com maior frequência de notas baixas e Socorro e 
Brasilândia com notas altas, além de Parelheiros que indica $50 \%$ das respostas como A porém esta região conta com uma amostra de apenas 2 entrevistas.

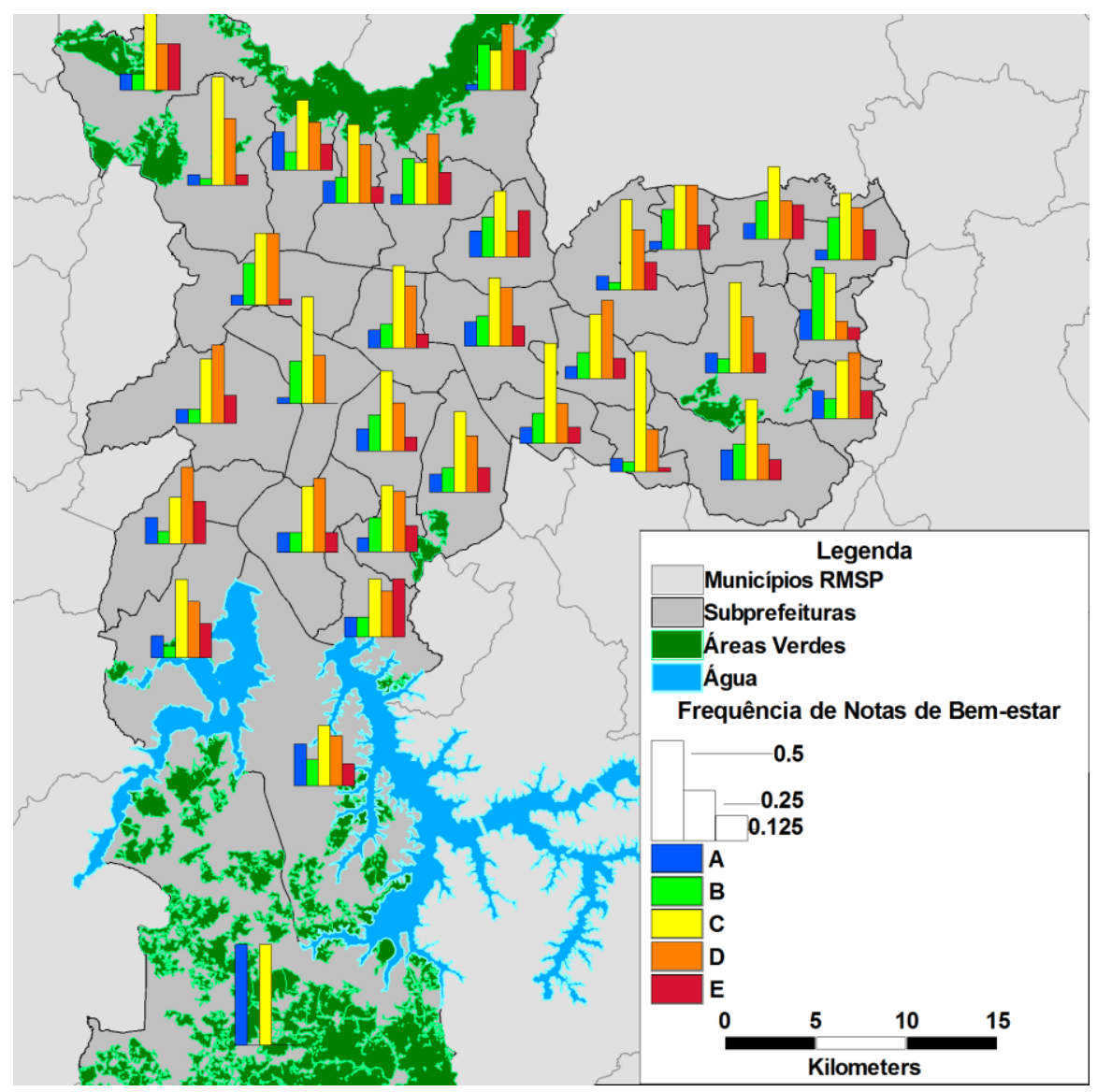

Figura 8. FrequÊnCIA dAS NotAS de BeM-eStar POR SUbPREFEITURA

Os mapas seguintes apresentam as porcentagens de frequência das notas de satisfação com o transporte em geral e de aspectos específicos do sistema de transporte que serão analisados na sequência deste capítulo, em cada subprefeitura. Se observa que as frequências das notas são relativamente parecidas entre si, com exceção da satisfação com a tarifa do transporte público que apresenta maior frequência de notas baixas em diversas subprefeituras, comparada aos demais aspectos analisados. 

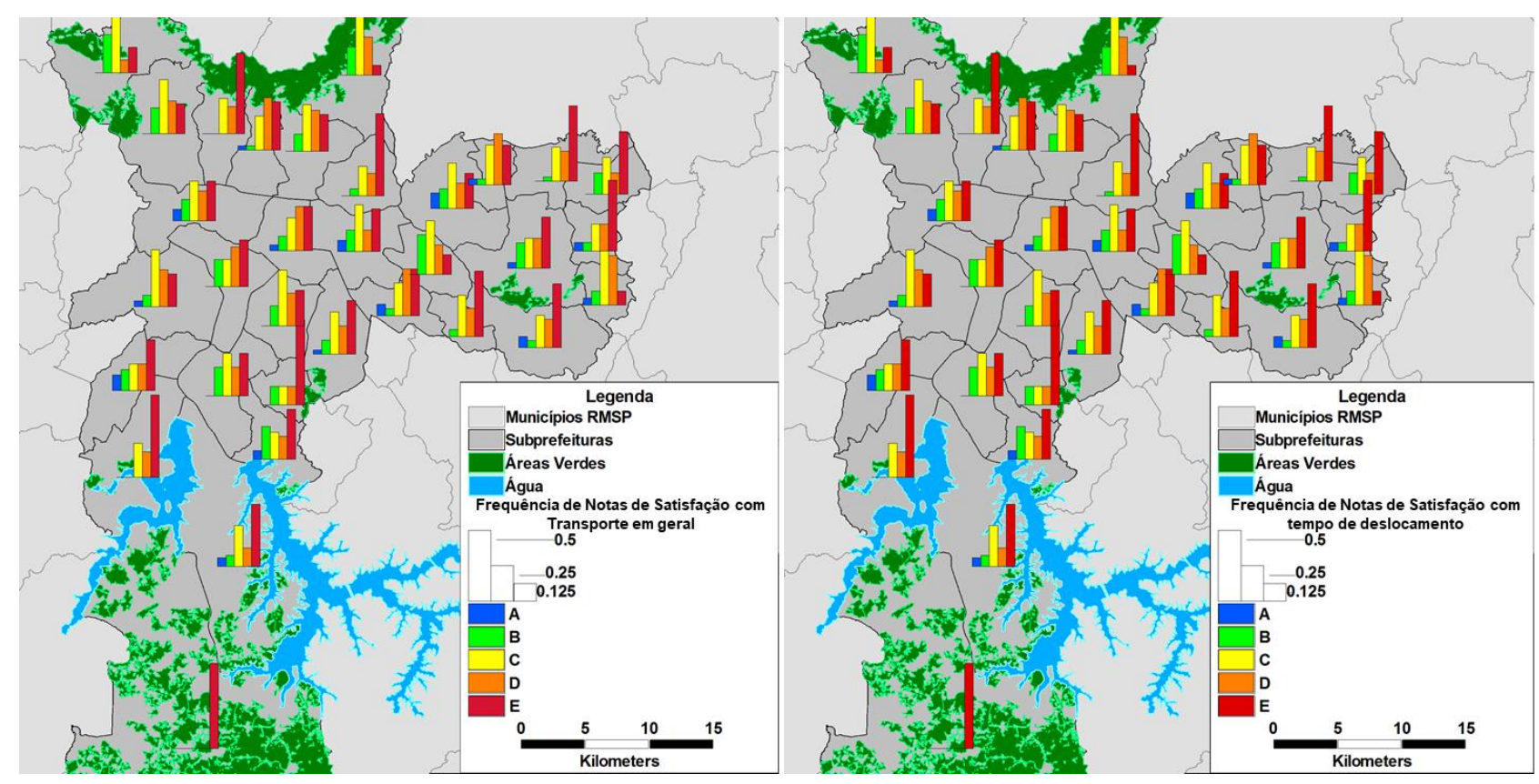

Figura 9. FrequênCia das notas de Satisfação com transporte EM GERAL POR SUBPREFEITURA

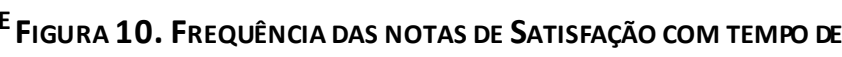
DESLOCAMENTO POR SUBPREFEITURA
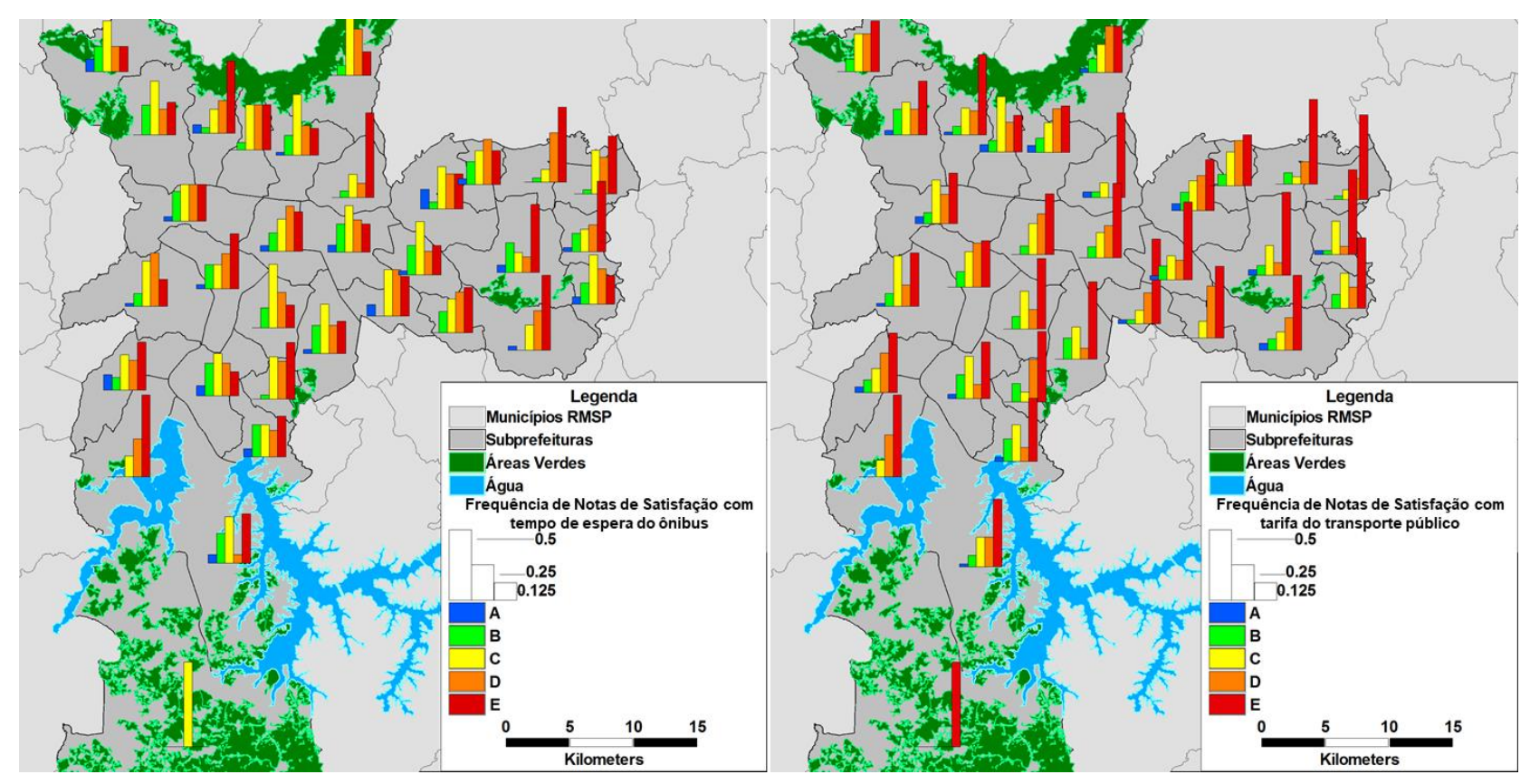

Figura 11. Frequência das notas de Satisfação com tempo deFigura 12. Frequência das notas de Satisfação com tarifa do ESPERA DO ÔNIBUS POR SUBPREFEITURA TRANSPORTE PÚBLICO POR SUBPREFETTURA

Nota-se que a simples comparação visual entre os mapas de bem-estar e de satisfação com o transporte não permite uma identificação clara de relação entre satisfação com transporte e satisfação com a própria vida (bem-estar). 


\subsection{Relação entre bem-estar e dificuldade de transporte}

Partindo de uma ampla revisão bibliográfica acerca da relação entre bem-estar e dificuldade de transporte em diversos locais e sobre diferentes aspectos, buscaram-se alternativas para melhor compreender como esta relação ocorre no caso de São Paulo, tendo como base para observação os dados resultantes da Pesquisa IRBEM de 2016. Assim como Delbosc e Currie (2011b), foram utilizados vários indicadores representativos da dificuldade de transporte para investigar a sua relação com bemestar.

As primeiras análises valeram-se da associação da variável de bem-estar e de variáveis socioeconômicas, como renda, escolaridade, ocupação, entre outras, devido a percepção de que o nível econômico e social, e por consequências os privilégios que isso proporciona em uma sociedade desigual, pudesse estar relacionado com a satisfação subjetiva com a vida. Entretanto, apesar de existir uma correspondência entre as variáveis de bem-estar e renda familiar e grau de instrução, não se verificou uma direção clara de correspondência, pela análise do mapa perceptual.

Buscou-se então, de forma mais direta quanto possível com os dados disponíveis, associar-se a variável de bem-estar a dificuldade de transporte por meio de variáveis referentes a qualidade do transporte, presentes no próprio banco de dados da Pesquisa IRBEM de 2016.

A primeira hipótese avaliada foi de correspondência entre o bem-estar e o tempo de espera de ônibus, única pergunta objetiva em relação ao transporte realizada na pesquisa. Para associar a variável inteira tempo de espera com a categórica bem-estar, foi preciso categorizar o tempo de espera. Foram feitas algumas tentativas de agrupamento em categorias do tempo de espera do ônibus para identificar a correspondência com o bem-estar, porém as análises indicam que não há correspondência direta entre o tempo de espera dos ônibus e o bem-estar. $\mathrm{Na}$ sequência, os testes de correspondência foram aplicados com as variáveis das perguntas subjetivas, que avaliam a satisfação das pessoas em relação a diferentes aspectos de transporte.

Verificou-se que os diversos aspectos sobre os quais se avaliam o transporte acabam por ter relação com o bem-estar subjetivo. No decorrer deste capítulo serão apresentados os três elementos mais interessantes e que permitiram análises complementares a partir de outros dados. Os resultados obtidos nas análises dos demais aspectos são apresentados no Anexoll.

\subsubsection{Bem-estar e satisfação com o tempo de deslocamento}

Em diversos estudos já se verificou que o tempo de viagem afeta a satisfação com a viagem e, de forma mais específica, que o alto tempo de viagem está relacionado a menor satisfação com o deslocamento (PRITCHARD, 2019). Inclusive, o Índice de Bemestar Urbano (IBEU) calculado para os municípios brasileiros considera o tempo de 
deslocamento como fator representativo para considerar a mobilidade urbana cálculo do índice (RIBEIRO e RIBEIRO, 2016).

Para o caso dos dados analisados da Pesquisa IRBEM de 2016, também se verificou a associação entre as variáveis de bem-estar e satisfação com o tempo de deslocamento.

A correspondência entre as variáveis é demonstrada na tabela de contingências a seguir pelo Prob. $\chi^{2}$ menor que 0,05 , ao nível de significância de $5 \%$. Pela análise dos resíduos padronizados ajustados, observa-se correspondência entre as categorias, ao nível de significância de $5 \%$. As categorias correspondentes entre si estão destacadas em azul quando há correspondência positiva e vermelho quando há correspondência negativa. Pela análise dos resíduos padronizados ajustados se observa que as categorias de alto grau de bem-estar ( $A$ e $B$ ) correspondem positivamente as categorias de alto grau de satisfação com tempo de deslocamento (A, B e C) e correspondem negativamente a categorias de baixo grau de satisfação com tempo de deslocamento ( $D$ e E). O contrário também ocorre, com a correspondência positiva das categorias de baixo grau de bem-estar ( $D$ e E) com baixo grau de satisfação com tempo de deslocamento $(E)$ e correspondência negativa com alto grau de com tempo de deslocamento ( $\mathrm{B}$ e C).

Por fim, os outputs da análise de correspondência a seguir indicam que 95,47\% da inércia principal total corresponde às dimensões 1 e 2, permitindo assim que o mapa perceptual seja uma boa ferramenta para visualização da correspondência entre categorias. 
Categorias das variáveis analisadas

\begin{tabular}{|c|c|}
\hline \multicolumn{2}{|c|}{ P1 - BEM-ESTAR } \\
\hline 9 E 10 & $\mathrm{~A}$ \\
\hline $7 \mathrm{E} 8$ & $\mathrm{~B}$ \\
\hline $5 \mathrm{E} 6$ & $\mathrm{C}$ \\
\hline $3 \mathrm{E} 4$ & $\mathrm{D}$ \\
\hline 1 E 2 & $\mathrm{E}$ \\
\hline
\end{tabular}

\begin{tabular}{|c|c|}
\hline $\begin{array}{c}\text { ST5 - SATISFAÇÃO COM O TEMPO DE } \\
\text { DESLOCAMENTO }\end{array}$ \\
\hline $9 \mathrm{E} 10$ & $\mathrm{~A}$ \\
\hline $7 \mathrm{E} 8$ & $\mathrm{~B}$ \\
\hline $5 \mathrm{E} 6$ & $\mathrm{C}$ \\
\hline $3 \mathrm{E} 4$ & $\mathrm{D}$ \\
\hline $1 \mathrm{E} 2$ & $\mathrm{E}$ \\
\hline
\end{tabular}

Tabela de contingência

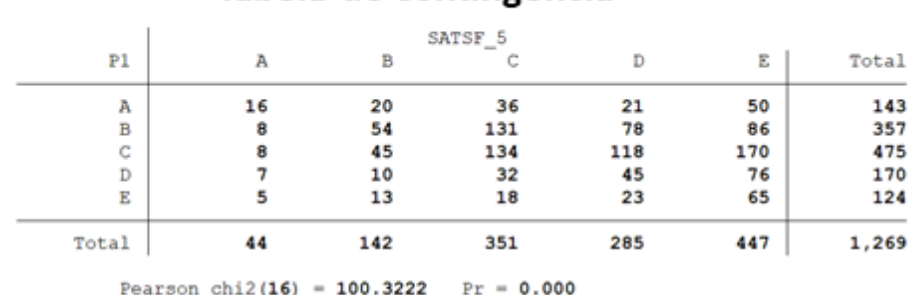

Tabela de frequências e de resíduos padronizados ajustados

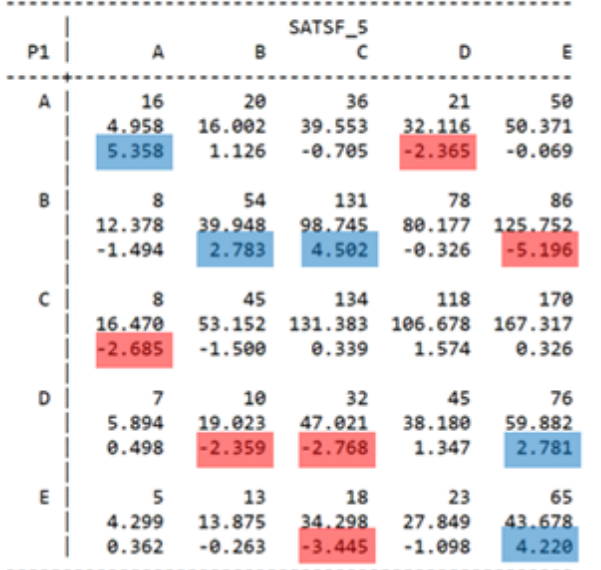

observed frequency

expected frequency

adjusted residual

2 cells with expected frequency $<5$

$\begin{array}{rlr}\text { Pearson chi2 (16) } & =100.3222 & \mathrm{Pr}=0.000 \\ \text { likelihood-ratio } \operatorname{chi2}(16) & =94.4116 & \mathrm{Pr}=0.000\end{array}$
Outputs da Análise de Correspondência Simples

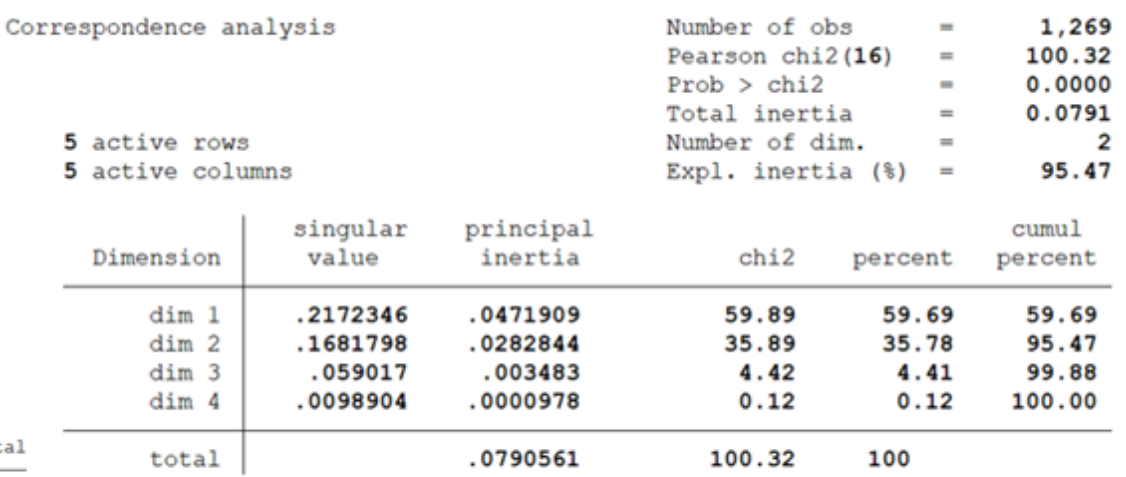

\section{Mapa Perceptual}

Correspondence analysis biplot

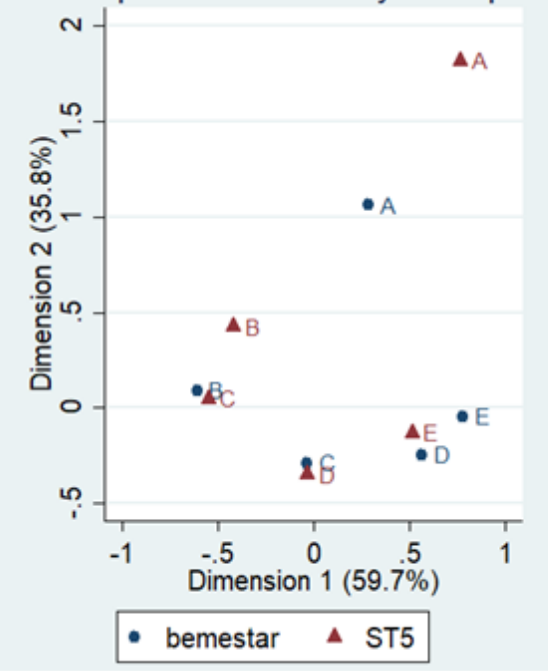

Figura 13. Análise de CorrespondênCia entre Bem-estar e Satisfação com Tempo de Deslocamento 
Observando o mapa perceptual verifica-se que há uma associação positiva entre os termos, uma vez que, no gráfico, os grupos com maior satisfação com o tempo de deslocamento estão posicionados próximos aos grupos com maior bem-estar.

Apesar de não haver informação quanto ao tempo de deslocamento na base de respostas da Pesquisa de Bem-estar e dessa forma relacioná-lo diretamente ao bemestar, é possível ter a percepção de como, em média, este fator ocorre para os moradores das diferentes zonas do município de São Paulo. Esta análise foi feita por meio dos dados da Pesquisa OD 2017, em que os entrevistados relatam o tempo de viagem. É importante pontuar que este dado, assim como ocorre na Pesquisa IRBEM, trata de uma percepção do usuário sobre o tempo de deslocamento, uma vez que não é medido nem calculado tempo realmente gasto na viagem e sim considerado o tempo relatado, que considera a percepção do entrevistado.

Para esta análise foram consideradas apenas as viagens mandatórias (trabalho e estudo) que ocorrem no período pico da manhã. Optou-se por este recorte para conseguir evidenciar as viagens que têm maior relevância na rotina das pessoas.

As figuras a seguir apresentam, portanto, a média do tempo de deslocamento por viagem percebido, segundo a Pesquisa OD 2017, a partir das zonas de origem da viagem. Os mapas diferem quanto ao modo de viagem e período que foi realizada. $\mathrm{Na}$ primeira linha são apresentados os resultados considerando as viagens realizadas no período pico manhã e na segunda linha no período pico tarde. Já nas colunas, o primeiro mapa considera todos os modos de transporte, o segundo apenas modos motorizados e o terceiro somente as viagens realizadas por meio de transporte coletivo. 

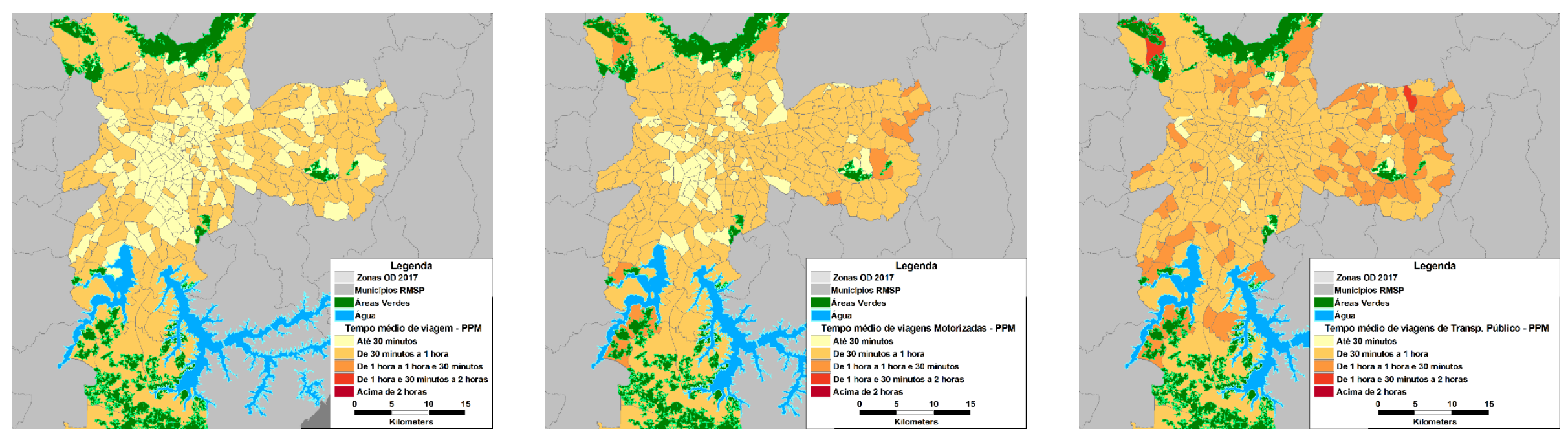

Figura 14. Tempo médio de deslocamento no período pico figura 15. Tempo médo de deslocamento por modos figura 16. Tempo médio de deslocamento de tRansporte MANHÃ-OD 2017

MOTORIZADO NO PERÍODO PICO MANHÃ S - OD 2017

PÚBLICO NO PERÍODO PICO MANHÃ - OD 2017
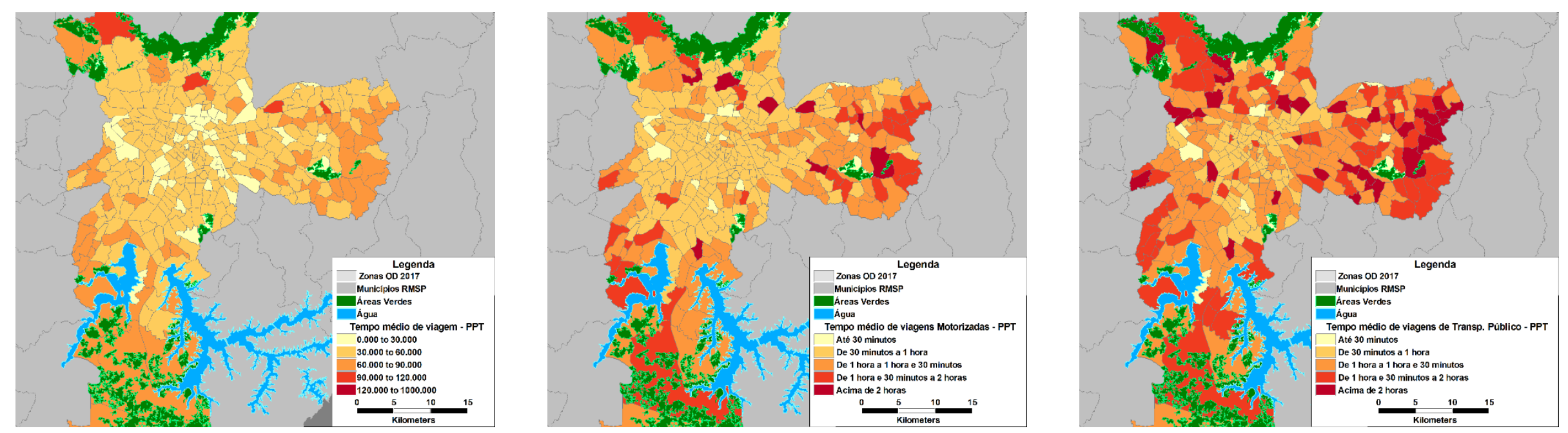

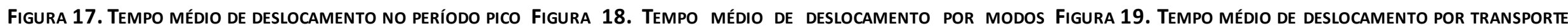
TARDE - OD 2017 MOTORIZADOS NO PERÍODO PICO TARDE - OD 2017

PÚBLICO NO PERÍODO PICO TARDE - OD 2017 
Assim, observa-se que a distribuição da percepção de tempo médio de deslocamento é desigual no território de São Paulo, sendo consideravelmente maior nas zonas periféricas considerando os diferentes modos de transporte e períodos do dia.

Pela associação verificada da satisfação do tempo de deslocamento com o bemestar subjetivo, e utilizando os resultados obtidos por Pritchard (2019) de que o alto tempo de deslocamento está associado à uma alta insatisfação com a viagem, tem-se a indicação de que as zonas mais distantes do centro expandido teriam índices mais baixos de bem-estar.

\subsubsection{Bem-estar e Satisfação com tempo de espera do ônibus}

O segundo elemento que se mostrou relevante no entendimento da relação entre transporte e bem-estar foi a satisfação com o tempo de espera do ônibus.

Primeiramente avaliou-se a relação direta entre bem-estar e tempo de espera, ambos presentes na base de resposta da Pesquisa IRBEM de 2016, para aqueles que utilizam ônibus. Entretanto, observou-se que não há correspondência entre estes elementos, uma vez que a hipótese de igualdade entre as tabelas de frequência esperada e observada não foi refutada, como se observa pelo Prob. $\chi^{2}$ superior a $5 \%$.

Categorias das variáveis analisadas

\begin{tabular}{|c|c|}
\hline \multicolumn{2}{|c|}{ P1 - BEM-ESTAR } \\
\hline 9 E 10 & $\mathrm{A}$ \\
\hline $7 \mathrm{E} 8$ & $\mathrm{~B}$ \\
\hline $5 \mathrm{E} 6$ & $\mathrm{C}$ \\
\hline $3 \mathrm{E} 4$ & $\mathrm{D}$ \\
\hline 1 E 2 & $\mathrm{E}$ \\
\hline
\end{tabular}

\begin{tabular}{|c|}
\hline TBus - TEMPO DE ESPERA DE ÔNIBUS \\
\hline ATÉ 5 MINUTOS \\
\hline DE 6 A 10 MINUTOS \\
\hline DE 11 A 20 MINUTOS \\
\hline DE 21 A 30 MINUTOS \\
\hline DE 31 A 40 MINUTOS \\
\hline MAIS DE 40 MINUTOS \\
\hline
\end{tabular}

Tabela de contingência

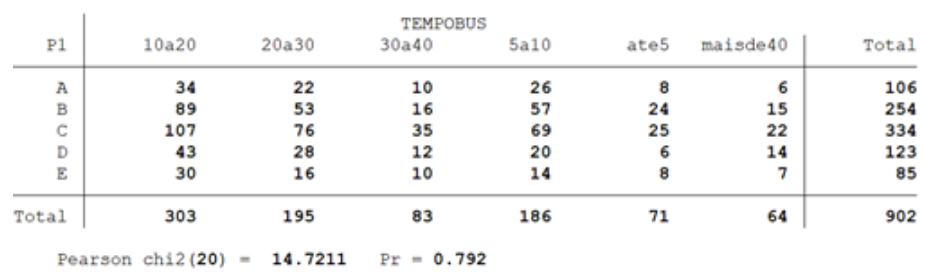

Figura 20. AnÁlise de CORRESPONdÊnCIA entre Bem-estare Tempo de ESPERA do ônibus

Analisou-se então a relação entre bem-estar e a satisfação com o tempo de espera do ônibus. Neste caso, a tabela de contingências demonstra que há associação entre as variáveis para o nível de significância de $5 \%$. E pela análise dos resíduos padronizados ajustados, verifica-se correspondência entre as categorias, ao nível de significância de 5\%. Destaca-se em azul quando há correspondência positiva entre as categorias e em vermelho quando há correspondência negativa.

Observa-se pela análise dos resíduos padronizados ajustados que as categorias de alto grau de bem-estar ( $A$ e $B$ ) correspondem positivamente a categorias de alto grau de satisfação com tempo de espera do ônibus ( $A, B$ e $C$ ) e correspondem negativamente 
a categoria de baixo grau de satisfação com tempo de espera do ônibus (E). O contrário também ocorre, com a correspondência positiva das categorias de baixo grau de bemestar ( $D$ e E) com baixo grau de satisfação com tempo de espera do ônibus (E) e correspondência negativa com médio grau de com tempo de espera do ônibus (C).

Ao final, a análise de correspondência em si indica que $94,37 \%$ da inércia principal total corresponde às dimensões 1 e 2 , permitindo assim que o mapa perceptual seja uma boa ferramenta para visualização da correspondência entre categorias. $E$ observando o mapa perceptual, se vê a associação positiva entre os termos, uma vez que, no gráfico, os grupos com menor satisfação com o tempo de espera do ônibus estão posicionados próximos aos grupos com bem-estar mais baixo. 
Categorias das variáveis analisadas

\begin{tabular}{|c|c|}
\hline \multicolumn{2}{|c|}{ P1 - BEM-ESTAR } \\
\hline $9 \mathrm{E} 10$ & $\mathrm{~A}$ \\
\hline $7 \mathrm{E} 8$ & $\mathrm{~B}$ \\
\hline $5 \mathrm{E} 6$ & $\mathrm{C}$ \\
\hline $3 \mathrm{E} 4$ & $\mathrm{D}$ \\
\hline $1 \mathrm{E} 2$ & $\mathrm{E}$ \\
\hline
\end{tabular}

\begin{tabular}{|c|c|}
\hline $\begin{array}{c}\text { ST4 - SATISFAÇÃO COM O TEMPO DE } \\
\text { ESPERA DO ÔNIBUS }\end{array}$ \\
\hline $9 \mathrm{E} 10$ & $\mathrm{~A}$ \\
\hline $7 \mathrm{E} 8$ & $\mathrm{~B}$ \\
\hline $5 \mathrm{E} 6$ & $\mathrm{C}$ \\
\hline $3 \mathrm{E} 4$ & $\mathrm{D}$ \\
\hline $1 \mathrm{E} 2$ & $\mathrm{E}$ \\
\hline
\end{tabular}

Tabela de contingência

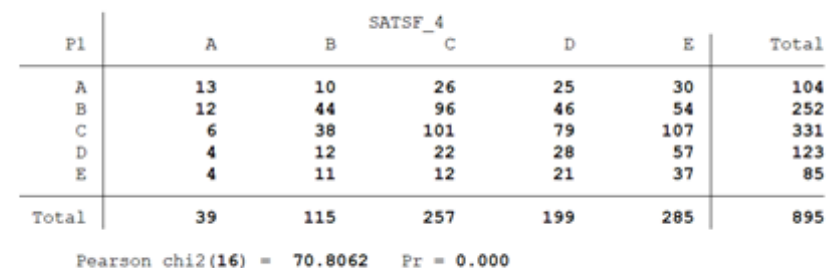

Tabela de frequências e de resíduos padronizados ajustados

\begin{tabular}{|c|c|c|c|c|c|}
\hline $\mathbf{p 1}_{1}$ & \multicolumn{5}{|c|}{ SATSF_4 } \\
\hline \multirow[t]{3}{*}{ A } & 13 & 10 & 26 & 25 & 30 \\
\hline & & 13.363 & 29.864 & $\begin{array}{r}23.124 \\
\end{array}$ & 33.117 \\
\hline & 4.327 & -1.848 & -0.891 & 0.471 & -0.698 \\
\hline \multirow[t]{3}{*}{ B } & & 44 & & & \\
\hline & 10.981 & 32.380 & 72.362 & 56.031 & 80.246 \\
\hline & 0.371 & 2.581 & 3.883 & -1.793 & -4.187 \\
\hline \multirow[t]{3}{*}{ c } & & 38 & 101 & 79 & \\
\hline & 14.423 & 42.531 & 95.047 & 73.597 & 105.402 \\
\hline & $-2.857 \mid$ & -0.937 & 0.911 & 0.900 & 0.237 \\
\hline \multirow[t]{3}{*}{ D } & 4 & & & & \\
\hline & 5.360 & 15.804 & 35.320 & 27.349 & 39.168 \\
\hline & -0.647 & -1.104 & -2.858 & 0.152 & 3.716 \\
\hline \multirow[t]{2}{*}{ E } & & & & & \\
\hline & $\begin{array}{l}3.784 \\
8.165\end{array}$ & $\begin{array}{r}10.922 \\
0.027\end{array}$ & $\begin{array}{r}24.408 \\
-3.127\end{array}$ & $\begin{array}{r}18.899 \\
0.576\end{array}$ & $\begin{array}{r}27.067 \\
2.431\end{array}$ \\
\hline
\end{tabular}

\section{Outputs da Análise de Correspondência Simples}

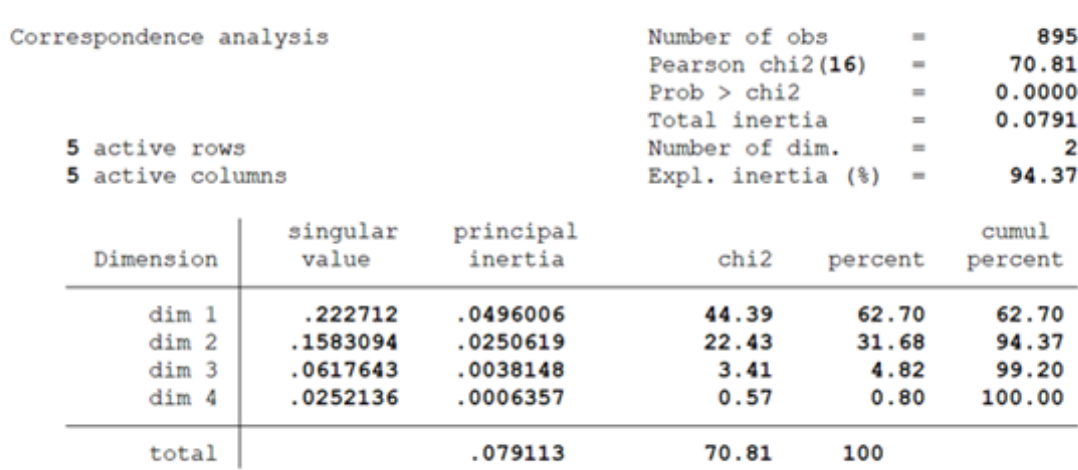

\section{Mapa Perceptual}

Correspondence analysis biplot

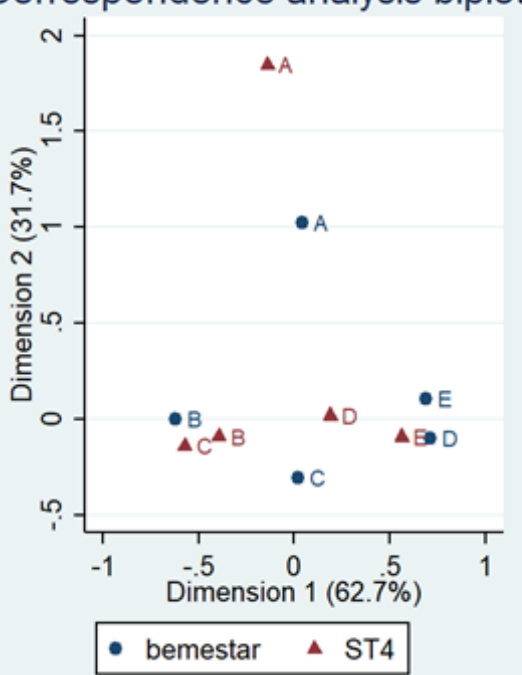

Figura 21. AnÁlise de correspondênCia entre Bem-estare Satisfação com tempo de espera dos ônibus 


\subsubsection{Satisfação com tempo de espera dos ônibus e tempo de espera do ônibus}

Apesar de não se verificar uma associação entre bem-estar e tempo de espera do ônibus, investigou-se a possiblidade de associação entre as variáveis de "satisfação com tempo de espera dos ônibus" e "tempo de espera do ônibus".

Pela tabela de contingências, verificou-se há associação entre as variáveis para o nível de significância de 5\%. E pela análise dos resíduos padronizados ajustados, observa-se que, ao nível de significância de 5\%, a correspondência entre as categorias das duas variáveis não ocorre de forma clara, pois não há um padrão explicativo para suas associações, sendo destacadas em azul quando a correspondência é positiva e em vermelho é negativa.

Enfim, os outputs da análise de correspondência a seguir indicam que $98.84 \%$ da inércia principal total corresponde às dimensões 1 e 2, permitindo assim que o mapa perceptual seja uma boa ferramenta para visualização da correspondência entre categorias, onde se observa a associação positiva entre os termos, uma vez que, no gráfico, os grupos com maior satisfação com o tempo de espera do ônibus estão posicionados próximos aos grupos de baixo tempo de espera, assim como os com menor satisfação estão próximos dos grupos de alto tempo de espera. 
Categorias das variáveis analisadas

\begin{tabular}{|c|c|c|}
\hline \multirow{2}{*}{\multicolumn{2}{|c|}{$\begin{array}{l}\text { ST4- SATISFACC̃̃O COM TEMPO } \\
\text { DE ESPERA DO ÔNIBUS }\end{array}$}} & TBUS - TEMPO DE ESPERA DE ÔNIBUS \\
\hline & & ATÉ 5 MINUTOS \\
\hline $9 \mathrm{E} 10$ & A & DE 6 A 10 MINUTOS \\
\hline 7 E 8 & B & DE 11 A 20 MINUTOS \\
\hline $5 \mathrm{E} 6$ & C & DE 21 A 30 MinUtos \\
\hline 3 E 4 & D & DE 31 a 40 MINUTOS \\
\hline $1 \mathrm{E} 2$ & $\mathrm{E}$ & MAIS DE 40 MINUTOS \\
\hline
\end{tabular}

Outputs da Análise de Correspondência Simples

Tabela de contingência

\begin{tabular}{r|rrrrrr|r} 
& \multicolumn{7}{|c}{ TEMPOBUS } \\
SATSE_4 & 10 a20 & 20 a 30 & 30 a 40 & 5 a 10 & ate5 & maisde 40 & Total \\
\hline A & 10 & 4 & 1 & 13 & 11 & 0 & 39 \\
B & 39 & 13 & 4 & 39 & 17 & 3 & 115 \\
C & 94 & 48 & 11 & 73 & 20 & 11 & 257 \\
D & 70 & 45 & 25 & 33 & 8 & 18 & 199 \\
E & 89 & 83 & 42 & 27 & 12 & 32 & 285 \\
\hline Tota1 & 302 & 193 & 83 & 185 & 68 & 64 & 895
\end{tabular}

Pearson chi2 200$)=136.1459-\mathrm{Pr}=0.000$

\section{Tabela de frequências e de resíduos padronizados ajustados}

\begin{tabular}{|c|c|c|c|c|c|c|c|}
\hline \multirow[b]{2}{*}{ SATSF_4 } & \multirow[b]{2}{*}{$10 \mathrm{a} 20$} & \multirow[b]{2}{*}{$20 a 30$} & \multicolumn{2}{|c|}{ TEMPOBUS } & \multirow[b]{2}{*}{ ates } & \multirow[b]{2}{*}{ maisde40 } & \\
\hline & & & $38 \mathrm{a} 40$ & $5 a 10$ & & & \\
\hline A & $\begin{array}{r}10 \\
13.160 \\
-1.094\end{array}$ & $\begin{array}{r}4 \\
8.410 \\
-1.756\end{array}$ & $\begin{array}{r}1 \\
3.617 \\
-1.477\end{array}$ & $\begin{array}{r}13 \\
8.061 \\
1.997\end{array}$ & $\begin{array}{r}11 \\
2.963 \\
4.966\end{array}$ & $\begin{array}{r}2.0 \\
2.789 \\
-1.772\end{array}$ & \\
\hline в & $\begin{array}{r}39 \\
38.884 \\
8.041\end{array}$ & $\begin{array}{r}13 \\
24.799 \\
-2.866\end{array}$ & $\begin{array}{r}4 \\
10.665 \\
-2.295\end{array}$ & $\begin{array}{r}39 \\
23.771 \\
3.757\end{array}$ & $\begin{array}{r}17 \\
8.737 \\
3.115\end{array}$ & $\begin{array}{r}3 \\
8.223 \\
-2.025\end{array}$ & $\begin{array}{l}\text { observed frequency } \\
\text { expected frequency } \\
\text { adjusted residual }\end{array}$ \\
\hline c & $\begin{array}{r}94 \\
86.720 \\
1.138\end{array}$ & $\begin{array}{r}48 \\
55.42 \theta \\
-1.333\end{array}$ & $\begin{array}{r}11 \\
23.834 \\
-3.269\end{array}$ & $\begin{array}{r}73 \\
53.123 \\
3.627\end{array}$ & $\begin{array}{r}20 \\
19.526 \\
0.132\end{array}$ & $\begin{array}{r}11 \\
18.378 \\
-2.115\end{array}$ & 3 cells with expected frequency $<5$ \\
\hline o & $\begin{array}{r}70 \\
67.149\end{array}$ & $\begin{array}{r}45 \\
42.913\end{array}$ & 18.455 & 41.134 & $\begin{array}{r}8 \\
15.128 \\
-2.169\end{array}$ & $\begin{array}{r}18 \\
14.230\end{array}$ & $\begin{aligned} \text { Pearson } \operatorname{chi} 2(2 \theta) & =136.1459 \\
\text { likelihood-ratio } \operatorname{chi2}(2 \theta) & =135.2317\end{aligned}$ \\
\hline E & $\begin{array}{r}0.485 \\
89 \\
96.168 \\
-1.888\end{array}$ & $\begin{array}{r}0.408 \\
83 \\
61.458 \\
3.758\end{array}$ & $\begin{array}{r}1.814 \\
42 \\
42.48 \\
3.851\end{array}$ & $\begin{array}{r}-1.615 \\
27 \\
58.911 \\
-5.654\end{array}$ & $\begin{array}{r}-2.160 \\
12 \\
22.654 \\
-2.614\end{array}$ & $\begin{array}{r}1.176 \\
32 \\
28.389 \\
3.236\end{array}$ & $\begin{array}{l}P r=\theta .000 \\
P r=\theta .000\end{array}$ \\
\hline
\end{tabular}

\begin{tabular}{|c|c|c|}
\hline & Number of obs \\
\hline Pearson ch & (20) & 136.15 \\
\hline Prob $>$ chi & $=$ & 0.0000 \\
\hline Total iner & a & 0.1521 \\
\hline Number of & & 2 \\
\hline Expl. iner & a (8) & 98.84 \\
\hline chi2 & percent & $\begin{array}{l}\text { cumul } \\
\text { percent }\end{array}$ \\
\hline 119.84 & 88.02 & 88.02 \\
\hline 14.73 & 10.82 & 98.84 \\
\hline 1.51 & 1.11 & 99.95 \\
\hline 0.06 & 0.05 & 100.00 \\
\hline & & \\
\hline
\end{tabular}

\section{Mapa Perceptual}

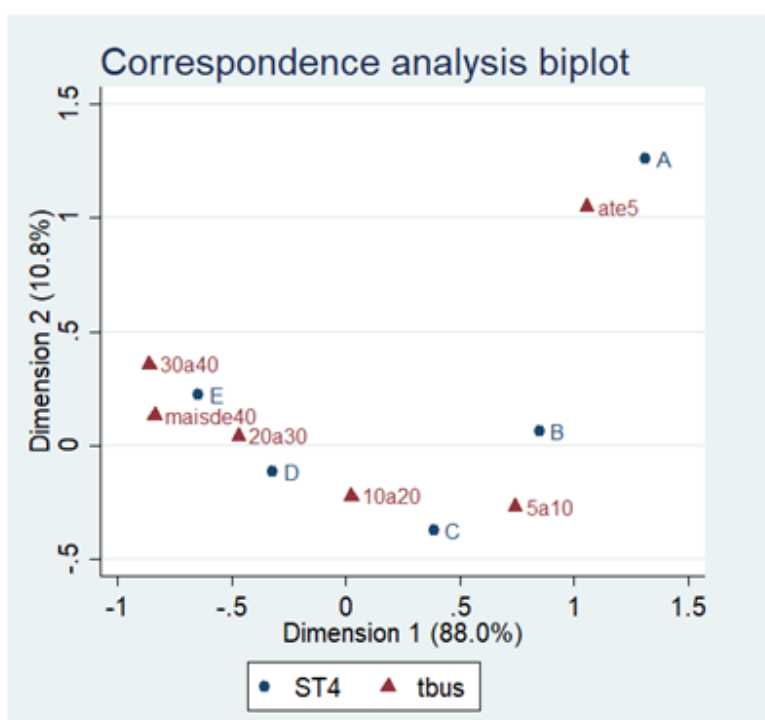

Figura 22. ANÁlISE de CORRESPONDÊNCIA ENTRE SATISFAÇÃo COM TEMPO dE ESPERA Do ÔNIBUSE TEMPO dE ESPERA DO ÔNIBUS 


\subsubsection{Tempos de espera dos ônibus na cidade de São Paulo}

Pelos dados operacionais do GTFS, calculou-se os tempos médio e máximo de espera das linhas de ônibus em pontos e terminais no município, de modo entender como este elemento varia espacialmente na cidade de São Paulo.

O mapa a seguir apresenta a curva de densidade dos tempos de espera, com azul representando regiões com maior frequência das linhas e, portanto, menor tempo de espera, e vermelho para regiões em que praticamente não há atendimento de ônibus.

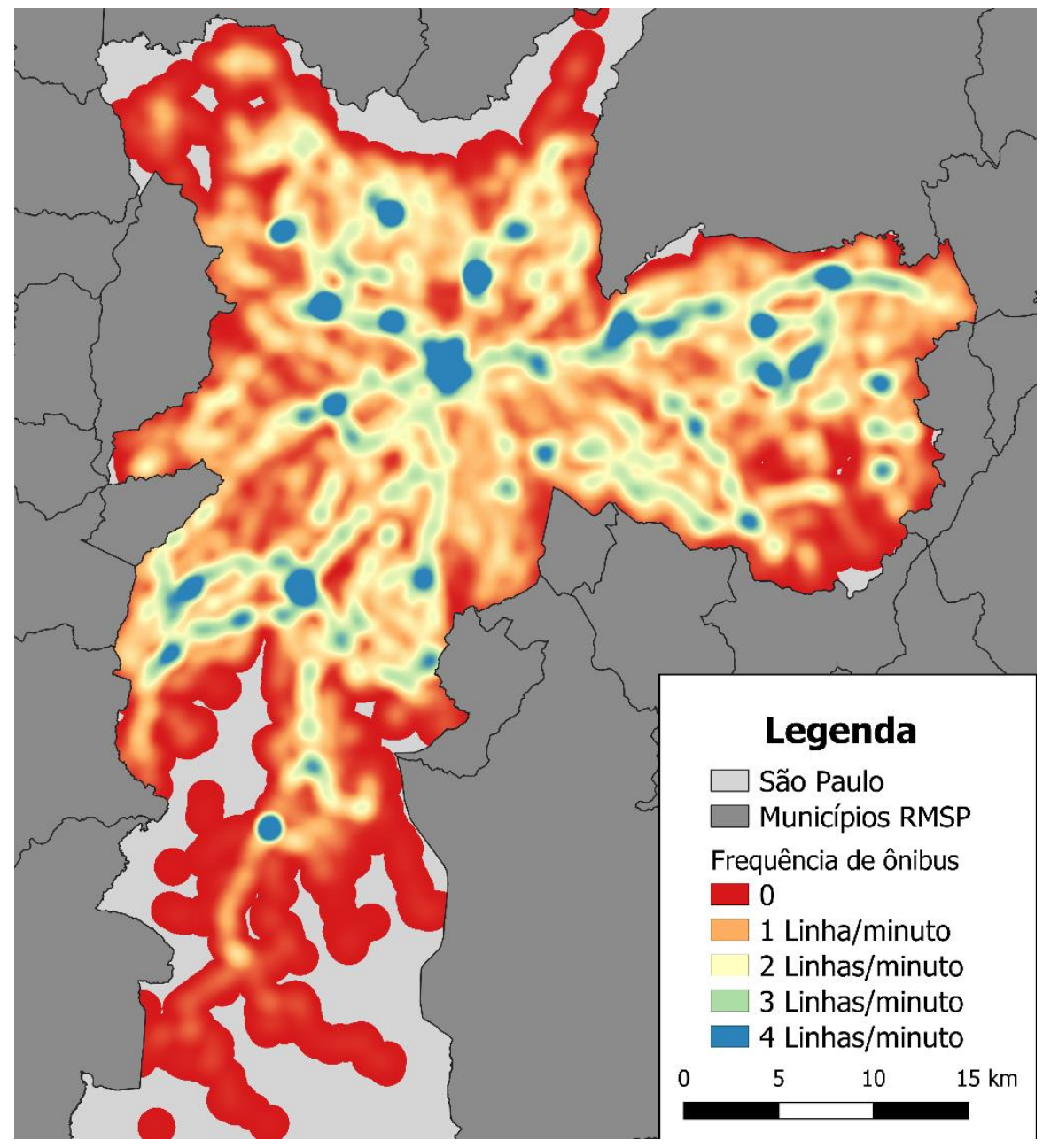

FIGURA 23. DeNSIDAdE de FREQUÊNCIA DAS LINHAS de ÔNIBUS 


\subsubsection{Bem-estar e Satisfação com a tarifa do transporte público}

Por fim, a satisfação com a tarifa do transporte público foi o terceiro aspecto que apresentou correspondência relevante com o bem-estar na Pesquisa IRBEM de 2016.

A associação entre as variáveis é demonstrada na tabela de contingências para o nível de significância de $5 \%$ e a análise dos resíduos padronizados ajustados apresenta correspondência entre as categorias, ao nível de significância de 5\%. Nela, as categorias que são correspondentes positivamente são destacadas em azul e negativamente em vermelho.

A análise dos resíduos padronizados ajustados permite observar que as categorias de alto grau de bem-estar ( $\mathrm{A}$ e $\mathrm{B}$ ) correspondem positivamente a categorias de alto grau de satisfação com a tarifa de transporte público ( $A, B$ e $C)$ e correspondem negativamente a categoria de baixo grau de satisfação com a tarifa de transporte público (E). O contrário também ocorre, com a correspondência positiva das categorias de baixo grau de bem-estar ( $D$ e E) com baixo grau de satisfação com a tarifa de transporte público (E) e correspondência negativa com alto grau de satisfação com a tarifa de transporte público (B e C).

Com a análise de correspondência se obtém que 98,82\% da inércia principal total corresponde às dimensões 1 e 2 , permitindo assim que o mapa perceptual seja uma boa ferramenta para visualização da correspondência entre categorias, onde se observa a associação positiva entre os termos, uma vez que, no gráfico, a disposição dos grupos com menor satisfação com o tempo de espera do ônibus estão posicionados próximos aos grupos com bem-estarmais baixo. 
Categorias das variáveis analisadas

\begin{tabular}{|c|c|}
\hline \multicolumn{2}{|c|}{ P1 - BEM-ESTAR } \\
\hline $9 \mathrm{E} 10$ & $\mathrm{~A}$ \\
\hline $7 \mathrm{E} 8$ & $\mathrm{~B}$ \\
\hline $5 \mathrm{E} 6$ & $\mathrm{C}$ \\
\hline $3 \mathrm{E} 4$ & $\mathrm{D}$ \\
\hline $1 \mathrm{E} 2$ & $\mathrm{E}$ \\
\hline
\end{tabular}

\begin{tabular}{|c|c|}
\hline $\begin{array}{c}\text { ST8 - SATISFAÇÃO COM A TARIFA DE } \\
\text { TRANSPORTE PÚBLICO }\end{array}$ \\
\hline $9 \mathrm{E} 10$ & $\mathrm{~A}$ \\
\hline $7 \mathrm{E} 8$ & $\mathrm{~B}$ \\
\hline $5 \mathrm{E} 6$ & $\mathrm{C}$ \\
\hline $3 \mathrm{E} 4$ & $\mathrm{D}$ \\
\hline $1 \mathrm{E} 2$ & $\mathrm{E}$ \\
\hline
\end{tabular}

Tabela de contingência

\begin{tabular}{r|rrrrr|r}
$\mathrm{P} 1$ & $\mathrm{~A}$ & $\mathrm{~B}$ & SATSF $_{-}{ }_{\mathrm{C}}$ & $\mathrm{D}$ & $\mathrm{E}$ & Total \\
\hline $\mathrm{A}$ & 9 & 12 & 40 & 24 & 58 & 143 \\
$\mathrm{~B}$ & 6 & 45 & 95 & 79 & 132 & 357 \\
$\mathrm{C}$ & 6 & 38 & 90 & 109 & 232 & 475 \\
$\mathrm{D}$ & 3 & 6 & 22 & 31 & 108 & 170 \\
$\mathrm{E}$ & 3 & 5 & 15 & 21 & 80 & 124 \\
\hline Total & 27 & 106 & 262 & 264 & 610 & 1,269
\end{tabular}

Pearson chi2 (16) -79.1406 Pr -0.000

Tabela de frequências e de resíduos padronizados ajustados

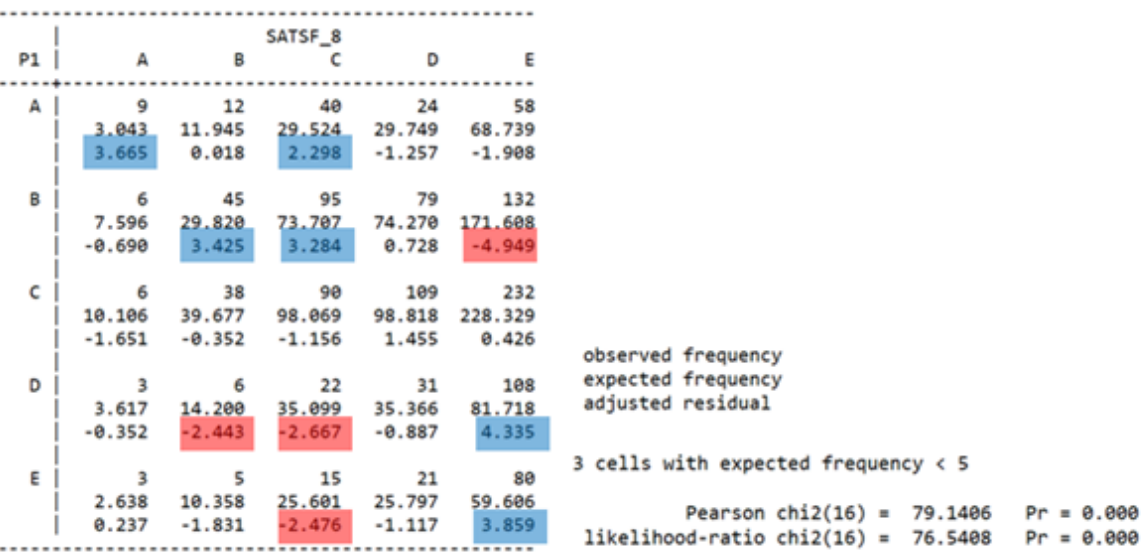

Outputs da Análise de Correspondência Simples

\begin{tabular}{|c|c|c|c|c|c|}
\hline \multicolumn{3}{|c|}{ prespondence analysis } & \multicolumn{2}{|c|}{ Number of obs } & \multirow{2}{*}{$\begin{array}{r}1,269 \\
79.14\end{array}$} \\
\hline & & & Pearson $\mathrm{ch}$. & (16) & \\
\hline & & & Prob $>$ chi & $=$ & \\
\hline \multirow{3}{*}{\multicolumn{2}{|c|}{$\begin{array}{l}5 \text { active rows } \\
5 \text { active columns }\end{array}$}} & & Total iner: & a & 0.0624 \\
\hline & & & Number of & $\mathrm{m}$. & \\
\hline & & & Expl. iner: & $\mathrm{a}(8)=$ & 98.82 \\
\hline & singular & principal & & \multirow[b]{2}{*}{ percent } & cumul \\
\hline Dimension & value & inertia & chi2 & & percent \\
\hline $\operatorname{dim} 1$ & .2183581 & .0476803 & 60.51 & 76.45 & 76.45 \\
\hline $\operatorname{dim} 2$ & .1180992 & .0139474 & 17.70 & 22.36 & 98.82 \\
\hline $\operatorname{dim} 3$ & .0258035 & .0006658 & 0.84 & 1.07 & 99.89 \\
\hline $\operatorname{dim} 4$ & .0084276 & .000071 & 0.09 & 0.11 & 100.00 \\
\hline total & & .0623645 & 79.14 & 100 & \\
\hline
\end{tabular}

\section{Mapa Perceptual}

Correspondence analysis biplot

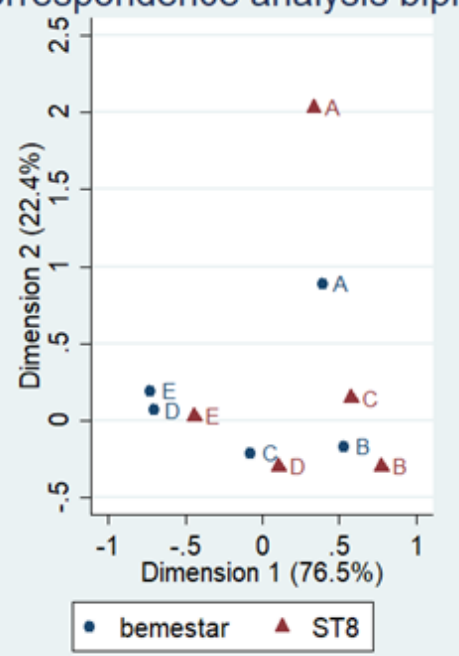

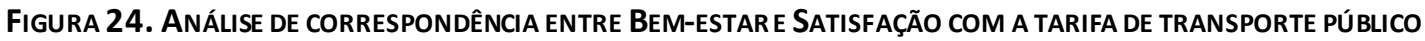




\subsubsection{Bem-estar e Renda familiar}

A análise de correspondência entre bem-estar e renda familiar foi uma das primeiras a serem realizadas neste estudo, uma vez que diversos estudos apontam que a renda ou atributos relacionados a ela influenciam a qualidade de vida e sua percepção (HEADEY et al., 2004; DEINER e SELIGMAN, 2004; LAYARD, 2005; WINKELMANN e WINKELMANN, 1998; DELBOSC e CURRIE, 2011a).

Como apresentado a seguir, utilizando os dados da Pesquisa IRBEM de 2016, não é possível estabelecer uma boa correspondência entre essas variáveis. A opção de apresentá-la aqui, e não nos anexos com o demais histórico de análises, deve-se a sua relação com a percepção da tarifa de transporte público.

Primeiramente, a associação entre as variáveis bem-estar e renda familiar é comprovada pelo teste chi-quadrado na tabela de contingências, para o nível de significância de $5 \%$. E pela análise dos resíduos padronizados ajustados, observa-se correspondência entre as categorias, ao nível de significância de 5\%. Nesta análise, vêse uma correspondência negativa, destacado em vermelho, entre o mais alto grau de bem-estar ( $A$ ) e a mais alta faixa de renda $(A)$ e uma correspondência positiva, destacada em azul, entre o mais baixo grau de bem-estar (E) e a mais baixa faixa de renda (E). As correspondências entre as demais categorias não ocorrem de forma clara, demonstrando que há um padrão explicativo para suas associações.

Por fim, a análise de correspondência a seguir indicam que $95,47 \%$ da inércia principal total corresponde às dimensões 1 e 2 , permitindo assim que o mapa perceptual seja uma boa ferramenta para visualização da correspondência entre categorias, onde se observa que há consistência na correspondência dos níveis mais baixos de renda ( $E$ ) e de bem-estar (E) e dos grupos intermediários de renda (B, C e D) e de bem-estar (B e $C)$. Entretanto, a proximidade do nível $D$ de bem-estar com o grupo de maior renda (A) não é consistente. 
Categorias das variáveis analisadas

\begin{tabular}{|c|c|}
\hline \multicolumn{2}{|c|}{ P1 - BEM-ESTAR } \\
\hline $9 \mathrm{E} 10$ & $\mathrm{~A}$ \\
\hline $7 \mathrm{E} 8$ & $\mathrm{~B}$ \\
\hline $5 \mathrm{E} 6$ & $\mathrm{C}$ \\
\hline $3 \mathrm{E} 4$ & $\mathrm{D}$ \\
\hline $1 \mathrm{E} 2$ & $\mathrm{E}$ \\
\hline
\end{tabular}

\begin{tabular}{|c|c|}
\hline \multicolumn{2}{|c|}{ Renda FAMILIAR } \\
\hline ACIMA DE 10 SM & A \\
\hline DE 5 A 10 SM & B \\
\hline DE 2 A 5 SM & C \\
\hline DE 1 A 2 & D \\
\hline ATÉ 1 SM & E \\
\hline
\end{tabular}

\section{Tabela de contingência}

\begin{tabular}{r|rrrrr|r} 
P1 & A & B & REND2 & D & E & Tota1 \\
\hline A & 4 & 20 & 48 & 50 & 21 & 143 \\
B & 24 & 59 & 141 & 102 & 31 & 357 \\
C & 39 & 69 & 172 & 145 & 50 & 475 \\
D & 18 & 29 & 57 & 43 & 23 & 170 \\
E & 6 & 9 & 47 & 39 & 23 & 124 \\
\hline Total & 91 & 186 & 465 & 379 & 148 & 1,269
\end{tabular}

Pearson chi2 $(16)=28.9516 \quad \mathrm{Pr}=0.024$

Tabela de frequências e de resíduos padronizados ajustados

\begin{tabular}{|c|c|c|c|c|c|c|c|}
\hline & & & REND2 & & & & \\
\hline$P_{1}$ & A & B & c & D & E & & \\
\hline A & 4 & 20 & 48 & 50 & 21 & & \\
\hline & 10.255 & 20.960 & 52.400 & 42.798 & 16.678 & & \\
\hline & -2.152 & -0.241 & -0.811 & 1.414 & 1.195 & & \\
\hline B & & 59 & 141 & 102 & 31 & observed frequency & \\
\hline & 25.600 & 52.326 & 130.816 & 106.622 & 41.636 & expected frequency & \\
\hline & -0.387 & 1.178 & 1.320 & -0.630 & -2.069 & adjusted residual & \\
\hline c & 39 & 69 & 172 & 145 & 50 & & \\
\hline & 34.062 & 69.622 & 174.054 & 141.864 & 55.398 & & \\
\hline & 1.110 & -0.102 & -0.247 & 0.398 & -0.976 & & \\
\hline$D$ & & & & & & Pearson chi2(16) $=$ & 28.9516 \\
\hline & 12.191 & 24.917 & 62.293 & 50.772 & 19.827 & likelihood-ratio $\operatorname{chi2}(16)=$ & 30.2538 \\
\hline & 1.856 & 0.951 & -0.905 & -1.400 & 0.815 & & \\
\hline E & 6 & & & 39 & & $\mathrm{Pr}=0.024$ & \\
\hline & 8.892 & 18.175 & 45.437 & 37.034 & 14.462 & $\mathrm{Pr}=0.017$ & \\
\hline & -1.060 & -2.453 & 0.307 & 0.406 & 2.515 & & \\
\hline
\end{tabular}

Correspondence analysis

5 active rows

active colunns

\begin{tabular}{r|ccrrr} 
Dimension & $\begin{array}{c}\text { singular } \\
\text { value }\end{array}$ & $\begin{array}{c}\text { principal } \\
\text { inertia }\end{array}$ & chi2 & percent & $\begin{array}{c}\text { cumul } \\
\text { percent }\end{array}$ \\
\hline dim 1 & .1194396 & .0142658 & 18.10 & 62.53 & 62.53 \\
dim 2 & .075451 & .0056929 & 7.22 & 24.95 & 87.48 \\
dim 3 & .0438548 & .0019232 & 2.44 & 8.43 & 95.91 \\
dim 4 & .0305385 & .0009326 & 1.18 & 4.09 & 100.00 \\
\hline total & & .0228145 & 28.95 & 100 &
\end{tabular}

Mapa Perceptual

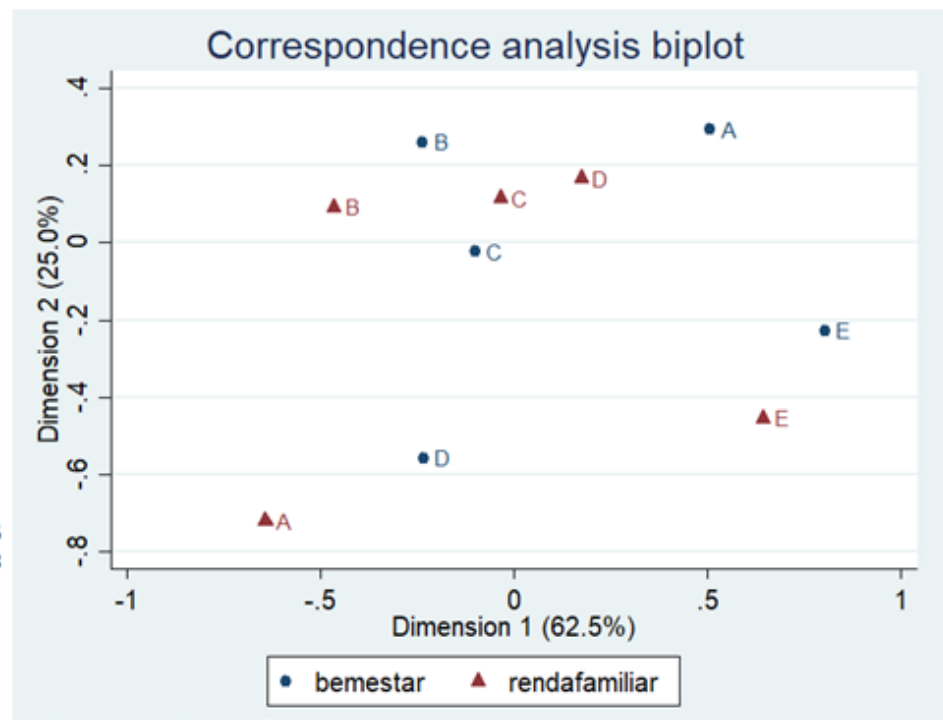

FIGURA 25. MAPA PERCEPTUAL RESULTANTE dA ANÁLISE DE CORRESPONDÊNCIA ENTRE BEM-ESTAR E SATISFAÇÃo COM A TARIFA DE TRANSPORTE PÚBLICO 


\subsubsection{Satisfação com a tarifa de transporte e Renda familiar}

Uma vez que a correspondência entre bem-estare renda familiar não se mostra conforme o esperado, mas a percepção da tarifa do transporte público tem boa correspondência com o bem-estar, decidiu-se fazer a investigação da relação entre renda familiar e satisfação com a tarifa de transporte público. Contudo, a associação entre elas não ocorre para um nível de significância de $5 \%$.

\section{Categorias das variáveis analisadas}

\begin{tabular}{|c|c|}
\hline $\begin{array}{c}\text { ST8 - SATISFAÇÃO COM A TARIFA DE } \\
\text { TRANSPORTE PÚBLICO }\end{array}$ \\
\hline 9 E 10 & A \\
\hline 7 E 8 & B \\
\hline 5 E 6 & C \\
\hline 3 E 4 & D \\
\hline 1 E 2 & E \\
\hline
\end{tabular}

\begin{tabular}{|c|c|}
\hline \multicolumn{2}{|c|}{ Renda FAMiliar } \\
\hline ACIMA DE 10 SM & A \\
\hline DE 5 A 10 SM & B \\
\hline DE 2 A 5 SM & C \\
\hline DE 1 A 2 & D \\
\hline ATÉ 1 SM & E \\
\hline
\end{tabular}

Tabela de contingência

\begin{tabular}{r|rrrrr|r} 
SATSE_8 & A & B & REND2 & D & E & Total \\
\hline A & 0 & 4 & 8 & 11 & 4 & 27 \\
B & 3 & 20 & 49 & 23 & 11 & 106 \\
C & 17 & 38 & 97 & 76 & 34 & 262 \\
D & 23 & 40 & 105 & 74 & 22 & 264 \\
E & 48 & 84 & 206 & 195 & 77 & 610 \\
\hline Total & 91 & 186 & 465 & 379 & 148 & 1,269
\end{tabular}

Pearson $\operatorname{chi2}(16)=21.4081 \quad \mathrm{Pr}=0.163$

Figura 26 ANÁlISE dE CORRESPONDÊNCIA ENTRE SATISFAÇÃo COM TARIFA dE TRANSPORTE PÚBLICO E RENDA FAMILIAR

\subsubsection{Gasto com tarifa de transporte público em São Paulo}

No intuito de representar espacialmente a satisfação com a tarifa de transporte público, que apresenta correspondência com o bem-estar subjetivo, calculou-se a partir dos dados da Pesquisa OD, o percentual de custo médio com transporte público frente a renda mensal, em cada zona. 


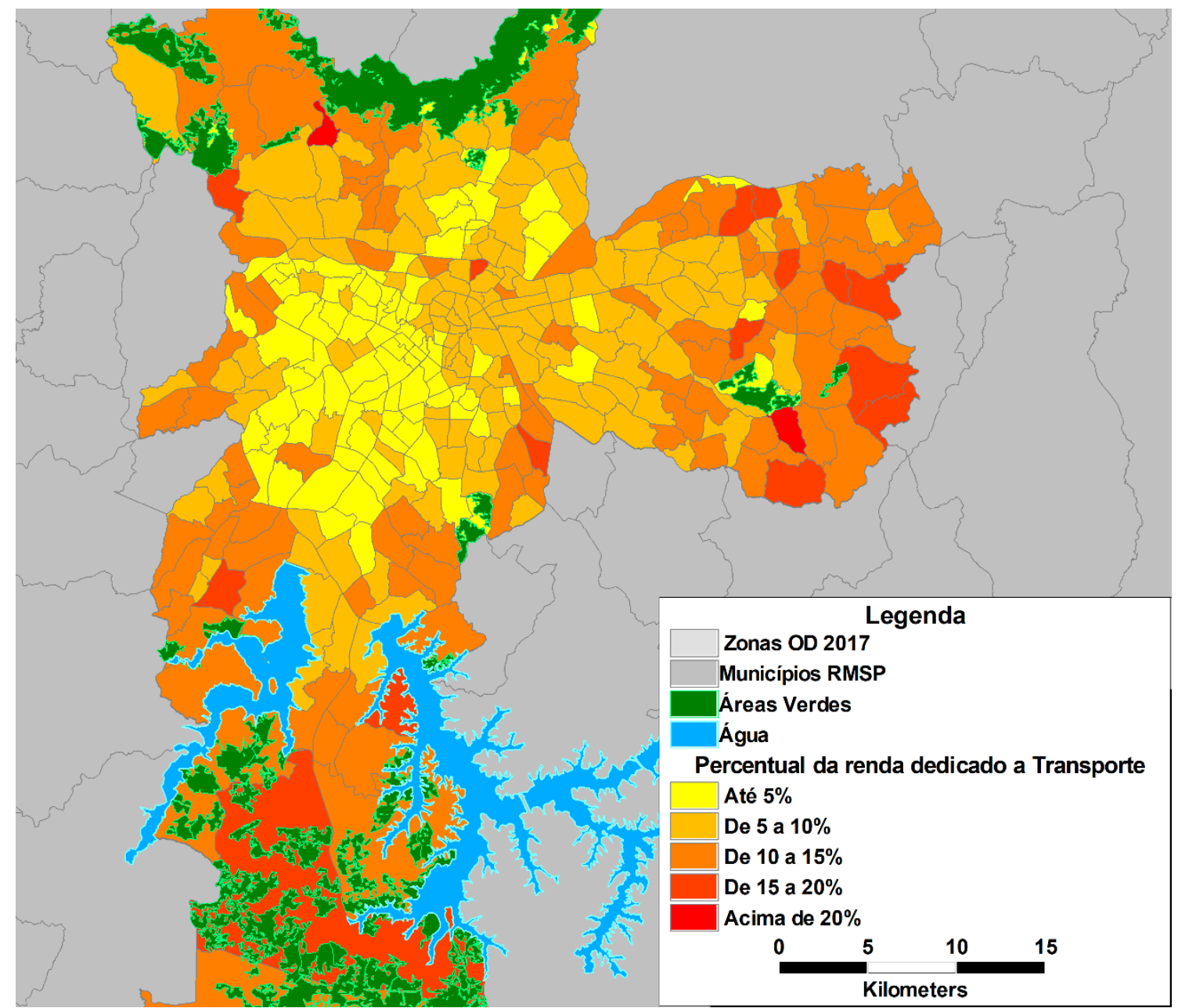

Figura 27. Distribuição POR ZONAS do PERCENTUAL MÉdIO de GASTO MENSAl COM TRANSPORTE COletivo, PELAS PESSOAS QUE UTILIZAM TRANSPORTE COLETIVO

Observa-se, portanto, que o custo mais representativo com transporte público recai sobre as pessoas residentes das áreas mais distantes do centro, especialmente na zona Leste da cidade. É importante destacar que a PNAD de 2019 identificou que na região sudeste do Brasil as famílias estão sacrificando uma parcela maior de sua renda com transporte do que com alimentação (IBGE,2019). 


\section{CONCLUSÕES}

A pesquisa em planejamento de transporte muito debate acerca das desigualdades econômicas e sociais e suas relações com a dificuldade de transporte, uma vez que é por meio do transporte que as pessoas podem acessar as oportunidades da cidade e, ao desempenhá-las, alcançam melhores níveis sociais e econômicos.

Com a expectativa de que os projetos e políticas de transporte tenham como objetivo a melhoria do bem-estar como proposto por diversos autores (KANHe JUSTER, 2002; STANLEY e STANLEY, 2007), este trabalho buscou olhar para além dos aspectos sociais e econômicos e enxergar como dificuldade de transporte impacta no bem-estar subjetivo das pessoas.

Estudos com este objetivo foram realizados em países desenvolvidos, em especial no Reino Unido e na Austrália, utilizando indicadores de bem-estar consagrados na literatura acadêmica da área de psicologia e relacionando-os a indicadores de transporte urbano e sociais. As conclusões obtidas foram de que o bem-estar subjetivo mais alto se associe positivamente à satisfação no deslocamento (CHALOUX, 2019; VOS e WITLOX, 2017) e que o bem-estar é diretamente relacionado a avaliação de satisfação com as viagens e com as atividades realizadas diariamente (BESTGARD et al., 2011).

Tendo em vista, portanto, as relações entre bem-estar e transporte verificadas em outros países por meio de diversos estudos, o presente trabalho propôs a análise de como se estabelece a relação entre estes elementos em regiões com maior desigualdade, utilizando dados da cidade de São Paulo para estudo de caso. Para isso, primeiro se avaliou a associação entre indicadores de bem-estar e de dificuldade de transporte por uma abordagem estatística e não espacializada, devido ao tipo e quantidade de dados dispostos na Pesquisa IRBEM 2016. Posteriormente, por meio de análise complementar para os elementos que resultaram correspondência, utilizando dados de operação da SPTrans e da Pesquisa Origem-Destino do Metrô de São Paulo, avaliou-se sua distribuição espacial na cidade e seus possíveis reflexos na vida dos habitantes da cidade.

Verificou-se a correspondência entre bem-estar e a dificuldade de transporte por meio do método de análise de correspondência entre variáveis subjetivas que representam a percepção sobre a qualidade de vida e a percepção sobre os aspectos do sistema de transporte, contidos na Pesquisa IRBEM de 2016. Porém, estes dados não permitiram análises aprofundadas quanto a sua distribuição espacial e por isso esta análise foi complementada com outras fontes.

A satisfação de tempo de deslocamento, que resultou como altamente correspondente ao bem-estar, pôde ser avaliada espacialmente, uma vez que os dados apresentados na Pesquisa OD são a própria declaração de duração da viagem do respondente, sendo influenciada por sua percepção. A diferença observada entre as 
regiões centrais e periféricas, e nos diferentes modos de transporte, revelam como a cidade é desigual no aspecto de duração de viagem.

O segundo aspecto analisado é o tempo de espera de ônibus, que apresenta alta correspondência com a satisfação com tempo de espera de ônibus e este, por sua vez, é altamente correspondente a bem-estar. Para a compreensão espacial deste aspecto no município de São Paulo, recorreu-se à análise do Mapa de densidade de Kernel, que permite observar que há muitos eixos com baixos tempos de espera dos ônibus, porém há várias regiões na cidade com tempos de espera de ônibus elevados.

Finalmente, a satisfação do custo da tarifa de transporte público se mostrou altamente correspondente ao bem-estar em São Paulo. Para a avaliação espacial deste aspecto recorreu-se a representação da satisfação com a tarifa pelo impacto que esta tem no orçamento familiar, considerando que o dispêndio de grande parte da renda com custos de transporte leva a uma maior insatisfação. E, novamente, pela análise espacial, verifica-se que os residentes de zonas periféricas são os mais prejudicados.

Considerando o exposto, este estudo conclui que a qualidade do transporte é um dos fatores que impactam o bem-estar subjetivo e que, devido as suas características desiguais no território de São Paulo, há locais com fatores relacionados ao transporte que favorecem a satisfação com a vida (em geral localizados em áreas centrais) e locais em que estes elementos desfavorecem o bem-estar (regiões mais periféricas da cidade). Com isso, se tem que em uma cidade marcada pela desigualdade econômica, social e de acesso a oportunidades, adiciona-se ainda a desigualdade em aspectos altamente correspondentes ao bem-estar.

Para futuros pesquisadores que busquem a maior compreensão de como o transporte pode impactar no bem-estar, sugere-se a busca por dados que permitam a exploração quantitativa do conceito de bem-estar ou que considere a natureza ordinal das notas de bem-estar das pesquisas IRBEM e Viver em São Paulo. Ainda se recomenda a análise da relação direta de indicadores de bem-estar com dados operacionais do sistema de transporte. 


\section{REFERÊNCIAS BIBLIOGRÁFICAS}

BANISTER, D.; BOWLING, A. Quality of life for the elderly: the transport dimension. Transport Policy v.11, p.105-115. 2004.

BRADSHAW, J.; KEMP, P.; BALDWIN, S.; ROWE, A. The Drivers of Social Exclusion: A Review of the Literature for the Social Exclusion Unit in the Breaking the Cycle Series. Office of the Deputy Prime Minister, London. 2004.

BRASIL. Lei no 12.587, de 03 de janeiro de 2012.

BOSTOCK, L. Pathways of disadvantage? Walking as a mode of transport among lowincome mothers. Health and Social Care in the Community, v. 9, n. 1, p. $11-18,2001$.

CARDOSO C. E. P. Análise do transporte coletivo urbano sob a ótica dos riscos e carências sociais. 2008. 139 f. Tese de Doutorado, Programa de Pós-graduação em Serviço Social, Pontifícia Universidade Católica de São Paulo, São Paulo, SP, 2008.

CHALOUX, N., BOISJOLY, G., GRISÉ, E., EL-GENEIDY, A., and LEVINSON, D. I only get some satisfaction: Introducing satisfaction into measures of accessibility. Paper presented at the 98th Annual Meeting of the Transportation Research Board, Washington D.C., USA. 2019.

CHURCH, A.; FROST, M.; SULLIVAN, K. Transport and social exclusion in London. Transport Policy v.7, n.3, p.195-205. 2000.

CLARK, A. E., OSWALD, A. J. Unhappiness and unemployment. The Economic Journal v.104, p.648-659. 1994.

CLOUTIER, S.; KARNER, A.; BREETZ, H. L.; TOUFANI, P.; ONAT, N.; PATEL, S.; PARALKAR, S.; BEREJNOI, E.; MORRISON, B. A.; PAPENFUSS, J.; BRIGGS, A. D.; CARLSON, C. Measures of a Sustainable Commute as a Predictor of Happiness. Sustainability, v.9, 1214. 2017.

CURRIE, G., RICHARDSON, T., SMYTH, P., VELLA-BRODERICK, D., HINE, J., LUCAS, K., STANLEY, J., MORRIS, J., KINNEAR, R., STANLEY, J. Investigating links between transport disadvantage, social exclusion and well-being in Melbourne - updated results. Transportation Economics, v29, p.287 - 295, 2010.

CURRIE, G., DELBOSC, A. Transport Disadvantage: A Review In: CURRIE, G. New Perspectives and Methods in Transport and Social Exclusion Research. 1 ed. Bingley, Reino Unido: Emerald Group. 2011. cap. 2.1. pp.15 - 25.

DELBOSC, A. The role of well-being in transport policy. Transport Policy. v. 23, p. 25-33, 2012. 
DELBOSC, A. CURRIE, G. Exploring the relative influences of transport disadvantage and social exclusion on well-being. Transport Policy. v. 18, p. 555 - 562, 2011a.

The spatial context of transport disadvantage, social exclusion and well-being. Journal of Transport Geography.v. 19, p. 1130 - 1137, 2011 b.

. Transport problems that matter - social and psychological links to transport disadvantage. Journal of Transport Geography.v.16, p. 170 - 178, 2011c.

DEINER, E.; SELIGMAN, M. Beyond Money: Toward an Economy of Well-Being. Psycological Science in the Public Interest, Vol. 5. 2004.

DIENER, E. Subjective Well-being. Psychological Bulletin, v. 95, n. 3, p. 542 - 575, 1984.

DIENER, E., EMMONS, R. A., LARSEN, R. J., \& GRIFFIN, S. The Satisfaction with Life Scale. Journal of Personality Assessment, 49, 71-75, 1985.

DOWLING, R., A. GOLLNER. Understanding Women's Travel: From Transport Disadvantage to Mobility. Sydney, NRMA. 1997.

. Women and transport: from disadvantage to mobility through the automobile. 21st Australasian Transport Research Forum, Adelaide, 1997.

DODSON, J., GLEESON, B., SIPE, N. Transport Disadvantage and Social Status: A review of literature and methods. 2004. 63 f. Pesquisa de monografia. Programa de Políticas Urbanas, Griffith University, Brisbane, Austrália, 2004.

EASTERLIN, R. A. Does Economic Growth Improve the Human Lot? Some Empirical Evidence. Nations and Households in Economic Growth, p. 89-125, 1974. https://doi.org/10.1016/B978-0-12-205050-3.50008-7

FAVERO, L. P.; BELFIORE, P. Manual de Análise de Dados: Estatística e Modelagem Multivariada com Excel ${ }^{\circledR}$, SPSS ${ }^{\circledR}$ e Stata ${ }^{\circledR}$. Elsevier Academic. 2017.

FEITOSA, F. F., CAMARA, G., MONTEIRO, A. M. V., KOSCHITZKI, T., SILVA, M. P. S. Global and local spatial indices of urban segregation. International Journal of Geographical Information Science, v. 21, n. 3, p. 299-323, 2007.

FERRAZ, A. C. P.; TORRES, I. G. E. Transporte público urbano. São Carlos: Rima, 2004.

FORATTINI, O. P. Qualidade de vida e meio urbano. A cidade de São Paulo, Brasil. Rev. Saúde Pública, São Paulo, v. 25, p. 75 - 86, 1991.

FRANK, L. D.; SALLIS, J. F.; CONWAY, T. L.; CHAPMAN, J. E.; SAELENS, B. E.; BACHMAN, W. Many pathways from land use to health: associations between neighborhood walkability and active transportation, Body mass index, and air quality. Journal of the American Planning Association v.72, p.75-87. 2006. 
GALLUP. Gallup Global Wellbeing - The Behavioral Economics of GDP Growth. Gallup, Inc. Washington. 2010.

GOMIDE, A. A. Transporte urbano e inclusão social: elementos para políticas públicas. Brasília: Ipea, 2003. (Texto para Discussão n. 960).

- Mobilidade urbana, iniquidade e políticas sociais. Políticas Sociais: acompanhamento e análise, Brasília, n.12, p. 242-250, fev. 2006.

HANSEN, W. G. How accessibility shapes land use. Journal of the American Institute of planners, v. 25(2), p. 73-76, 1959.

HANSON, S. Context of Urban Travel. In: The Geography of Urban Transportation. 3a. ed. Nova Iorque: The Guilford Press, cap1. p. 4, 2004.

HANSSON, E.; MATTISSON, K.; BJORK, J.; ÖSTERGREN, P.-O.; JAKOBSSON, K. Relationship between commuting and health outcomes in a cross-sectional population survey in Southern Sweden. BMC Public Health 11:834. 2011.

HEADEY, B., MUFFELS, R.; WOODEN, M. Well-Being over time in Britain and in USA. IZA Working Paper n. 218. 2004.

HINE, J., MITCHELL, F. Transport Disadvantage and Social Exclusion: Exclusionary Mechanisms in Transport in Urban Scotland. Ashgate, Aldershot, UK. 2003.

HUMPHREY, N. P. Does the Built Environment Influence Physical Activity? Transportation Research Board, Washington, DC. 2005.

IBGE - INSTITUTO BRASILEIRO DE GEOGRAFIA E ESTATISTICA, 2010. Base de informações do Censo Demográfico 2010: Resultados do Universo por setor censitário. Rio de Janeiro, IBGE, 2011. Disponível em < https://censo2010.ibge.gov.br/ > Acessado em 30 de outubro de 2017

. Pesquisa de Orçamentos Familiares 2017-2018. Primeiros resultados. Rio de Janeiro, $\quad$ IBGE, 2019. Disponível em < https://biblioteca.ibge.gov.br/visualizacao/livros/liv101670.pdf $>$. Acessado em $01 \mathrm{de}$ maio de 2020.

IBOPE. Pesquisa de opinião pública sobre indicadores de percepção - JOB1423/2008. São Paulo, 2008. Disponível em: < https://www.nossasaopaulo.org.br/sites/default/files/pesquisas/relatoriopesquisainte gral.pdf >. Acessado em 01 de março de 2019. 
IBOPE INTELIGÊNCIA. Pesquisa de opinião pública - Viver em São Paulo - Bem-estar, qualidade de vida e avaliação administrativa - JOB1005/2017. São Paulo, 2018. Disponível em:

https://www.nossasaopaulo.org.br/sites/default/files/arquivos/viver_em_sp 2018 ta belas.pdf > . Acessado em 01 de março de 2019.

. Pesquisa de opinião pública sobre a satisfação com a qualidade de vida na cidade

- JOB0939/2016. São Paulo, 2017. Disponível em: < https://nossasaopaulo.org.br/pesquisas/tabelas-irbem2017.pdf $>$. Acessado em $01 \mathrm{de}$ março de 2019.

. Pesquisa de opinião pública sobre a satisfação com a qualidade de vida na cidade e avaliação de serviços públicos - JOB0903/2015. São Paulo, 2016. Disponível em: < https://nossasaopaulo.org.br/portal/arquivos/irbem/irbem2016-tabelas.pdf $>$. Acessado em 01 de março de 2019.

. Pesquisa de opinião pública sobre a satisfação com a qualidade de vida na cidade e avaliação de serviços públicos - JOB1395/2014. São Paulo, 2015. Disponível em: < https://nossasaopaulo.org.br/portal/arquivos/irbem/irbem2015-tabelas.pdf >. Acessado em 01 de março de 2019.

. Pesquisa de opinião pública sobre a satisfação com a qualidade de vida na cidade e avaliação de serviços públicos - JOB1265/2013. São Paulo, 2014. Disponível em: < https://www.nossasaopaulo.org.br/sites/default/files/pesquisas/relatorio de tabelas 24 01.pdf >. Acessado em 01 de março de 2019.

. Pesquisa de opinião pública sobre a satisfação com a qualidade de vida na cidade e avaliação de serviços públicos - JOB1609/2012. São Paulo, 2013. Disponível em: < https://www.nossasaopaulo.org.br/sites/default/files/pesquisas/pesquisa_irbem ibop e 2013 tabelas.pdf >. Acessado em 01 de março de 2019.

. Pesquisa de opinião pública sobre a satisfação com a qualidade de vida na cidade e avaliação de serviços públicos - JOB2171/2010. São Paulo, 2011. Disponível em: < https://www.nossasaopaulo.org.br/sites/default/files/pesquisas/pesquisa irbem ibop e 2011 tabelas.pdf >. Acessado em 01 de março de 2019.

. Pesquisa de opinião pública sobre a satisfação com a qualidade de vida na cidade e avaliação de serviços públicos - JOB1650/2009. São Paulo, 2010. Disponível em: < https://www.nossasaopaulo.org.br/sites/default/files/pesquisas/pesquisa irbem ibop e 2010 completa.pdf >. Acessado em 01 de março de 2019. 
Pesquisa de opinião pública sobre indicadores de percepção - JOB2204/2008.

São Paulo, 2009. Disponível em: <

https://www.nossasaopaulo.org.br/sites/default/files/pesquisas/pesquisacompletaibo pe2009.pdf > . Acessado em 01 de março de 2019.

INTERNATIONAL WELL-BEING GROUP (2013). Personal Wellbeing Index. 5th Edition. Melbourne, Austrália. Centre on Quality of Life, Deakin University. Disponível em < http://www.acqol.com.au/uploads/pwi-a/pwi-a-english.pdf $>$. Acessado em 07 de fevereiro de 2019.

ITAMARATY. Objetivos de desenvolvimento sustentável. 2016. Disponível em < http://www.itamaraty.gov.br/pt-BR/politica-externa/desenvolvimento-sustentavel-emeio-ambiente/134-objetivos-de-desenvolvimento-sustentavel-ods >. Acessado em 03 de abril de 2019.

JACKSON, T.; MCBRIDE, N., ABDALLAH, S.; MARKS, N. Measuring Regional Progress: A Regional Index of Sustainable Economic Well-Being (R-ISEW) for all the English Regions. The New Economic Foundation. Nottingham Trent University. 2008.

JANUZZI, P. M. Indicadores para diagnóstico, monitoramento e avaliação de programas sociais o Brasil. Revista do Serviço Público Brasília 56 (2): 137-160 Abr/Jun 2005

KAHN, R. L. e JUSTER, F. T. Well-being: Concepts and Measures. Journal of Social Issues, v. 58, n. 4 , p. $627-644.2002$.

LAYARD, R. Happiness - Lessons from a New Science, Penguin Press, New York. 2005.

LUCAS, K. Transport and social exclusion: Where are we now? Transport Policy, v. 20, p. 105 - 113, 2012. https://doi.org/10.1016/j.tranpol.2012.01.013 .

LUCAS, K.; TYLER, S.; CHRISTODOULOU, G. Assessing the 'value' of new transport initiatives in deprived neighborhoods in the UK. Transport Policy, v. 16, p. $115-122$, 2009.

LYUBOMIRSKY, S.; SHELDON, K. M.; SCHKADE, D. Pursuing Happiness: The Architecture of Sustainable Change. Review of General Psychology v. 9, n. 2, p. 111-131. 2005.

MA, L.; KENT. J. L.; MULLEY, C. Transport disadvantage, social exclusion, and subjective wellbeing: The role of the neighborhood environment-evidence from Sydney, Australia. Journal of Transport and Land Use, v.2, n.1, p. 31 -47, 2018.

MACKIE, P.J.; JARA-DIAZ, S.; FOWKES, A. S. The value of travel time savings in evaluation. Transportation Research Part E: Logistics and Transportation Review v. 37, p.91-106. 2001. 
MALHOTRA, N. K. Concepção de Pesquisa Exploratória: Dados Secundários e por Assinatura. In: Pesquisa de Marketing: Uma Orientação. 3a. ed. Porto Alegre: Bookman, 2001, cap. 4, p. $80-104$.

MARICATO, E. Metrópole, legislação e desigualdade. Estudos Avançados v.17(48), p.151166. 2003.

MARQUES, E. Estrutura Social e Segregação em São Paulo: Transformações na Década de 2000*. DADOS - Revista de Ciências Sociais, Rio de Janeiro, vol. 57, no 3, 2014.

MARQUES, E. C.; TORRES, H. DA G. Pobreza e distribuição espacial de grupos sociais na metrópole de São Paulo. Cadernos Adenauer, n. 1, 2004.

METRÔ-SP. Pesquisa Origem Destino 2007 - Região Metropolitana de São Paulo: Síntese das Informações. São Paulo, 2008.

Pesquisa Origem Destino 2017 - 50 anos: A Mobilidade Urbana da Região Metropolitana de São Paulo em detalhes. São Paulo, v.4, 2019.

METZ, D. H. Mobility for older people and their quality of life. Transport policy, v. 7, p. $149-152,2000$.

MOKHTARIAN, P.L.; SALOMON, I. How derived is the demand for travel? Some conceptual and measurement considerations. Transportation Research Part A: Policy and Practice, v. 35, p. $695-$ 719, 2001.

MOLLENKOPF, H.; BAAS, S.; MARCELLINI, F.; OSWALD, F.; RUOPPILA, I.; SZEMAN, Z.; TACKEN, M.; WAHL, H. W. Mobility and quality of life. IN: MOLLENKOPF, H.; MARCELLINI, F.; RUOPPILA, I.; SZEMAN, Z.; TACKEN, M. (Eds.), Enhancing Mobility in Later Life: Personal Coping, Environmental Resources and Technical Support, eds. IOS Press, Amsterdam. cap. 12, p.279-288. 2005

MORENO-MONROY, A. I.; LOVELACE, R.; RAMOS, F. R. Public transport and school location impacts on educational inequalities: Insights from São Paulo. Journal of Transport Geography, v.67, p. 110 - 118, 2018.

MURRAY, A. T.; DAVID, R.; STIMSON R. J.; FERREIRA, L. Public Transportation Access. Transportation Research Part D: Transportation and Environment, v.3, n.5, p. $319-328$, 1998.

ONS. Measuring National Well-being: Quality of Life in the UK. 2018. Disponível em < https://www.ons.gov.uk/peoplepopulationandcommunity/wellbeing/articles/measuri ngnationalwellbeing/qualityoflifeintheuk2018 >. Acessado em 03 de março de 2019.

ORTUZAR, J. D.; WILLUMSEN, L. G. Modelling Transport. 4a Edição. Jonh Wiley \& Sons, Chichester, 2011. 
PÁEZ, A; WHALEN, K. Enjoyment of commute: A comparison of different transportation modes. Transportation Research Part A: Policy and Practice, v. 44, p. 537-549, 2010.

PÁEZ, A.; SCOTT, D. M.; MORENCY, C. Measuring accessibility: Positive and normative implementations of various accessibility indicators. Journal of Transport Geography, v. 25, p. 141-153, 2012.

PALMATEER, C.; LEVINSON, D. M. (2017). Justice, Exclusion, and Equity: An Analysis of 48 U.S. Metropolitan Areas. University of Minnesota Digital Conservancy. Disponível em: <http://hdl.handle.net/11299/189908>. Acessado em 31 de outubro de 2017.

PEREIRA, R. H. M., BANISTER, D., SCHWANEN, T., \& WESSEL, N. (2017). Distributional effects of transport policies on inequalities in access to opportunities in Rio de Janeiro.

PEREIRA, E. F., TEIXEIRA, C. S., SANTOS, A. Qualidade de vida: abordagens, conceitos e avaliação. Revista brasileira de Educação Física e Esporte, São Paulo, v. 26, n.2, p. 241 250. 2012.

POPOVA, Y. Relations between Wellbeing and Transport Infrastructure of the Country. Procedia Engineering v. 178 p. 579 - 588. 2017.

PRITCHARD, J. P., GEURS, K., GIANNOTTI, M., HAGEN-ZANKER, A., KUMAR, P., NARDOCCI, A., SLOVIC, A. and TOMASIELLO, D. B. (2020). Satisfaction, Desired commuting and Accessibility to Employment. ASTRID PROJECT.

RIBEIRO, L. Q., RIBEIRO, M. G. IBEU Municipal - Índice de Bem-estar Urbano dos Municípios Brasileiros. Rio de Janeiro: Observatório das Metrópoles, Letra Capital. 2016.

ROSA, S. J. Transporte e Exclusão Social: A Mobilidade da População de Baixa Renda da Região Metropolitana de São Paulo e Trem Metropolitano. Tese Escola Politécnica, Universidade de São Paulo, São Paulo, 2006.

RODRIGUE, J.-P., COMTOIS, C., SLACK B., (2009). The Geography of Transport Systems. Routledge, New York.

ROLNIK, R.; CYMBALISTA, R. (Orgs.) Instrumentos urbanísticos contra a exclusão social. Revista Pólis, v. 1. São Paulo, 1997.

SANTOS, B. M. dos. O Programa Minha Casa Minha Vida no município de São Paulo: uma análise de inserção urbana a partir de indicadores de segregação e acessibilidade. Trabalho de conclusão de curso. Escola Politécnica, Universidade de São Paulo, São Paulo, 2016.

SEADE - FUNDAÇÃO SISTEMA ESTADUAL DE ANÁLISE DE DADOS. Informações dos Municípios Paulistas. Disponível em:<http://www.imp.seade.gov.br >. Acessado em 21 de dezembro de 2020. 
SILVA, Y. V. Análise de Correspondência: Uma abordagem geométrica. Tese de Mestrado no Programa de Pós-Graduação em Estatística Aplicada e Biometria - Universidade Federal de Viçosa, Viçosa, MG, 2012.

SOCIAL EXCLUSION UNIT. Making the connections: Final Report on Transport and Social Exclusion. Office of the Deputy Prime Minister, Londres, 2003.

SPOSATI, A. Exclusão social abaixo da linha do Equador. Texto da apresentação no seminário sobre exclusão social realizado na PUC/SP, em abril de 1998.

. Mapa da Exclusão/Inclusão Social. São Paulo - Brasil - 2000. PUC-SP Pontifícia

Universidade Católica - Núcleo de Estudos e Pesquisas sobre Seguridade e Assistência Social.

. Mapa da Exclusão/Inclusão Social. São Paulo - Brasil - 2010. In: V Fórum Social Sul. 2013. PUC-SP Pontifícia Universidade Católica, INPE - Instituto Nacional de Pesquisas Espaciais e CEDEST - Centro de Estudos de Desigualdades Socioterritoriais.

SPINNEY, J. E. L.; SCOTT, D. M.; NEWBOLD, K. B. Transport mobility benefits and quality of life: a time-use perspective of elderly Canadians. Transport Policy v.16, p.1-11. 2009.

STANLEY, J.; STANLEY, J., Public transport and social policy goals. Road and Transport Research v.16, p.20-30. 2007.

STANLEY, J.; VELLA-BODRICK, D. The usefulness of social exclusion to inform social policy in transport. Transport Policy v.16, p.90 - 96. 2009.

STANLEY, J.; HENSHER, D. A.; STANLEY, J. R.; VELLA-BODRICK, D. Mobility, social exclusion and well-being: Exploring the links. Transport Research Part A v.45, p.789 801. 2011.

STANLEY, J.; HENSHER, D. A.; STANLEY, J. R.; CURRIE, G.; GREENE, W. H.; VELLA-BODRICK, D. Social Exclusion and the Value of Mobility. Journal of Transport Economics and Policy v.45, p.197 - 222. 2011b.

SVAB, H. Evolução dos padrões de deslocamento na Região Metropolitana de São Paulo: a necessidade de uma análise de gênero. 2016. Tese Escola Politécnica, Universidade de São Paulo, São Paulo, 2016.

TOMASIELLO, D. B. Modelos de rede de transporte público e individual para estudos de acessibilidade em São Paulo. 2016. Tese Escola Politécnica, Universidade de São Paulo, São Paulo, 2016.

TOMASIELLO, D. B., GIANNOTTI, M., ARBEX, R., \& DAVIS, C. Multi-temporal transport network models for accessibility studies. Transactions in GIS, 23(2), 203-223. 2019. DOI: 10.1111/tgis.12513 
VASCONCELLOS, E. A. de. A cidade, o transporte e o trânsito. São Paulo: Pró livros, 2005. VAN WEE, B; GEURS, K. T. Discussing Equity and Social Exclusion in Accessibility Evaluations. In: EJTIR v.11(4), p. 350-367. 2011.

VAN WEE, B; HAGOORT, M., ANNEMA, J. A. Accessibility measures with competition. Journal of Transport Geography, v.9, p.199 - 208. 2001.

VELLA-BRODERICK, D., DELBOSC, A. Measuring well-being. In: CURRIE, G. New Perspectives and Methods in Transport and Social Exclusion Research. 1 ed. Bingley, Reino Unido: Emerald Group. 2011. cap. 3.3. pp.91 - 110.

VILLAÇA, F. São Paulo: segregação urbana e desigualdade. Estudos Avançados, v. 25, n. 71, p. 37-58, 2011.

VOS, J. D.; WILTOX, F. Travel satisfaction revisited. On the pivotal role of travel satisfaction in conceptualising a travel behaviour process. Transportation Research Part A: Policy and Practice v.106 p. 364-373. 2017

WATSON, D., CLARK, L. A., \& TELLEGEN, A. Development and validation of brief measures of positive and negative affect: the PANAS scales. Journal of personality and social psychology, v.54(6), 1063. 1988.

WHELAN, M., LANGFORD, J., OXLEY, J., KOPPEL, S., CHARLTON, J. The Elderly and Mobility: A Review of the Literature. Monash University Accident Research Centre, Clayton. 2006.

WINKELMANN, L., WINKELMANN, R. Why are the unemployed so unhappy? Evidence from panel data. Economica v.65, p.1-15. 1998.

XIA, J. C.; NESBITT, J.; DALEY, R.; NAJNIN, A.; LITMAN, T.; TIWARI, S. P. A multidimensional view of transport-related social exclusion: A comparative study of Greater Perth and Sydney. Transportation Research Part A v. 94, p. 205 --221. 2016. 


\title{
ANEXO I. BEM-ESTAR E VARIÁVEIS SOCIOECONÔMICAS
}

\section{Análises de Correspondência Simples}

\author{
Bem-estar e Ocupação
}

Como Prob. $\chi^{2}$ é maior que 0,05 , conclui-se que a associação entre as variáveis ocorre de forma aleatória e que não há correspondência entre elas, para o nível de significância de $5 \%$.

\section{Categorias das variáveis analisadas}

\begin{tabular}{|c|c|c|}
\hline \multicolumn{2}{|c|}{$\begin{array}{l}\text { ST4- SATISFAÇÃO COM TEMPO } \\
\text { DE ESPERA DO ÔNIBUS }\end{array}$} & \multirow[b]{2}{*}{ OCUPAÇÃO } \\
\hline $9 \mathrm{E} 10$ & A & \\
\hline 7 E 8 & B & TRABALHA \\
\hline $5 \mathrm{E} 6$ & C & NÃO TRABALHA \\
\hline $3 \mathrm{E} 4$ & D & \\
\hline $1 \mathrm{E} 2$ & $\mathrm{E}$ & \\
\hline
\end{tabular}

Tabela de contingência

\begin{tabular}{|c|c|c|c|}
\hline \multirow[b]{2}{*}{ P1 } & \multicolumn{2}{|c|}{ OCUPACAO } & \multirow[b]{2}{*}{ Total } \\
\hline & não traba & trabalha & \\
\hline A & 59 & 84 & 143 \\
\hline B & 120 & 237 & 357 \\
\hline c & 147 & 328 & 475 \\
\hline D & 48 & 122 & 170 \\
\hline E & 48 & 76 & 124 \\
\hline Total & 422 & 847 & 1,269 \\
\hline
\end{tabular}

Figura 28. ANálise de CorrespondênCia entre Bem-estare OCupação

Bem-estar e Idade

A correspondência entre as variáveis é demonstrada na tabela de contingências a seguir pelo Prob. $\chi^{2}$ menor que 0,05, ao nível de significância de 5\%.

E pela análise dos resíduos padronizados ajustados, observa-se correspondência entre as categorias, ao nível de significância de 5\%. As categorias correspondentes entre si estão destacadas em azul quando há correspondência positiva e vermelho quando há correspondência negativa. Contudo, se percebe que as correspondências entre as categorias das duas variáveis não ocorrem de forma clara, pois não há um padrão explicativo para suas associações.

Por fim, os outputs da análise de correspondência revelam que $99,35 \%$ da inércia principal total corresponde às dimensões 1 e 2 , permitindo assim que o mapa perceptual seja uma boa ferramenta para visualização da correspondência entre categorias. No mapa se observa uma associação entre maiores nível de bem-estar com pessoas de maior idade (grupo D) e de menor idade (grupo A), enquanto não há uma correspondência evidente do nível de bem-estar para os grupos de idade de 25 a 64 anos. 
Categorias das variáveis analisadas

\begin{tabular}{|c|c|}
\hline \multicolumn{2}{|c|}{ P1 - BEM-ESTAR } \\
\hline 9 E 10 & A \\
\hline 7 E 8 & B \\
\hline 5 E 6 & C \\
\hline 3 E 4 & D \\
\hline 1 E 2 & E \\
\hline
\end{tabular}

\begin{tabular}{|c|}
\hline IDADE \\
\hline DE 16 A 24 ANOS \\
\hline DE 25 A 44 ANOS \\
\hline DE 45 A 64 ANOS \\
\hline 65 ANOS OU MAIS \\
\hline
\end{tabular}

Tabela de contingência

\begin{tabular}{r|rrrr|r} 
P1 & A & IDAD & C & D & Tota1 \\
\hline A & 26 & 40 & 44 & 33 & 143 \\
B & 74 & 145 & 100 & 38 & 357 \\
C & 79 & 207 & 151 & 38 & 475 \\
D & 26 & 76 & 58 & 10 & 170 \\
E & 16 & 47 & 41 & 20 & 124 \\
\hline Total & 221 & 515 & 394 & 139 & 1,269
\end{tabular}

Pearson chi2 (12) $=43.7927 \quad \mathrm{Pr}=0.000$

Tabela de frequências e de resíduos padronizados ajustados

\begin{tabular}{|c|c|c|c|c|}
\hline P1 & \\
\hline \multirow[t]{3}{*}{ a } & 26 & 40 & 44 & 33 \\
\hline & 24.904 & 58.034 & 44.399 & 15.664 \\
\hline & 0.257 & -3.260 & -0.077 & 4. 928 \\
\hline \multirow{3}{*}{ в } & 74 & 145 & 100 & 38 \\
\hline & 62.173 & 144.882 & 110.842 & 39.104 \\
\hline & 1.947 & 0.015 & -1.463 & -0.221 \\
\hline \multirow{3}{*}{ c } & 79 & 207 & 151 & 38 \\
\hline & 82.723 & 192.770 & 147.478 & 52.029 \\
\hline & -0.569 & 1.681 & 0.442 & -2.606 \\
\hline \multirow[t]{3}{*}{ D } & 26 & 76 & 58 & 10 \\
\hline & 29.606 & 68.991 & 52.782 & 18.621 \\
\hline & -0.784 & 1.176 & 0.929 & -2.275 \\
\hline \multirow[t]{3}{*}{$\Sigma$} & & & 41 & 20 \\
\hline & 21.595 & 50.323 & 38.500 & 13.582 \\
\hline & -1.395 & -0.640 & 0.511 & 1.943 \\
\hline
\end{tabular}

Outputs da Análise de Correspondência Simples

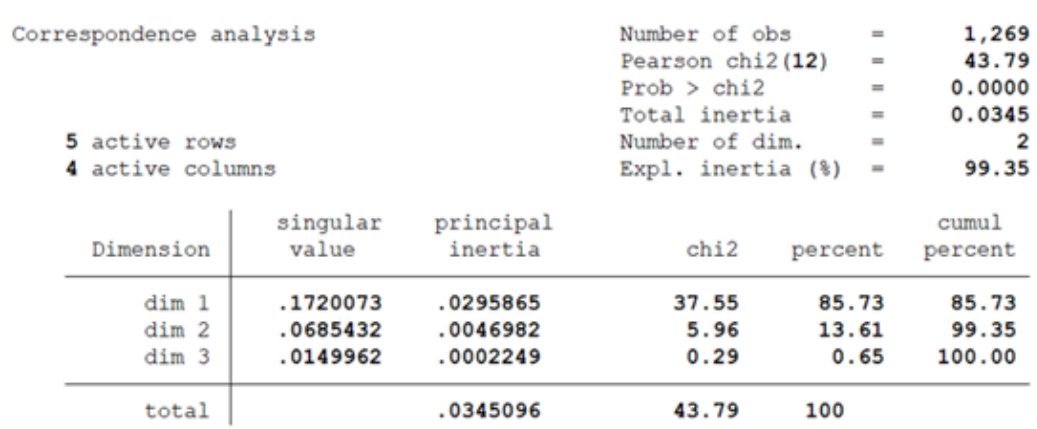

\section{Mapa Perceptual}

Correspondence analysis biplot

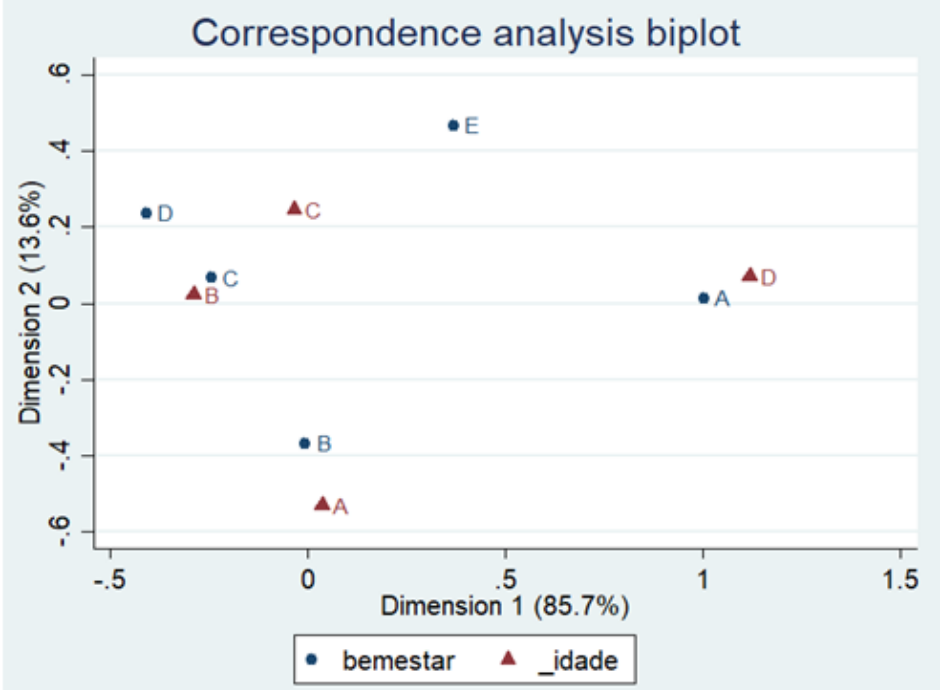

Figura 29. ANÁLISE de CORRESPONDÊnCIA ENTRE Bem-eStAR E IDADE 


\section{Bem-estar e Grau de instrução}

A correspondência entre as variáveis é demonstrada na tabela de contingências a seguir pelo Prob. $x^{2}$ menor que 0,05 , ao nível de significância de $5 \%$.

E pela análise dos resíduos padronizados ajustados, observa-se correspondência entre as categorias, ao nível de significância de $5 \%$, se percebe que as correspondências entre as categorias das duas variáveis não ocorrem de forma clara, pois não há um padrão explicativo para suas associações.

Já a análise de correspondência indica que 99,49\% da inércia principal total corresponde às dimensões 1 e 2 , permitindo assim que o mapa perceptual seja uma boa ferramenta para visualização da correspondência entre categorias, onde se observa uma correspondência muito boa para os baixos níveis de instrução (D) com baixas notas de bem-estar (E) e níveis altos de instrução (B) e de bem-estar(B), porém para as demais categorias, não há uma consistência clara na associação. 
Categorias das variáveis analisadas

\begin{tabular}{|c|c|}
\hline GRAU DE INSTRUÇÃo & \\
\hline ANALF. & \multirow{3}{*}{ D } \\
\hline $\begin{array}{l}\text { SABE LER/ ESCR. MAS NÃO } \\
\text { CURSOU ESCOLA }\end{array}$ & \\
\hline PRIM. INC. & \\
\hline PRIM. COMP. & \multirow{3}{*}{ C } \\
\hline GINÁS. INC. & \\
\hline GINÁS. COMP. & \\
\hline COLÉG. INC. & \multirow{2}{*}{ B } \\
\hline COLÉG. COMP. & \\
\hline SUP. INC. & \multirow{2}{*}{ A } \\
\hline SUP. COMP. & \\
\hline
\end{tabular}

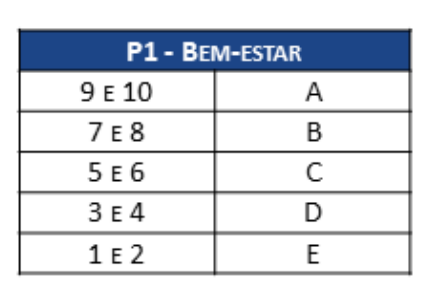

Tabela de contingência

\begin{tabular}{r|rrrr|r}
$\mathrm{P} 1$ & $\mathrm{~A}$ & INST & $\mathrm{C}$ & $\mathrm{D}$ & Tota1 \\
\hline $\mathrm{A}$ & 19 & 45 & 64 & 15 & 143 \\
$\mathrm{~B}$ & 98 & 154 & 85 & 20 & 357 \\
$\mathrm{C}$ & 152 & 185 & 113 & 25 & 475 \\
$\mathrm{D}$ & 57 & 60 & 46 & 7 & 170 \\
$\mathrm{E}$ & 18 & 46 & 47 & 13 & 124 \\
\hline Total & 344 & 490 & 355 & 80 & 1,269 \\
Pearson chi2(12) - & 62.2771 & $\mathrm{Pr}-0.000$ & &
\end{tabular}

Outputs da Análise de Correspondência Simples

Correspondence analysis

5 active rows
4 active colum

$$
\begin{aligned}
& \text { Number of obs }=1,269 \\
& \text { Pearson chi2(12) }=\quad 62.28
\end{aligned}
$$$$
\begin{array}{ll}
\text { Pearson chi2 (12) } & =62.28 \\
\text { Prob }>\text { chi2 } & =0.0000
\end{array}
$$

Total inertia $=0.0491$

\begin{tabular}{r|ccrrr} 
Dimension & $\begin{array}{c}\text { singular } \\
\text { value }\end{array}$ & $\begin{array}{c}\text { principal } \\
\text { inertia }\end{array}$ & chi2 & percent & $\begin{array}{c}\text { cumul } \\
\text { percent }\end{array}$ \\
\hline $\operatorname{dim} 1$ & .211538 & .0447483 & 56.79 & 91.18 & 91.18 \\
$\operatorname{dim} 2$ & .0638357 & .004075 & 5.17 & 8.30 & 99.49 \\
$\operatorname{dim} 3$ & .0158863 & .0002524 & 0.32 & 0.51 & 100.00 \\
\hline tota1 & & .0490757 & 62.28 & 100 &
\end{tabular}

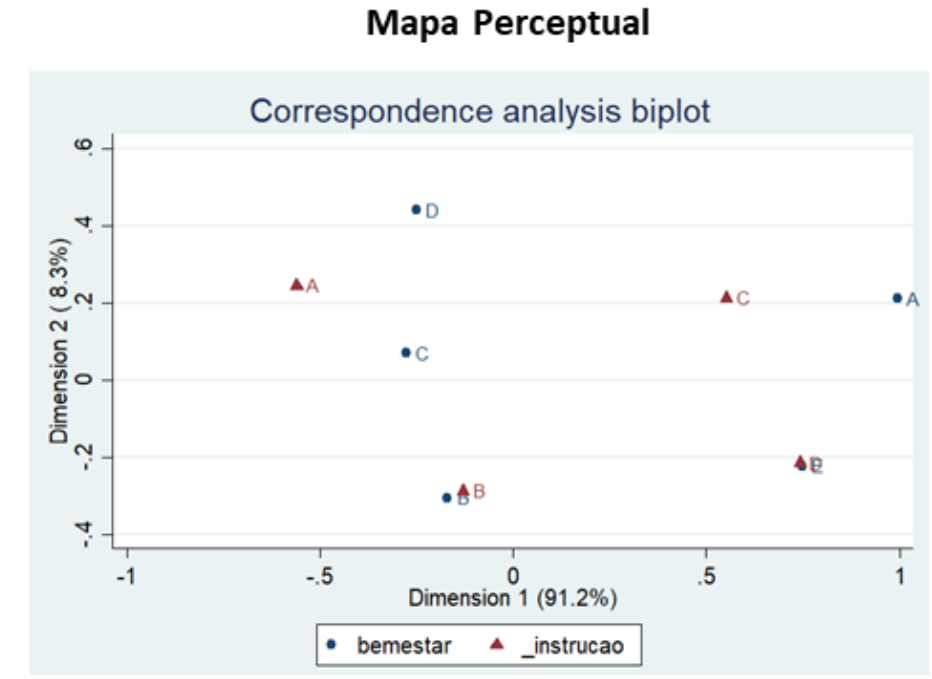

Figura 30. Análise de Correspondência entre Bem-estar e Grau de instrução 


\section{Bem-estar e Sexo}

Como Prob. $x^{2}$ é maior que 0,05 , conclui-se que a associação entre as variáveis ocorre de forma aleatória e que não há correspondência entre elas, para o nível de significância de $5 \%$.

Categorias das variáveis analisadas

\begin{tabular}{|c|c|}
\hline $\begin{array}{c}\text { STT-SATISFAÇÃO COM TEMPO } \\
\text { DE ESPERA DO ÔNIBUS }\end{array}$ \\
\hline 9 E 10 & $\mathrm{~A}$ \\
\hline 7 E 8 & $\mathrm{~B}$ \\
\hline $5 \mathrm{E} 6$ & $\mathrm{C}$ \\
\hline $3 \mathrm{E} 4$ & $\mathrm{D}$ \\
\hline $1 \mathrm{E} 2$ & $\mathrm{E}$ \\
\hline
\end{tabular}

Tabela de contingência

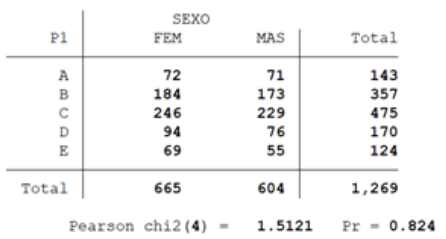

Figura 31. AnÁlise de CorrespondênCia entre Bem-estare Sexo

\section{Bem-estar e Estado civil}

Como Prob. $\chi^{2}$ é maior que 0,05 , conclui-se que a associação entre as variáveis ocorre de forma aleatória e que não há correspondência entre elas, para o nível de significância de $5 \%$.

Categorias das variáveis analisadas

\begin{tabular}{|c|c|}
\hline \multicolumn{2}{|c|}{$\begin{array}{c}\text { ST4- SATISFAC̃̃̃ COM TEMPO } \\
\text { DE ESPERA DO ÔNIBUS }\end{array}$} \\
\hline 9 E 10 & A \\
\hline 7 E 8 & B \\
\hline 5 E 6 & C \\
\hline 3 E 4 & D \\
\hline 1 E 2 & E \\
\hline
\end{tabular}

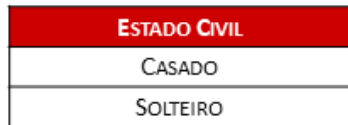

Tabela de contingência

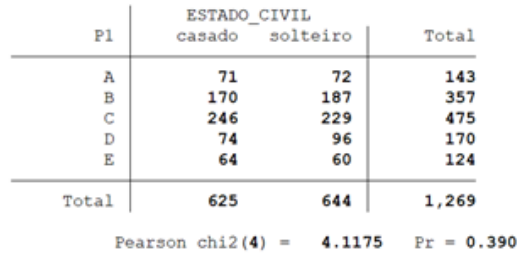

Figura 32. AnÁlise de CORRESPONdÊnCIA ENTRE Bem-eStar e Estado CiVIL 


\section{Análises de Correspondência Múltiplas}

Bem-estar, Renda Familiar e Grau de instrução

As associações entre bem-estar e renda familiar e bem-estare grau de instrução já foram verificadas, faltando verificar ainda a associação entre renda familiar e grau de instrução.

Como Prob. $\chi^{2}$ é menor que 0,05 , conclui-se que há correspondência entre as variáveis. E pela análise dos resíduos padronizados ajustados, observa-se, ao nível de significância de $5 \%$ que as correspondências entre as categorias das duas variáveis não ocorrem de forma clara, pois não há um padrão explicativo para suas associações.

Os outputs da análise de correspondência múltipla revelam que $83,13 \%$ da inércia principal total corresponde às dimensões 1 e 2, permitindo assim que o mapa perceptual seja uma boa ferramenta para visualização da correspondência entre categorias. No mapa se vê que, apesar da correspondência entre as categorias das variáveis renda familiar e grau de instrução se mostrarem consistentes, a correspondência com os níveis de bem-estarnão são muito evidentes. 
Categorias das variáveis analisadas

\begin{tabular}{|c|c|}
\hline \multicolumn{2}{|c|}{ GRAU DE INSTRUÇÃO } \\
\cline { 1 - 1 } ANALF. & \multirow{2}{*}{ D } \\
\cline { 1 - 1 } $\begin{array}{c}\text { SABE LER/ ESCR. MAS NÃO } \\
\text { CURSOU ESCOLA }\end{array}$ & \multirow{2}{*}{ C } \\
\cline { 1 - 1 } PRIM. INC. & \\
\cline { 1 - 1 } PRIM. COMP. & \multirow{2}{*}{ B } \\
\cline { 1 - 1 } GINÁS. INC. & \multirow{2}{*}{ A } \\
\cline { 1 - 1 } GINÁS. COMP. & \\
\cline { 1 - 1 } COLÉG. INC. &
\end{tabular}

\begin{tabular}{|c|c|}
\hline \multicolumn{2}{|c|}{ Renda Familiar } \\
\hline Acima de 10 SM & A \\
\hline De 5 A 10 SM & B \\
\hline De 2 A 5 SM & C \\
\hline De 1 A 2 & D \\
\hline AtÉ 1 SM & E \\
\hline
\end{tabular}

\section{Tabela de contingência}

\begin{tabular}{r|rrrrr|r} 
INST & A & B & REND2 & D & E & Tota1 \\
\hline A & 58 & 88 & 143 & 48 & 7 & 344 \\
B & 21 & 63 & 194 & 165 & 47 & 490 \\
C & 8 & 30 & 111 & 139 & 67 & 355 \\
D & 4 & 5 & 17 & 27 & 27 & 80 \\
\hline Total & 91 & 186 & 465 & 379 & 148 & 1,269
\end{tabular}

Pearson chi2 (12) $=237.5518 \quad \mathrm{Pr}=0.000$

Tabela de frequências e de resíduos padronizados ajustados

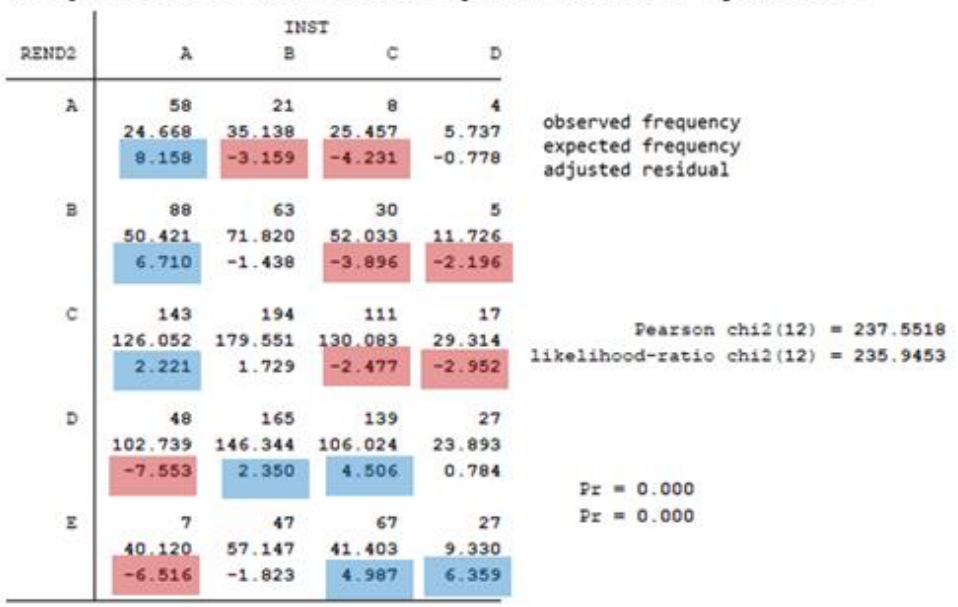

itiple/Joint correspondence analysis Number of obs = 1,269

Method: Burt/adjusted inertias $\quad$ Number of axes $=\frac{.08636211}{2}$

\begin{tabular}{r|crr} 
Dimension & $\begin{array}{c}\text { principal } \\
\text { inertia }\end{array}$ & percent & $\begin{array}{c}\text { cumul } \\
\text { percent }\end{array}$ \\
\hline $\operatorname{dim} 1$ & .0634367 & 73.45 & 73.45 \\
$\operatorname{dim} 2$ & .0083581 & 9.68 & 83.13 \\
$\operatorname{dim} 3$ & .0012694 & 1.47 & 84.60 \\
$\operatorname{dim} 4$ & .0003334 & 0.39 & 84.99 \\
$\operatorname{dim} 5$ & .0001015 & 0.12 & 85.11 \\
\hline Tota1 & .0863621 & 100.00 &
\end{tabular}

\section{Mapa Perceptual}

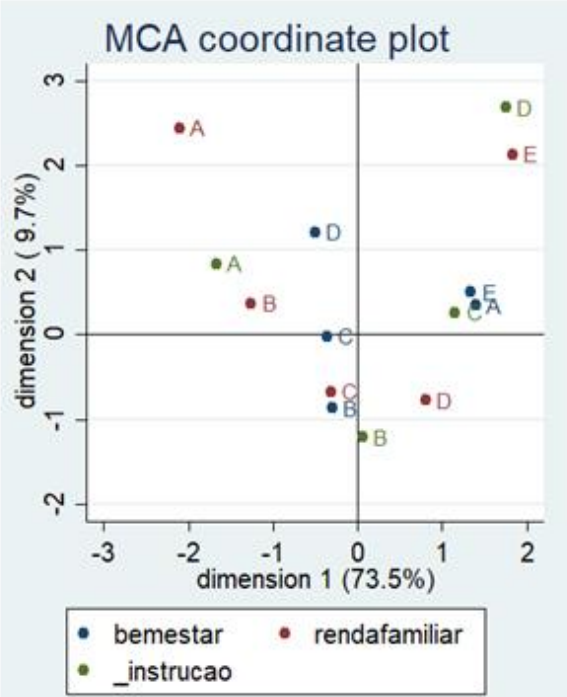

Figura 33. Análise de correspondênCia Múltipla entre Bem-estar, Renda Familiar e Grau de instrução 


\section{Bem-estar, Renda Familiar e Idade}

As associações entre bem-estar e renda familiar e bem-estar e idade já foram verificadas, faltando verificar ainda a associação entre renda familiar e idade.

Como Prob. $x^{2}$ é maior que 0,05 , conclui-se que não há correspondência entre as variáveis, não permitindo a realização da Análise de Correspondência Múltipla considerando as três variáveis.

Categorias das variáveis analisadas

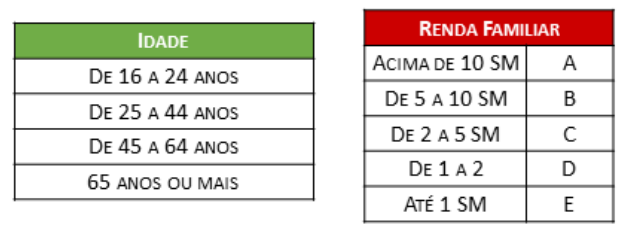

Tabela de contingência

\begin{tabular}{r|rrrrr|r} 
IDAD & A & B & REND2 & D & E & Tota1 \\
\hline A & 14 & 33 & 89 & 66 & 19 & 221 \\
B & 44 & 79 & 195 & 148 & 49 & 515 \\
C & 25 & 56 & 141 & 118 & 54 & 394 \\
D & 8 & 18 & 40 & 47 & 26 & 139 \\
\hline Total & 91 & 186 & 465 & 379 & 148 & 1,269 \\
\multicolumn{2}{|c}{ Pearson chi2 (12) $=18.3504$} & $\mathrm{Pr}=0.105$ & &
\end{tabular}

Figura 34. TABela de ContingênCIA Gerada no StATA - Renda Familiar E IDADE 


\section{ANEXO II. BEM-ESTAR E VARIÁVEIS DE TRANSPORTE}

\section{Análises de Correspondência Simples}

Bem-estar e Satisfação com as questões de transportee trânsito de maneira geral

A correspondência entre as variáveis é demonstrada na tabela de contingências a seguir pelo Prob. $\chi^{2}$ menor que 0,05, ao nível de significância de 5\%.

E pela análise dos resíduos padronizados ajustados, observa-se, ao nível de significância de $5 \%$, que as categorias de alto grau de bem-estar ( $\mathrm{A}$ e B) correspondem positivamente as categorias de alto grau de satisfação com transporte em geral ( $A, B$ e C). O contrário também ocorre, com a correspondência positiva das categorias de baixo grau de bem-estar (D e E) com baixo grau de satisfação com transporte (E).

Por fim, os outputs da análise de correspondência revelam que $95,70 \%$ da inércia principal total corresponde às dimensões 1 e 2 , permitindo assim que o mapa perceptual seja uma boa ferramenta para visualização da correspondência entre categorias. No mapa se observa uma associação entre maiores nível de bem-estar com aqueles com maior nível de satisfação com transporte e trânsito em geral ( $A$ e B) e entre os grupos de menor nível de satisfação com ambos (D e E). 
Categorias das variáveis analisadas

\begin{tabular}{|c|c|}
\hline \multicolumn{2}{|c|}{ P1 - BEM-ESTAR } \\
\hline $9 \mathrm{E} 10$ & $\mathrm{~A}$ \\
\hline $7 \mathrm{E} 8$ & $\mathrm{~B}$ \\
\hline $5 \mathrm{E} 6$ & $\mathrm{C}$ \\
\hline $3 \mathrm{E} 4$ & $\mathrm{D}$ \\
\hline $1 \mathrm{E} 2$ & $\mathrm{E}$ \\
\hline
\end{tabular}

\begin{tabular}{|c|c|}
\hline $\begin{array}{c}\text { ST1 - SATISFAÇÃO COM TRANSPORTE } \\
\text { E TRÂNSITO EM GERAL }\end{array}$ \\
\hline 9 E 10 & A \\
\hline 7 E 8 & B \\
\hline 5 E 6 & C \\
\hline 3 E 4 & D \\
\hline 1 E 2 & E \\
\hline
\end{tabular}

Tabela de contingência

\begin{tabular}{r|rrrrr|r} 
& \multicolumn{7}{|c}{ Tabela de contingência } \\
\hline P1 & A & B & SATSF $^{1}$ C & D & E & Tota1 \\
\hline A & 16 & 21 & 35 & 21 & 50 & 143 \\
B & 8 & 54 & 131 & 78 & 86 & 357 \\
C & 8 & 45 & 134 & 118 & 170 & 475 \\
D & 7 & 10 & 32 & 45 & 76 & 170 \\
E & 5 & 13 & 18 & 23 & 65 & 124 \\
\hline Total & 44 & 143 & 350 & 285 & 447 & 1,269
\end{tabular}

Pearson chi2 $(16)=101.0626 \quad \mathrm{Pr}=0.000$

Tabela de frequências e de resíduos padronizados ajustados

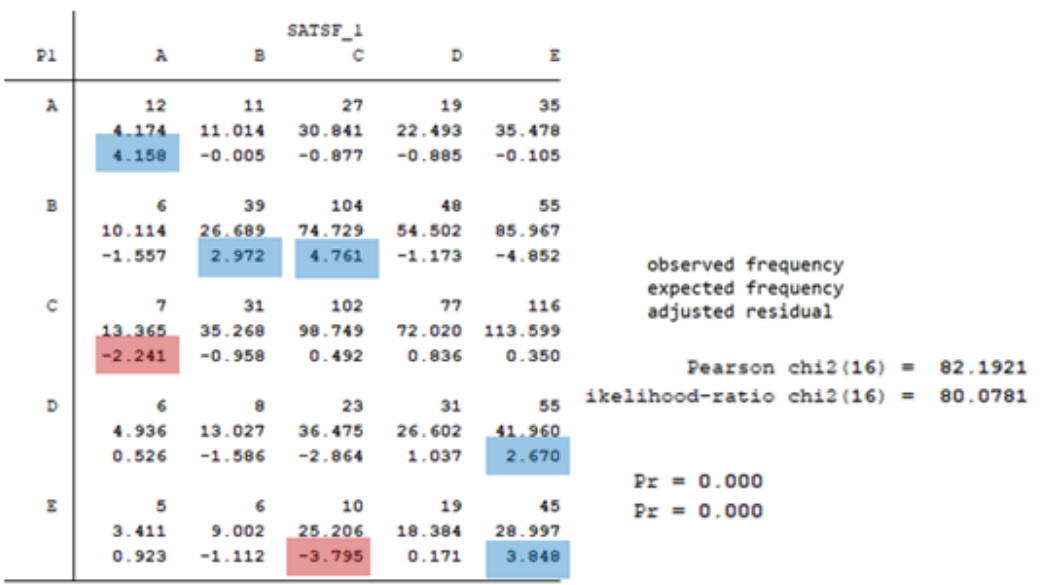

\section{Outputs da Análise de Correspondência Simples}

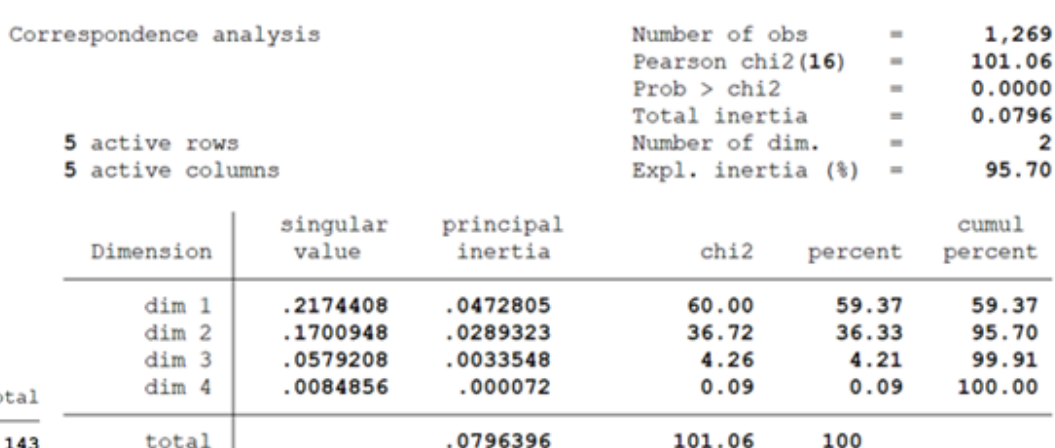

Mapa Perceptual

Correspondence analysis biplot

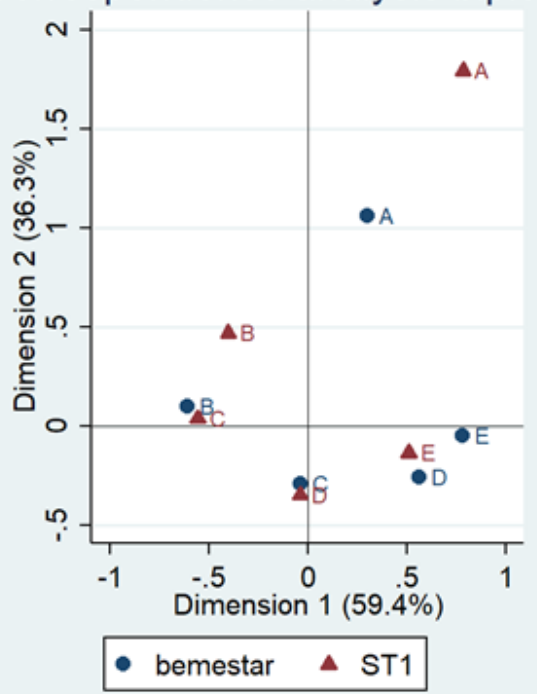

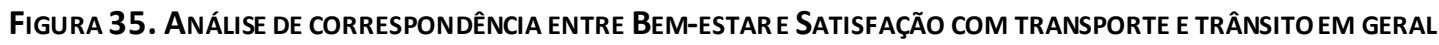




\section{Bem-estar e Satisfação com o tamanho da rede de Metrô}

A correspondência entre as variáveis é demonstrada na tabela de contingências a seguir pelo Prob. $\chi^{2}$ menor que 0,05, ao nível de significância de 5\%.

E pela análise dos resíduos padronizados ajustados, observa-se, ao nível de significância de 5\%, que as categorias de alto grau de bem-estar (A e B) correspondem positivamente as categorias de alto grau de satisfação com o tamanho da rede de metrô ( $A$ e B). O contrário também ocorre, com a correspondência positiva das categorias de baixo grau de bem-estar ( $D$ e E) com baixo grau de satisfação com o tamanho da rede de metrô ( $D$ e E). As correspondências positivas são destacadas em azul, no quadro a seguir.

Por fim, os outputs da análise de correspondência revelam que $92,58 \%$ da inércia principal total corresponde às dimensões 1 e 2, permitindo assim que o mapa perceptual seja uma boa ferramenta para visualização da correspondência entre categorias. No mapa, se observa uma associação entre maiores nível de bem-estar com aqueles com maior nível de satisfação com tamanho da rede de metrô ( $A$ e $B$ ) e entre os grupos de menor nível de satisfação com ambos (D e E). 
Categorias das variáveis analisadas

\begin{tabular}{|c|c|c|c|}
\hline \multicolumn{2}{|c|}{ P1 - BEM-ESTAR } & \multicolumn{2}{|c|}{$\begin{array}{c}\text { ST2 - SATISFAÇÃO COM TAMANHO } \\
\text { DA REDE DE METRÔ }\end{array}$} \\
\hline $9 \mathrm{E} 10$ & A & $0=10$ & A \\
\hline 7 E 8 & B & 9 E 10 & \\
\hline $5 \mathrm{E} 6$ & C & 7 E 8 & B \\
\hline $3 \mathrm{E} 4$ & D & $5 \mathrm{E} 6$ & C \\
\hline $1 \mathrm{E} 2$ & $\mathrm{E}$ & 3 E 4 & D \\
\hline & & $1 \mathrm{E} 2$ & $\mathrm{E}$ \\
\hline
\end{tabular}

Tabela de contingência

\begin{tabular}{|c|c|c|c|c|c|c|}
\hline P1 & A & B & $\mathrm{SF}_{-}{ }^{2}{ }_{\mathrm{C}}$ & D & E & Total \\
\hline A & 33 & 25 & 39 & 17 & 29 & 143 \\
\hline B & 32 & 88 & 133 & 52 & 52 & 357 \\
\hline$c$ & 28 & 86 & 146 & 97 & $\begin{array}{r}118 \\
55\end{array}$ & 475 \\
\hline${ }_{E}^{D}$ & $\begin{array}{l}11 \\
11\end{array}$ & $\begin{array}{l}21 \\
19\end{array}$ & $\begin{array}{l}477 \\
37\end{array}$ & $\begin{array}{l}41 \\
15\end{array}$ & $\begin{array}{l}50 \\
42\end{array}$ & $\begin{array}{l}170 \\
124\end{array}$ \\
\hline Total & 115 & 239 & 402 & 222 & 291 & 1,269 \\
\hline
\end{tabular}

\begin{tabular}{|c|c|c|c|c|c|}
\hline \multirow{2}{*}{\multicolumn{3}{|c|}{ Correspondence analysis }} & \multicolumn{2}{|c|}{ Number of obs = } & \multirow{3}{*}{$\begin{array}{r}1,269 \\
88.97\end{array}$} \\
\hline & & & Pearson ch: & (16) & \\
\hline & & & Prob $>$ chi? & $=$ & \\
\hline \multirow{3}{*}{\multicolumn{2}{|c|}{$\begin{array}{l}5 \text { active rows } \\
5 \text { active columns }\end{array}$}} & & Total inert & $=$ & 0.0701 \\
\hline & & & Number of & n. & \\
\hline & & & Expl. inert & a (8) $=$ & 92.58 \\
\hline & singular & principal & & \multirow[b]{2}{*}{ percent } & cumul \\
\hline Dimension & value & inertia & chi2 & & percent \\
\hline $\operatorname{dim} 1$ & .1992198 & .0396885 & 50.36 & \multirow[t]{2}{*}{56.61} & 56.61 \\
\hline $\operatorname{dim} 2$ & .1588086 & .0252202 & 32.00 & & 92.58 \\
\hline $\operatorname{dim} 3$ & .071139 & .0050608 & 6.42 & & 99.79 \\
\hline $\operatorname{dim} 4$ & .0119912 & .0001438 & 0.18 & 0.21 & 100.00 \\
\hline total & & .0701133 & 88.97 & 100 & \\
\hline
\end{tabular}

\section{Mapa Perceptual}

Tabela de frequências e de resíduos padronizados ajustados

\begin{tabular}{|c|c|c|c|c|c|c|}
\hline p1 & & B & $\mathrm{SATSF}_{\mathrm{C}}{ }_{\mathrm{C}}^{2}$ & D & $\Xi$ & \\
\hline \multirow[t]{3}{*}{ a } & 20 & 17 & 31 & 12 & 22 & \\
\hline & 10.143 & 19.488 & 32.025 & 18.349 & 21.996 & \\
\hline & 3.465 & -0.666 & -0.232 & -1.739 & 0.001 & \\
\hline \multirow{4}{*}{ B } & 26 & 62 & 89 & 38 & 36 & \\
\hline & 24.960 & 47.956 & 78.806 & 45.152 & 54.126 & \\
\hline & 0.259 & 2.658 & 1.634 & -1.386 & -3.280 & observed frequency \\
\hline & & & & & & expected frequency \\
\hline \multirow{2}{*}{$\mathrm{c}$} & 33.213 & 63.815 & 104.865 & 60.083 & 72.025 & adjusted residual \\
\hline & -2.128 & 0.033 & 0.467 & 1.605 & -0.508 & \\
\hline \multirow{3}{*}{ D } & & 14 & 31 & 33 & 35 & Pearson chi2 $(16)=55.2214$ \\
\hline & 12.231 & 23.501 & 38.618 & 22.126 & 26.524 & 1ikelihood-ratio chi2 (16) $=52.9430$ \\
\hline & -0.724 & -2.346 & -1.594 & 2.748 & 2.001 & $\mathrm{Px}=0.000$ \\
\hline \multirow[t]{3}{*}{$\Sigma$} & $\mathbf{9}$ & 14 & 22 & 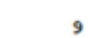 & & $P x=0.000$ \\
\hline & 8.453 & 16.240 & 26.687 & 15.291 & 18.330 & \\
\hline & 0.209 & -0.650 & -1.151 & -1.867 & 3.513 & \\
\hline
\end{tabular}

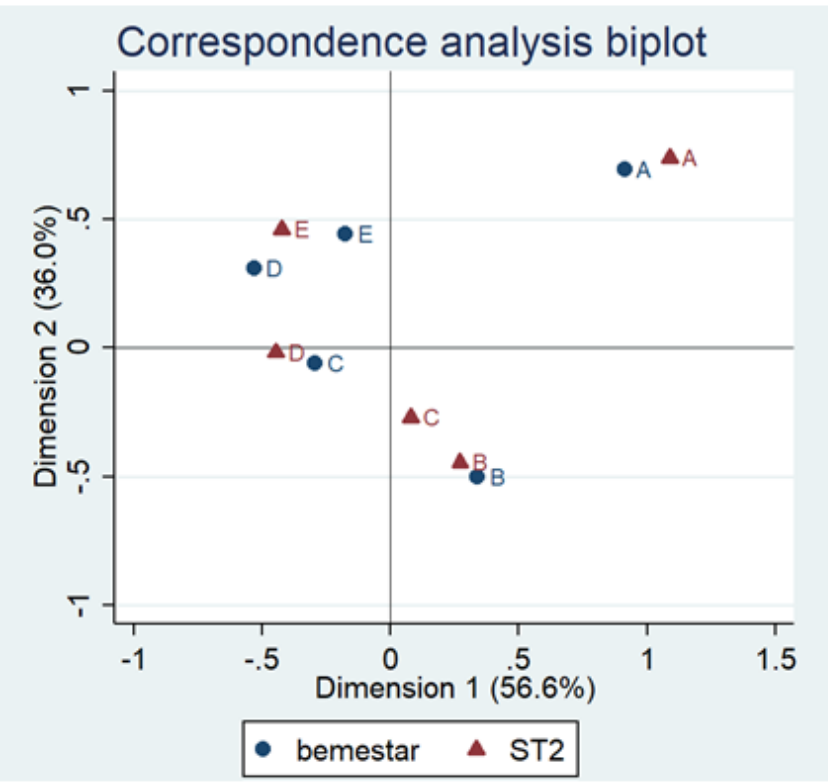

Figura 36. Análise de Correspondência entre Bem-estar e Satisfação com tamanho da Rede de metrô 
Bem-estar e Satisfação com soluções para diminuir o trânsito da cidade

A correspondência entre as variáveis é demonstrada na tabela de contingências a seguir pelo Prob. $\chi^{2}$ menor que 0,05, ao nível de significância de 5\%.

E pela análise dos resíduos padronizados ajustados, observa-se correspondência entre as categorias, ao nível de significância de $5 \%$. As categorias de alto grau de bemestar ( $A$ e B ) correspondem positivamente as categorias de alto grau de satisfação com as soluções para o trânsito ( $A, B$ e $C$ ), em azul, e negativamente as categorias que representam a baixa satisfação com as soluções de trânsito (D e E), em vermelho. $O$ contrário também ocorre, com a correspondência positiva das categorias de baixo grau de bem-estar (D e E) com baixo grau de satisfação com as soluções para o trânsito (E).

Por fim, os outputs da análise de correspondência revelam que $93,42 \%$ da inércia principal total corresponde às dimensões 1 e 2 , permitindo assim que o mapa perceptual seja uma boa ferramenta para visualização da correspondência entre categorias. No gráfico, se observa uma associação entre maiores nível de bem-estar com aqueles com maior nível de satisfação com as soluções para diminuir o trânsito ( $A$ e B) e entre os grupos de menor nível de satisfação com ambos (D e E). 
Categorias das variáveis analisadas

\begin{tabular}{|c|c|}
\hline \multicolumn{2}{|c|}{ P1 - BEM-ESTAR } \\
\hline $9 \mathrm{E} 10$ & $\mathrm{~A}$ \\
\hline $7 \mathrm{E} 8$ & $\mathrm{~B}$ \\
\hline $5 \mathrm{E} 6$ & $\mathrm{C}$ \\
\hline $3 \mathrm{E} 4$ & $\mathrm{D}$ \\
\hline $1 \mathrm{E} 2$ & $\mathrm{E}$ \\
\hline
\end{tabular}

Tabela de contingência

\begin{tabular}{|c|c|}
\hline \multicolumn{2}{|c|}{$\begin{array}{c}\text { ST3 - SATISFAÇÃO COM SOLUÇÕES } \\
\text { PARA DIMINUIR O TRÂNSITO }\end{array}$} \\
\hline 9 E 10 & A \\
\hline 7 E 8 & B \\
\hline 5 E 6 & C \\
\hline 3 E 4 & D \\
\hline 1 E 2 & E \\
\hline
\end{tabular}

\begin{tabular}{r|rrrrr|r} 
P1 & A & B & SATSF $^{3}{ }^{\circ}$ & D & E & Total \\
\hline A & 15 & 22 & 38 & 27 & 41 & 143 \\
B & 10 & 52 & 143 & 68 & 84 & 357 \\
C & 9 & 43 & 129 & 134 & 160 & 475 \\
D & 4 & 10 & 28 & 40 & 88 & 170 \\
E & 3 & 11 & 25 & 26 & 59 & 124 \\
\hline Tota1 & 41 & 138 & 363 & 295 & 432 & 1,269 \\
Pearson chi2 (16) - 112.8966 & Pr -0.000 & & &
\end{tabular}

Tabela de frequências e de resíduos padronizados ajustados

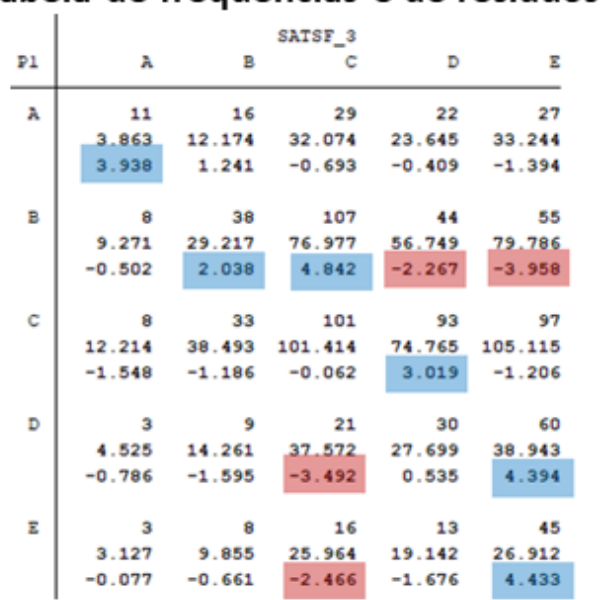

\section{Outputs da Análise de Correspondência Simples}

\begin{tabular}{|c|c|c|c|c|c|}
\hline \multirow{2}{*}{\multicolumn{3}{|c|}{ Correspondence analysis }} & \multirow{2}{*}{\multicolumn{2}{|c|}{$\begin{array}{l}\text { Number of obs } \\
\text { Pearson chi2(16) }\end{array}$}} & 1,269 \\
\hline & & & & & 112.90 \\
\hline & & & Prob $>$ chi & . & 0.0000 \\
\hline & & & Total iner & 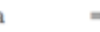 & 0.0890 \\
\hline 5 active row & & & Number of & n. & \\
\hline 5 active col & & & Expl. iner & $(8)=$ & 93.42 \\
\hline & singular & principal & & \multirow[b]{2}{*}{ percent } & cumul \\
\hline Dimension & value & Inertia & $\mathrm{ch} 12$ & & percent \\
\hline $\operatorname{dim} 1$ & .2440066 & .0595392 & 75.56 & 66.92 & 66.92 \\
\hline $\operatorname{dim} 2$ & .1535453 & .0235762 & 29.92 & 26.50 & 93.42 \\
\hline $\operatorname{dim} 3$ & .0759203 & .0057639 & 7.31 & \multirow{2}{*}{$\begin{array}{l}6.48 \\
0.10\end{array}$} & 99.90 \\
\hline $\operatorname{dim} 4$ & .0092607 & .0000858 & 0.11 & & 100.00 \\
\hline & & .088965 & 112.90 & 100 & \\
\hline
\end{tabular}

Mapa Perceptual

Correspondence analysis biplot

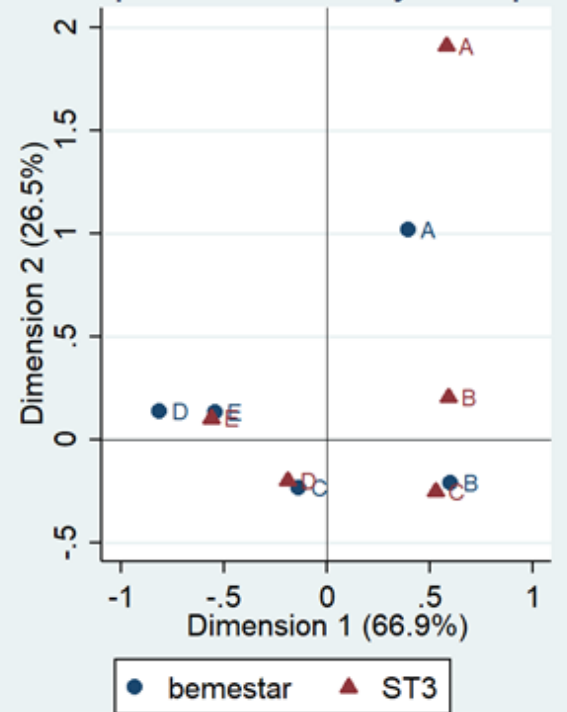

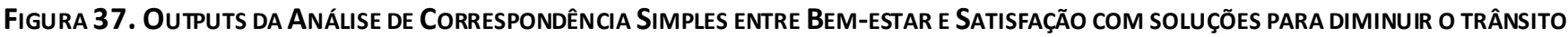




\section{Bem-estar e Satisfação com a segurança no trânsito}

As variáveis e suas categorias são apresentadas a seguir.

A correspondência entre as variáveis é demonstrada na tabela de contingências a seguir pelo Prob. $\chi^{2}$ menor que 0,05, ao nível de significância de 5\%.

E pela análise dos resíduos padronizados ajustados, observa-se correspondência entre as categorias, ao nível de significância de $5 \%$. As categorias de alto grau de bemestar ( $A$ e B) correspondem positivamente as categorias de alto grau de satisfação com a segurança trânsito $(A, B$ e $C$ ) e negativamente a categoria de baixa satisfação com a segurança trânsito (E). O contrário também ocorre, com a correspondência positiva das categorias de baixo grau de bem-estar ( $D$ e E) com baixo grau de satisfação com a segurança no trânsito $(E)$ e correspondência negativa a alta e média satisfação com a segurança ( $\mathrm{B}$ e $\mathrm{C})$.

Por fim, os outputs da análise de correspondência revelam que $89,75 \%$ da inércia principal total corresponde às dimensões 1 e 2 , permitindo assim que o mapa perceptual seja uma boa ferramenta para visualização da correspondência entre categorias. No mapa perceptual se observa uma associação entre maiores nível de bem-estar com aqueles com maior nível de satisfação com segurança no trânsito (B) e entre os grupos de menor nível de satisfação com ambos (D e E). 
Categorias das variáveis analisadas

\begin{tabular}{|c|c|}
\hline \multicolumn{2}{|c|}{ P1 - BEM-ESTAR } \\
\hline 9E 10 & $\mathrm{~A}$ \\
\hline $7 \mathrm{E} 8$ & $\mathrm{~B}$ \\
\hline $5 \mathrm{E} 6$ & $\mathrm{C}$ \\
\hline $3 \mathrm{E} 4$ & $\mathrm{D}$ \\
\hline 1E 2 & $\mathrm{E}$ \\
\hline
\end{tabular}

\begin{tabular}{|c|c|}
\hline $\begin{array}{c}\text { ST6 - SATISFAÇÃO COM SEGURANÇA } \\
\text { NO TRÂNSITO }\end{array}$ \\
\hline $9 \mathrm{E} 10$ & $\mathrm{~A}$ \\
\hline $7 \mathrm{E} 8$ & $\mathrm{~B}$ \\
\hline $5 \mathrm{E} 6$ & $\mathrm{C}$ \\
\hline $3 \mathrm{E} 4$ & $\mathrm{D}$ \\
\hline $1 \mathrm{E} 2$ & $\mathrm{E}$ \\
\hline
\end{tabular}

Tabela de contingência

\begin{tabular}{r|crrrr|r} 
P1 & A & B & SATSF $^{6}{ }_{\text {C }}$ & D & E & Total \\
\hline A & 9 & 18 & 28 & 30 & 58 & 143 \\
B & 2 & 46 & 102 & 85 & 122 & 357 \\
C & 0 & 34 & 104 & 140 & 197 & 475 \\
D & 3 & 5 & 28 & 44 & 90 & 170 \\
E & 1 & 11 & 11 & 25 & 76 & 124 \\
\hline Total & 15 & 114 & 273 & 324 & 543 & 1,269 \\
\multicolumn{2}{c}{ Pearson chi2 (16) -102.0290} & Pr -0.000 & & &
\end{tabular}

Tabela de frequências e de resíduos padronizados ajustados

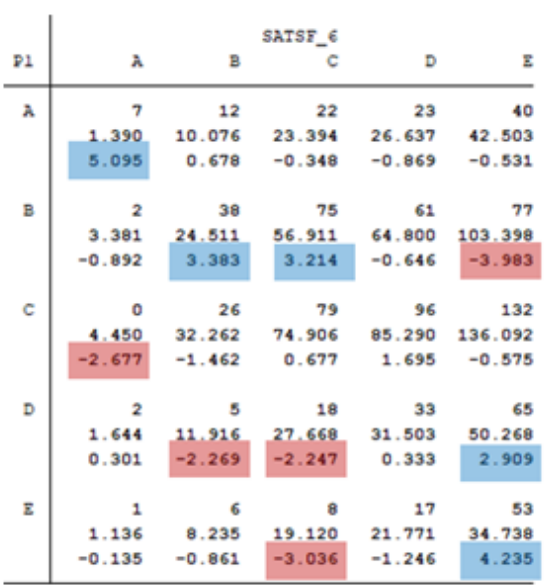

\section{Outputs da Análise de Correspondência Simples}

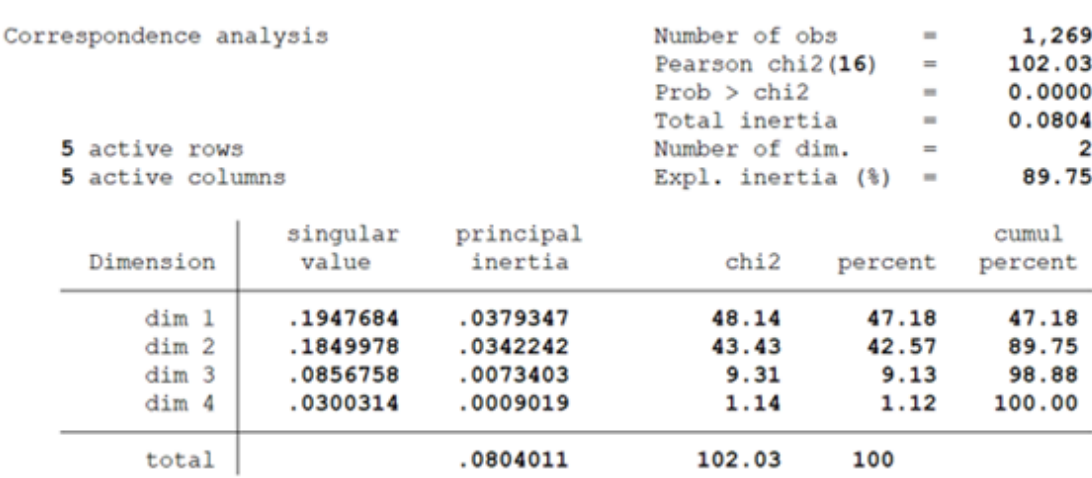

Mapa Perceptual

Correspondence analysis biplot

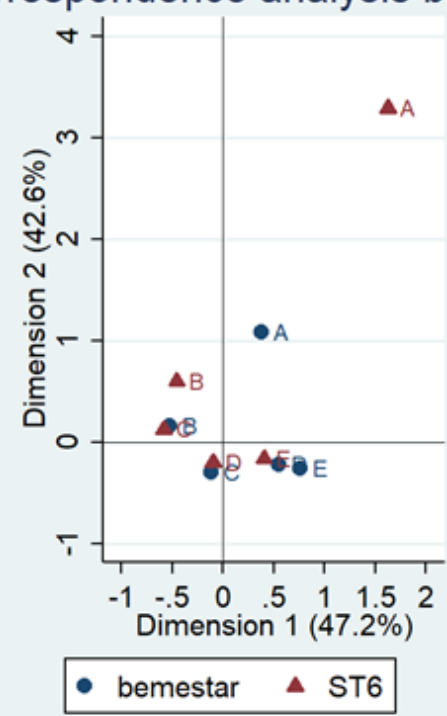

Figura 38. Análise de CorrespondênCia Simples entre Bem-estar e Satisfação com segurança no trânsito 
Bem-estar e Satisfação com a prioridade do transporte coletivo no sistema viário

A correspondência entre as variáveis é demonstrada na tabela de contingências a seguir pelo Prob. $x^{2}$ menor que 0,05 , ao nível de significância de $5 \%$.

E pela análise dos resíduos padronizados ajustados, observa-se correspondência entre as categorias, ao nível de significância de $5 \%$. O quadro a seguir apresenta que as categorias de alto grau de bem-estar ( $A$ e $B$ ) correspondem positivamente as categorias de alto grau de satisfação com a prioridade do Transporte Coletivo ( $A, B$ e $C$ ). O contrário também ocorre, com a correspondência positiva das categorias de baixo grau de bemestar (E) com baixo grau de satisfação com a prioridade do Transporte Coletivo (E).

Por fim, os outputs da análise de correspondência revelam que $90,36 \%$ da inércia principal total corresponde às dimensões 1 e 2 , permitindo assim que o mapa perceptual seja uma boa ferramenta para visualização da correspondência entre categorias. Pelo gráfico se observa uma associação entre maiores nível de bem-estar com aqueles com maior nível de satisfação com a prioridade do transporte coletivo ( $A$ e $B$ ) e entre os grupos de menor nível de satisfação com ambos (E). 
Categorias das variáveis analisadas

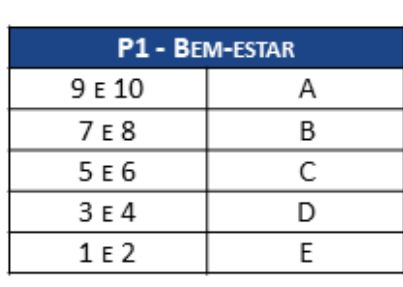

\section{Outputs da Análise de Correspondência Simples}

\begin{tabular}{|c|c|}
$\begin{array}{c}\text { ST7 - SATISFAÇÃO COM A PRIORIDADE } \\
\text { DO TRANSPORTE COLETIVO }\end{array}$ \\
\hline $9 \mathrm{E} 10$ & A \\
\hline $7 \mathrm{E} 8$ & B \\
\hline $5 \mathrm{E} 6$ & $\mathrm{C}$ \\
\hline $3 \mathrm{E} 4$ & $\mathrm{D}$ \\
\hline $1 \mathrm{E} 2$ & $\mathrm{E}$ \\
\hline
\end{tabular}

Correspondence analysis

\section{5 active rows}

$\begin{array}{lll}\text { Number of obs } & = & 1,269 \\ \text { Pearson chi2(16) } & = & 71.16\end{array}$ $\begin{array}{llr}\text { Pearson chi2 (16) } & = & 71.16 \\ \text { Prob }>\text { chi2 } & =0.0000\end{array}$ Prob $>$ chi2

Total inertia 0.0561

\section{5 active rows}

Exple inertia (8)

90.36

\begin{tabular}{r|ccrrr} 
Dimension & $\begin{array}{c}\text { singular } \\
\text { value }\end{array}$ & $\begin{array}{c}\text { principal } \\
\text { inertia }\end{array}$ & chi2 & percent & $\begin{array}{c}\text { cumul } \\
\text { percent }\end{array}$ \\
\hline $\operatorname{dim} 1$ & .1861275 & .0346435 & 43.96 & 61.78 & 61.78 \\
$\operatorname{dim} 2$ & .1265715 & .0160203 & 20.33 & 28.57 & 90.36 \\
$\operatorname{dim} 3$ & .073413 & .0053895 & 6.84 & 9.61 & 99.97 \\
$\operatorname{dim} 4$ & .0043011 & .0000185 & 0.02 & 0.03 & 100.00 \\
\hline total & & .0560718 & 71.16 & \multicolumn{1}{|c}{100} &
\end{tabular}

Tabela de contingência

\begin{tabular}{r|rrrrr|r} 
P1 & A & B & ${ }^{\text {SATSF }}{ }^{7}$ & D & E & Total \\
\hline A & 10 & 26 & 37 & 25 & 45 & 143 \\
B & 8 & 60 & 135 & 71 & 83 & 357 \\
C & 8 & 53 & 132 & 131 & 151 & 475 \\
D & 2 & 13 & 42 & 41 & 72 & 170 \\
E & 3 & 10 & 32 & 22 & 57 & 124 \\
\hline Total & 31 & 162 & 378 & 290 & 408 & 1,269
\end{tabular}

Mapa Perceptual

Pearson chi2 (16) $=71.1551 \quad \mathrm{Pr}=0.000$

Tabela de frequências e de resíduos padronizados ajustados

\begin{tabular}{|c|c|c|c|c|c|c|}
\hline P1 & A & 8 & $\operatorname{SATSE}_{-\mathrm{C}}{ }_{\mathrm{C}}$ & $D$ & $\mathrm{z}$ & \\
\hline \multirow[t]{3}{*}{ ^ } & 5 & 18 & 25 & 18 & 35 & \\
\hline & 2.047 & 13.080 & 32.416 & 21.610 & 31.847 & \\
\hline & 2.215 & 1.549 & -1.679 & -0.931 & 0.717 & \\
\hline \multirow[t]{3}{*}{$\mathrm{B}$} & & 44 & 104 & & & \\
\hline & & 32.376 & 80.236 & 53.491 & 78.829 & \\
\hline & -0.565 & 2.583 & 3.798 & -1.727 & -3.987 & \\
\hline \multirow{3}{*}{ c } & & & & & & $\begin{array}{l}\text { expected frequency } \\
\text { expenter }\end{array}$ \\
\hline & $6.689^{\circ}$ & 42.736 & 105.912 & 70.608 & 104.054 & adjusted residual \\
\hline & -0.340 & -1.600 & 0.013 & 1.929 & -0.456 & \\
\hline \multirow[t]{3}{*}{ D } & 1 & 12 & 31 & 29 & & Pearson chi2 (16) $=51.7982$ \\
\hline & 2.493 & 15.929 & 39.476 & 26.318 & 38.784 & 1ike1ihood-ratio chi2 $(16)=50.5993$ \\
\hline & -1.029 & -1.137 & -1.764 & 0.635 & 2.345 & \\
\hline$\Xi$ & & & 19 & 17 & & $\begin{array}{l}\mathrm{Pz}=0.000 \\
\mathrm{Px}=0.000\end{array}$ \\
\hline & 1.703 & 10.878 & 26.959 & 17.973 & 26.486 & \\
\hline
\end{tabular}

Correspondence analysis biplot

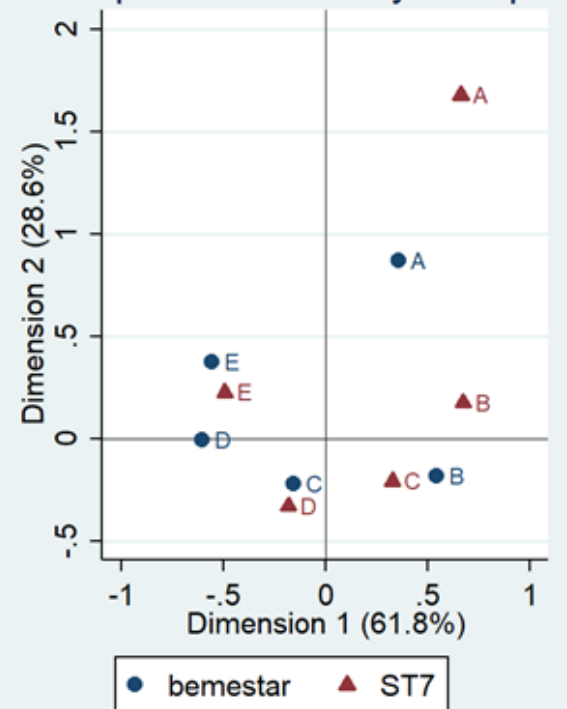

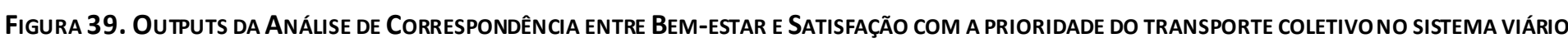

